\title{
Changes in throwing pattern and perceptual judgment as the function of task variations for young children
}

\author{
Yoojin Choi \\ West Virginia University
}

Follow this and additional works at: https://researchrepository.wvu.edu/etd

\section{Recommended Citation}

Choi, Yoojin, "Changes in throwing pattern and perceptual judgment as the function of task variations for young children" (2010). Graduate Theses, Dissertations, and Problem Reports. 2986.

https://researchrepository.wvu.edu/etd/2986

This Dissertation is protected by copyright and/or related rights. It has been brought to you by the The Research Repository @ WVU with permission from the rights-holder(s). You are free to use this Dissertation in any way that is permitted by the copyright and related rights legislation that applies to your use. For other uses you must obtain permission from the rights-holder(s) directly, unless additional rights are indicated by a Creative Commons license in the record and/ or on the work itself. This Dissertation has been accepted for inclusion in WVU Graduate Theses, Dissertations, and Problem Reports collection by an authorized administrator of The Research Repository @ WVU.

For more information, please contact researchrepository@mail.wvu.edu. 
Changes in Throwing Pattern and Perceptual Judgment as the Function of Task Variations for Young Children

\title{
Yoojin Choi
}

\author{
Dissertation submitted to \\ College of Physical Activity and Sport Sciences \\ at West Virginia University \\ in partial fulfillment of the requirements for the degree of
}

\author{
Doctor of Education \\ in \\ Physical Education
}

\author{
Andrew H. Hawkins, Ph.D., Chair \\ Richard Walls, Ph.D. \\ Robert L. Wiegand, Ed.D. \\ Sean M. Bulger, Ed.D. \\ Bobbi G. Warash, Ed.D.
}

\section{Morgantown, WV \\ 2010}

Keywords: Task variations, Ecological task analysis, Physical education, Throwing Copyright 2010 Yoojin Choi 


\begin{abstract}
Changes in Throwing Pattern and Perceptual Judgment as the Function of Task Variations for Young Children
\end{abstract}

Yoojin Choi

Ecological Task Analysis (ETA; Davis \& Burton, 1991) hypothesizes that movement change may emerge from dynamic interaction in given environmental conditions. In other words, task variability provides opportunities for the performer to choose skills suitable to his or her capabilities in order to achieve a task goal.

The purpose of the present study is to examine 4 year-old children's changes in throwing patterns and perceptual judgment as a function of task variation in specific throwing tasks. Each experiment identifies various task parameters (e.g., force, trajectory of throws) and attempts to adjust them to meet a task goal.

The modifications of tasks include changes in distance from targets, size of ball in relation to target size, and height of target in relation to eye- height level of children. The research designs for this study were alternating treatment design and simultaneous treatment design in single case study. Experiment 1of the study measured the extent to which throwing patterns change in accordance with variations in height of target, examine observable throwing patterns and measure the changes in humurus angle toward trunk. Experiment 2 examined the perceptual judgment of four-year-old children in seeking strategic solutions relative to the physical dimensions of balls and hoops, in the context of goal-scoring tasks.

The four year-old children responded to changes in the height of a target in relation to their eye height level and demonstrated lifting up the humerus to create higher trajectory at a high target. The strategy with the upper arm action cannot be believed to be effective for achieving the goal. However, it might be one of the solutions for scoring at the hoops, something individuals with the immature throwing skill might do. The distinct patterns of individual participant's throws may present the empirical evidences that they might be capable of comprehending the interaction well among constraints as changing a task condition in the way the developmentalists in dynamical systems theory explain changes in movements. 
Table of Contents

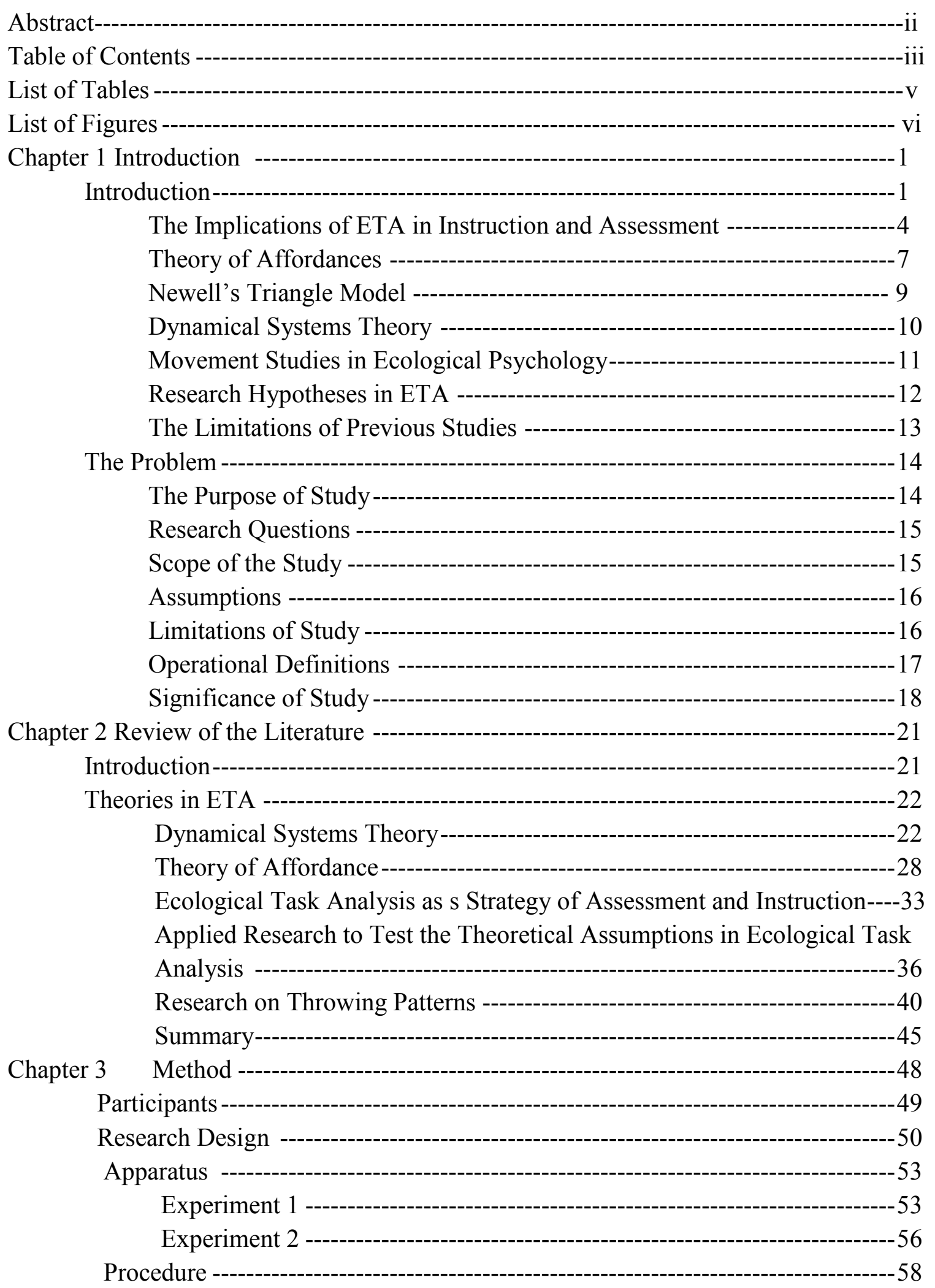


Instrument -------------------------------------------------------------------------------------61

Data Analyses ----------------------------------------------------------------------------'62

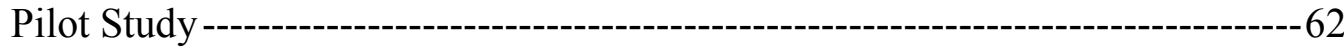

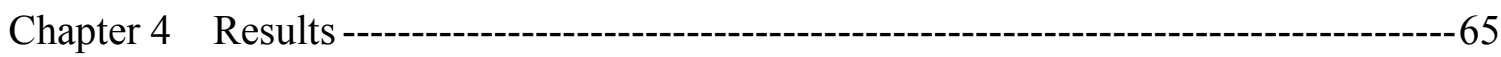

Experiment 1 ------------------------------------------------------------------------------------66

Experiment 2 ---------------------------------------------------------------------------------- 73

Chapter 5 Discussion------------------------------------------------------------------------ 104

Experiment 1 -------------------------------------------------------------------------------- 105

Experiment 2 ------------------------------------------------------------------------------------ 110

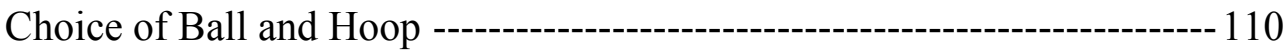

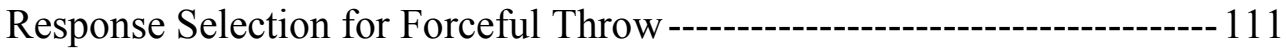

Suggestions --------------------------------------------------------------------------------- 114

References ---------------------------------------------------------------------------------------------- 116

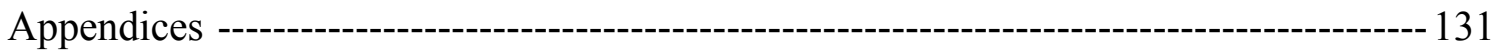

A Distributions of Changes in Humerus Angle in Experiment 1 -------------- 131

B Scoring Rates: Choices of Balls and Hoops in Experiment 2 --------------- 134

C Approval from Institutional Review Board ------------------------------------- 144

D Approval from the Co-Director of Chyleen Childcare Center ---------------- 145

E Informed Consent Form: Cover Letter ------------------------------------------- 146

F Informed Consent Forms: Parental or Guardian Consent and Information

Form---------------------------------------------------------------------------------------------- 147

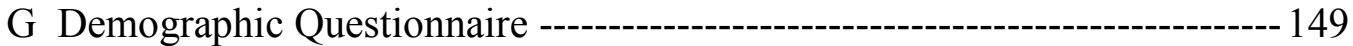

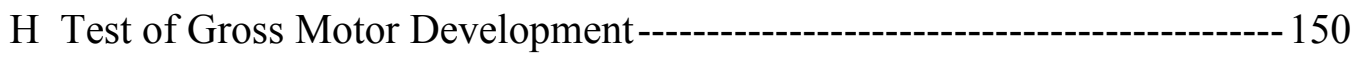

I Experiment Protocol (Instructor Reminders-------------------------------------153 


\section{List of Tables}

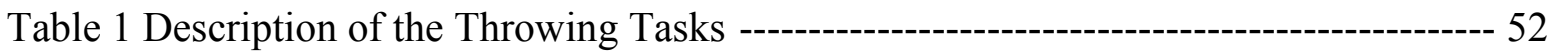

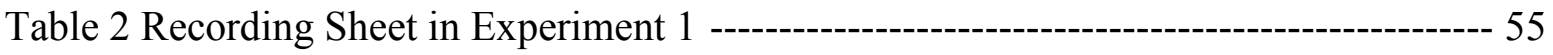

Table 3 Recording Sheet in Experiment 2 ------------------------------------------------------- 58

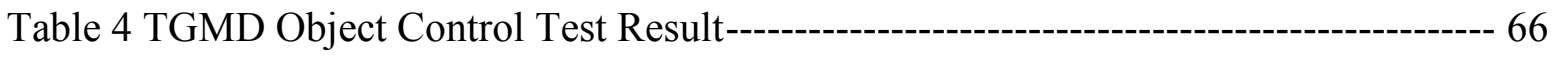

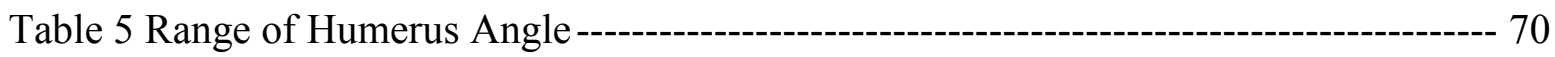

Table 6 Score Rate and Rank at the Horizontal Hoop and Range of Humerus Angle ------- 71

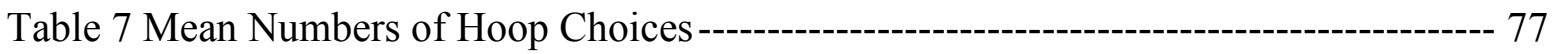

Table 8 Mean Numbers of Ball Choice at a Distance 75 inches --------------------------------- 84

Table 9 Mean Numbers of Ball Choice at a Distance of 150 inches -------------------------- 85

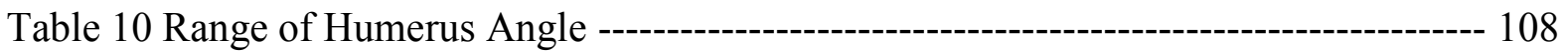

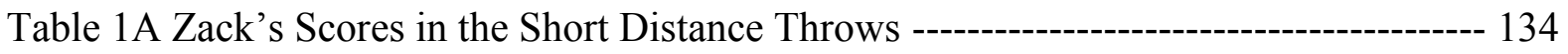

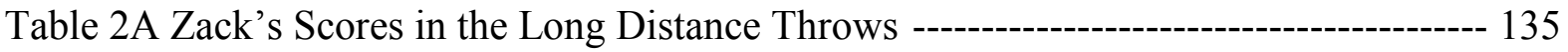

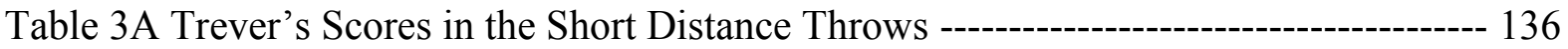

Table 4A Trever's Scores in the Long Distance Throws --------------------------------------- 137

Table 5A Payton's Scores in the Short Distance Throws ----------------------------------------- 138

Table 6A Payton's Scores in the Long Distance Throws ---------------------------------------- 139

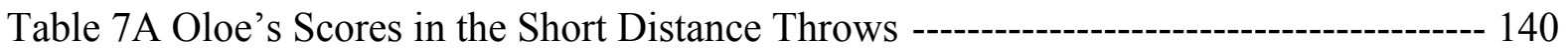

Table 8A Oloe's Scores in the Long Distance Throws--------------------------------------- 141

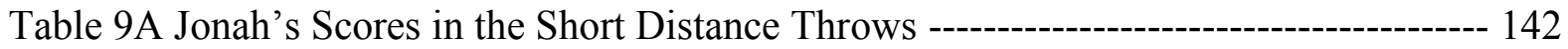

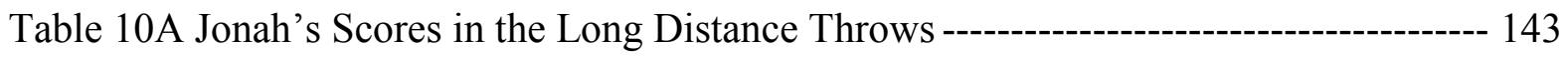




\section{List of Figures}

Figure1 Low horizontal orientation target ----------------------------------------------- 54

Figure 2 Example of the Target in Experiment 2 ---o- 56

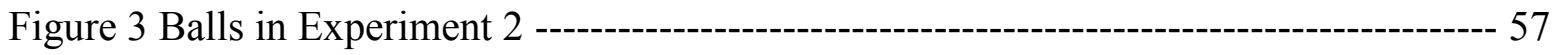

Figure 4 Four Different Orientations of the targets in the study (Choi et al., 2007):

Vertical, Horizontal, Slanted Hoop \#1 and Slanted Hoop \#2 ------------------------------ 63

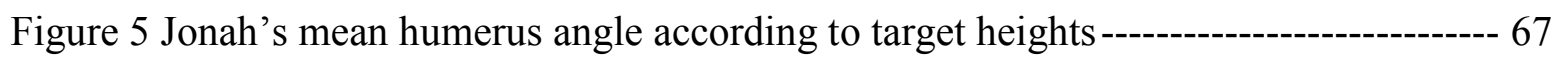

Figure 6 Oloe's mean humerus angle according to target heights ---

Figure 7 Trever's mean humerus angle according to target heights -------------------- 68

Figure 8 Payton's mean humerus angle according to target heights ----------------------- 69

Figure 9 Maximum and minimum of humerus angle according to target heights ----------- 70

Figure 10 Relation between score rates and ranges of humerus angle at the low target in

Experiment 1 ----------------------------------------------------------------------- 72

Figure 11 Relation between score rates and ranges of humerus angle at the high target in

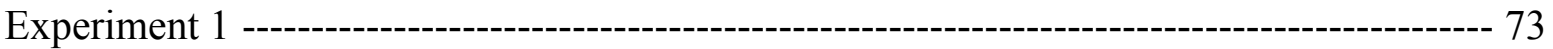

Figure 12 Jonah's choices of hoops aiming from 75 inches and 150 inches --------------- 74

Figure 13 Oloe's choices of hoops aiming from 75 inches and 150 inches ------------------ 75

Figure 14 Trever's choices of hoops aiming from 75 inches and 150 inches ----------------- 76

Figure 15 Zack's choices of hoops aiming from 75 inches and 150 inches ---------------- 76

Figure 16 Payton's choices of hoops aiming from 75 inches and 150 inches --------------- 77

Figure 17 Changes in mean number of hoop choices in relation to distances in

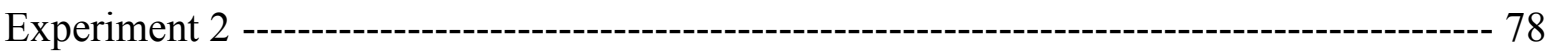

Figure 18. Jonah's choices of balls aiming at a big hoop and small hoop from 75 inches -- 79

Figure 19 Jonah's choices of balls aiming at a big hoop and small hoop from 150 inches - 79

Figure 20 Oloe's choices of balls aiming at a big hoop and small hoop from 75 inches---- 80

Figure 21 Oloe's choices of balls aiming at a big hoop and small hoop from 150 inches -- 80

Figure 22 Trever's choices of balls aiming at a big hoop and small hoop from 75 inches-- 81

Figure 23 Trever's choices of balls aiming at a big hoop and small hoop from 150 inches- 81

Figure 24 Zack's choices of balls aiming at a big hoop and small hoop from 75 inches---- 82

Figure 25 Zack's choices of balls aiming at a big hoop and small hoop from 150 inches -- 82

Figure 26 Payton's choices of balls aiming at a big hoop and small hoop from 75 inches - 83 
Figure 27 Payton's choices of balls aiming at a big hoop and small hoop from 75 inches - 84 Figure 28 Changes in mean number of ball choices in relation to size of targets from 75 inches in Experiment 2

Figure 29 Changes in mean number of ball choices in relation to size of targets from 150 inches in Experiment 2

Figure 30 Jonah's ratios of ball choices to number of attempts to score at distances of 75 inches and 150 inches.

Figure 31 Oloe's ratios of ball choices to number of attempts to score at distances of 75 inches and 150 inches.

Figure 32 Trever's ratios of ball choices to number of attempts to score at distances of 75 inches and 150 inches.

Figure 33 Zack's ratios of ball choices to number of attempts to score at distances of 75 inches and 150 inches.

Figure 34 Payton's ratios of ball choices to number of attempts to score at distances of 75 inches and 150 inches.

Figure 35 Homo-lateral stepping and contra-lateral stepping in Jonah's stepping action.-- 94

Figure 36 Homo-lateral steppings in Oloe's stepping action. 95

Figure 37 Contra-lateral steppings in Zack’s stepping action. --------------------------------- 96

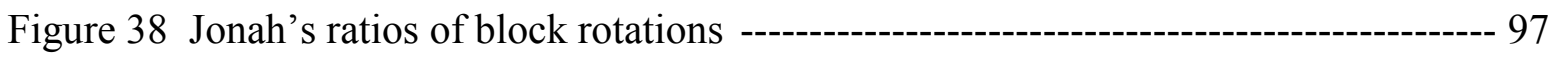

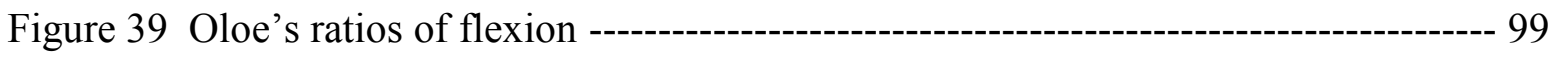

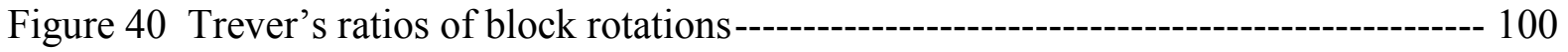

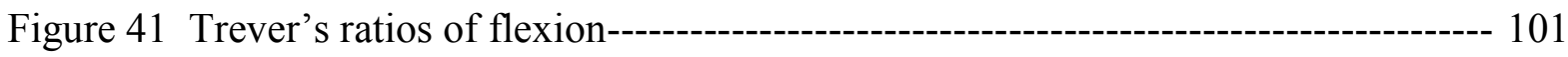

Figure 42 Zack's ratios of block rotations -------------------------------------------------------- 102

Figure 1A Jonah's humerus angle aiming at high target ------------------------------------------ 131

Figure 2A Jonah's humerus angle aiming at low target------------------------------------- 131

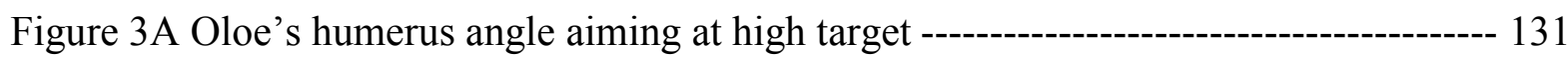

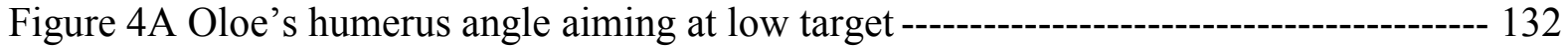

Figure 5A Trever's humerus angle aiming at high target ---------------------------------------- 132

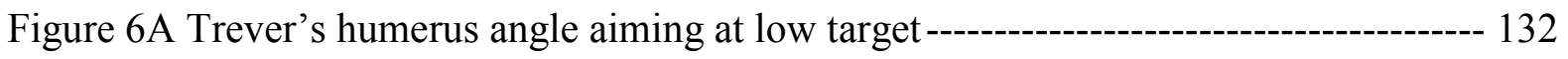

Figure 7A Payton's humerus angle aiming at high target----------------------------------------- 133

Figure 8A Payton's humerus angle aiming at low target --------------------------------------- 133 
Figure 9A Zack's scoring ratios at big hoop from a distance of 75 inches -------------------- 134

Figure 10A Zack's scoring ratios at small hoop from a distance of 75 inches ----------------- 134

Figure 11A Zack's scoring ratios at big hoop from a distance of 150 inches------------------ 135

Figure 12A Zack's scoring ratios at small hoop from a distance of 150 inches -------------- 135

Figure 13A Trever's scoring ratios at big hoop from a distance of 75 inches ----------------- 136

Figure 14A Trever's scoring ratios at small hoop from a distance of 75 inches--------------- 136

Figure 15A Trever's scoring ratios at big hoop from a distance of 150 inches ---------------- 137

Figure 16A Trever's scoring ratios at small hoop from a distance of 150 inches ------------- 137

Figure 17A Payton's scoring ratios at big hoop from a distance of 75 inches ----------------- 138

Figure 18A Payton's scoring ratios at small hoop from a distance of 75 inches ------------- 138

Figure 19A Payton's scoring ratios at big hoop from a distance of 150 inches -------------- 139

Figure 20A Payton's scoring ratios at small hoop from a distance of 75 inches ------------- 139

Figure 21A Oloe's scoring ratios at big hoop from a distance of 75 inches ------------------ 140

Figure 22A Oloe's scoring ratios at small hoop from a distance of 75 inches ----------------- 140

Figure 23A Oloe's scoring ratios at big hoop from a distance of 150 inches ----------------- 141

Figure 24A Oloe's scoring ratios at small hoop from a distance of 150 inches -------------- 141

Figure 25A Jonah's scoring ratios at big hoop from a distance of 75 inches ----------------- 142

Figure 26A Jonah's scoring ratios at small hoop from a distance of 75 inches---------------- 142

Figure 27A Jonah's scoring ratios at big hoop from a distance of 150 inches ---------------- 143

Figure 28A Jonah's scoring ratios at small hoop from a distance of 150 inches ------------- 143 


\section{CHAPTER ONE}

Introduction

Ecological task analysis (ETA: Davis \& Burton, 1991) is an alternative to traditional task analysis, which emphasizes performer-centered assessment in motor control and learning, and student-centered instructional design. ETA, in contrast, incorporates individual and environmental considerations into assessment and instruction in the domain of motor skills.

Traditional task analysis has been one way to create segmentation in tasks and goals, from simple to hard, to achieve the task goals in movement educations. The purpose of the task analysis is to assess the performance in the varying level of skills. Traditional approaches emphasize on a critical skill to be learned and on the implementation of the skill specific drills that range in difficulty from simple to hard. This is referred to as "Bottom - up assessment strategy" (p.307), (Burton \& Miller, 1998). Advocates of ETA claimed that ETA contrasts with traditional task analysis as it attempts to resolve some issues and problems in traditional approach. In assessment and instruction procedure, some relative terms (e.g., simple vs. complex, part vs. whole, and slow vs. fast in progression) have been commonly used without clear operational definitions, resulting in some degree of limitation in application of task analysis (Davis \& Burton, 1991).

In a cycle of assessing, planning/ revising, and implement of practice, ETA takes creating a high level of functional context into account for instruction and intervention, which eliminates focus on what students are already competent in and minimizes attention to less functional skills to achieve a task goal (Block, 1993). This type of 
assessment paradigm is more responsive to students' capabilities and enables planning of instructional sessions that are compatible with skills needed in order to succeed.

Burton and Miller (1998) asserted that in all professional fields related to movement skills assessment of movement skills with functional goal is gaining prominence over assessment of general movement ability. Movement ability refers to certain capabilities of performing movement skills such as balance, speed, reaction time, etc (Magill, 1993). The issue of motor ability assessment comes from the lack of validity of a movement task used in a test for a specific motor ability. The question is what common features of a task are used for a specific ability? They argued that a sum of performance scores from a set of related movement tasks cannot be interpreted to measure a motor ability.

In light of movement skill assessment with functional goal, a product rather than process (i.e., motor ability, specific pattern of skill) approach may be a promising paradigm for assessment strategy. The task goal can be conditioned by different requirements to achieve it. For example, traveling from point A to B does not necessarily have to be completed with bilateral walk from the functional goal standpoint. It depends on performers' characteristics and capabilities and changes what criteria would be imposed on the task assessment. Moreover, given the need to ensure the accountability of clinical and educational services, the demand for assessment in terms of performance outcomes with functional goal i.e. "Top-down assessment" (p.307), rather than in terms of the process of skill development, may increase in the future (Burton and Miller, 1998). Assessment and instructional approach on ETA attempt to assess performance outcomes relative to the capability of the performer and conceptualizes a dynamic 
relationship between performer and task on one hand and environmental components, on the other, in terms of relation between perception and motor control. We may find the logical understanding behind this approach in light of a Gestalt, holistic approach. Movement change is believed to emerge from the dynamic interaction between given environmental conditions, in the sense that task variability provides opportunities for the performer to choose skills to achieve a task goal as well as a task relative to his or her capability. A task goal (e.g., catching a ball with just two hands) and parameters in task and environment (e.g., catching a fast ball on outdoor field) within a performance also account for movement changes that define the performer's voluntary motor behavior. In terms of ecological view in assessing movement skill, we may find contradictions easily in early catching proficiency research. The early research disregarded environmental and task variables (e.g., goals, a size of ball) and performer's variable (e.g., a size of hand and capability), which prevented a consensual finding. Children do better in catching a medium or large ball, which is well known, among the studies. For example, Payne (1982) specified the diverse features of the catching tasks in the early studies and reported that some studies concluded that small ball gave more successes to 4-6 year old children (Gutteridge, 1939; Isaacs, 1980) and; others concluded that with medium and large balls they scored better (Meadly, 1941; Payne \& Koslow, 1981). By using ETA terms, we may simply define the factors the above studies disregarded: (1) inconsistency in distance, speed, and trajectory of projection toward catchers as in consideration of environment and task parameters; (2) mixed findings reported from either within subject comparison or between subject comparison studies, regardless of catchers' characteristics. 
A study (Burton, Greer, \& Wiese-Bjornstal, 1993) aligned with ETA premise examined the interaction of the absolute size of ball with the size of hands and reported that at mean ratios ranging from $0.99-1.20$ the transition from a one to a two-hand grasp occurred. A given performer will produce a different throwing pattern, depending on whether he or she is carrying a ball with one hand or with two hands because the variation in the absolute size of an object changes the way each individual can choose that object as a projectile and no wonder choose how they throw the object differently. As this paradigm translates into practice, teachers in physical education may gain insights into the need to shift pedagogical interest in assessment and implementation to a functional approach from a traditional approach.

\section{The Implications of ETA in Instruction and Assessment}

The issue of assessing functional movement skill rather than general movement ability has been addressed in the literature as far back as the 1950s (e.g., Brown, 1950a, 1950b, 1951) and 1960s (e.g., Bruett \& Overs, 1969), when occupational and physical therapists widely used the test of activities of daily living. Such function-oriented assessment, while in use for decades, has only recently received its current level of emphasis (Burton \& Miller, 1998). Burton and Davis (1992) claimed that in the functional approach to assessment and instruction of children with physical impairment, performance may be optimized by carefully manipulating constraints imposed by task, performer and environment. This reflects an acknowledgment of the fact that acquiring a certain level of skill may not represent any significant difference in the success of a task. But, the success of a task may be determined by the context of attempting to achieve a 
functional goal in a task (e.g., rolling over to get a toy, wheeling a chair in a game of tag, etc.).

Accordingly, in the assessment of performance, outcomes may be converted into criteria and qualitative measures relative to the various attributes of the performers. Task, equipment, and the settings of the task allow for variation in their physical dimensions in order to provide the individual performers with constraints that limit or allow movement of limb and body. In addition to manipulating the physical dimensions in a task, task goal may be an outcome that a performer is capable of achieving in terms of taking various constraints imposed on the task. The performers may use the different traveling skills to achieve a locomotion task. The rationale behind this approach to assessment is that success in the task is not the performance of a specific locomotion skill, but the completion of the locomotion task, the purposeful activity intended to achieve the goal. Working within the same perspective, Morris, Matyas, Iansek, and Cunnington (1996) provide support for this premise with their finding that optimization in motor action can be achieved through practice and feedback, typical motor learning processes, even in cases of people with a movement disorder, as long as their impairment is not due to brain damage. The emphasis on the assessment of functional movement skills has been driven by the demand of the therapeutic professions. The implication of this new assessment approach is that, given a particular situation, an individual with a movement disorder might choose a movement solution that is not optimal for this particular situation, but, which the individual uses effectively in a wide range of other situations (Walter \& Kamm, 1996). 
In addition to members of the therapeutic professions, practitioners in adapted physical education and special education have begun to take an interest in functional skills assessment (Davis \& Burton, 1991). In physical education, an achievement-based curriculum incorporating the concepts of functional skills assessment (Wessel \& Kelly, 1986) has been introduced, emphasizing the product (i.e. each student's competency relative to the specified objective) of instruction rather than the process. The National Association for Sport and Physical Education (2004) has published a document entitled Moving into the Future: National Physical Education Standards. This document addresses the issue of assessment in physical education based on testing students' performance in ways that assess the demonstration of skill and competence, rather than the proficiency of a select few skills in sport and physical activity. Activities in physical education provide opportunities for enjoyment, challenges, and social interaction, and not merely opportunities to acquire specific movement skills. This guide advocates authenticity in assessment, in terms of the nature of the tested activity and the testing environment, as well.

This transformation in assessment has led to non-standardized testing in physical education, which may include additional trials and manipulations of the environment and task. Non-standardization test is called alternative assessment (e.g., checklist, interview, observation, questionnaire, rating scale, teacher made test) because it refers to assessment based on direct observation and indirect information for better examination of the influence of environment on performance than standardization testing (Lufting, 1989). Flexibility in testing is a distinct feature of functional movement assessment and is obviously consistent with ETA. The rationale behind ETA is sending a message of 
curriculum innovation in physical education and is pushing forward a student-centered approach in instructional settings.

Student-centered instruction may provide more meaningful opportunities for higher order cognitive growth among students (Carson, Bulger, \& Townsend, 2007). Studies of teacher-centered direct instruction have reported that learning in more complex cognitive objectives proceeded best in instructional settings where students have more freedom to explore and interact with subject matter (Soar, 1977; Peterson, 1979); similarly, children were likely to succeed in highly cognitive, problem solving tasks, in more flexible classrooms that offered a variety of materials and activities (Stalling, 1977). Student-centered strategies enhance student motivation and the discovery of efficient ways of performing skills by each learner resulted in the creation of a cooperative and productive environment for learning and teaching (Monty \& Perlmuter, 1987). It has been known that children's sense of self-control and self-efficacy in the classroom could affect achievement (Wang, 1983) and those in highly structured classrooms could become helpless in their dispositions toward academic achievement (Wang \& Stiles, 1976). The growing interest in student-centered approach as an alternative to the direct instruction, teacher-centered model, has led to the introduction of ETA (Davis \& Burton, 1991), the sport education model (Siedentop, 1994), and the teaching games for understanding (Bunker \& Thorpe, 1982; Griffin, Mitchell, \& Oslin, 1997) into the physical education community (Carson, Bulger \& Townsend, 2007).

\section{Theory of Affordances}

Theory of affordance stipulates that an affordance contains ecological meaning when organisms are able to perceive a way of being visible, audible, tangible, etc. in the 
environment. Gibson (1979) claimed that organisms perceive information from the environment as they become attuned to invariance and disturbance. He described "the affordance of environment are what it offers animals, what it provides or furnishes, for good or ill" (p.65). When we say that environment affords us, the determination of being afforded is a matter of a specific combination of the properties of its substance and surfaces taken with references of our perceptions. Under his terms, if a substance is rigid and if its surface is flat, horizontal and spacious, it is stand-on-able and affords upright standing. The question in Gibson's theory is whether such information is available to organisms for the purpose of perception and if they are, they perceive physical properties in their environments in a manner that is relational in nature, in which the properties refer respectively to the performers and to the environments (Scarantino, 2003). In such a system, the performer is sensitive to the structured ambient energy from the task environment and makes perceptual judgments, which take place directly, rather than indirectly, by means of a cognitive structured processor and make an action. In turn, hypothetically, information to perform an action is always available and there is no need to store or retrieve them from cognitive structure when they are needed.

Therefore, picking up information is foremost procedure to make a move and the action allows organism to collect further information. Action and perception are inseparable terms and they are called to be coupling of action-perception (Warren, 1989). From an organism standpoint, it perceives an object in the environment in the scale of its body size and when it engages in performing a task, it understands the task as a relation between the task itself and its capacity to perform it. 
One of the major studies of perceptual judgment focusing on the relativity between the performer and the environment is the infant slope study (Eppler, Adolph \& Weiner, 1996). The purpose of this study was to examine the accuracy of infants' judgments about safe and risky slopes in relation to their proficiency in terms of locomotion. The 14-month-old walking infants were asked to travel $10^{\circ}, 20^{\circ}, 30^{\circ}$, and $40^{\circ}$ slopes. The result of the study indicated that infants displayed impressive flexibility in coping with the slopes, in that they show a tight fit between their own physical propensities and the properties of the environment (i.e., the steepness of the slopes), and discovered a variety of means to solve the novel problems presented by the tasks. Once infants recognized that they were on a risky slope, they chose alternative ways of achieving the task's goal of traveling downhill. At times, they did so by sliding in a sitting position, at others by backing down feet first, or by crawling on hands and knees in order to avoid falling headfirst. Considering the short length of walking involved in the task, the researchers concluded that the infants were capable of judging what locomotive skill was relevant in the slant task in accordance with their own walking proficiency.

\section{Newell's Triangle Model}

Newell's idea of coordinative paradigm, referring to movement as a product of a relation between task goal, performer attribute, and environmental constraints, (1986) is another theoretical ground to create the heuristic model of ETA. He emphasized that when a performer intends to generate a movement and interact with environmental (e.g., biochemical, biomechanical, morphological, neurological) constraints imposed onto the configuration of a movement, it reduces the degree of freedom for the emerging 
movement. Newell's coordinative structure recognized procedure of action as a dynamic process and furthermore, supported the notion of self-organization in dynamical systems theory.

Constraints residing in a performer are weight, height, and shape of body and in a micro perspective, synaptic connection is one of them. Constraints from environments refer to time independent constraints including gravity, natural ambient, temperature, and light, etc. When a movement takes place, that is, a performer interacts with the environment, the entity of the constraint from the environment changes. Task constraints were categorized in three and proposed as: "(1) goal of task; (2) rules specifying or constraining response dynamic; and (3) implements of machines specifying or constraining response dynamic" (Newell, 1986, p. 352).

\section{Dynamical Systems Theory}

Dynamical systems theory is widely applied to physical and psychological phenomena as a contemporary theoretical ground in human movement studies (i.e., motor control, motor learning, motor development). This approach introduced a new theoretical assumption concerning movement control and generation as a counterpart of movement program in the central nervous system. Proponents maintained that movement is produced naturally through dynamic interactions among elements such as properties of performer, task, and parameters in environment, rather than by commands in motor program of CNS. The assumption was originally conceptualized from common phenomenon we can observe in physics and chemistry labs like changes in water molecule patterns when its temperature drops or rises to boiling point (Schmidt \& 
Wrisberg, 2008). They considered changes in movement pattern of human being as a systemic change, as well, in its organization and structure as the same theoretical propositions explaining phenomenon in laboratory setting of chemistry.

A system, organism, can be defined as any set of interacting variables, whose state can be specified by establishing the values of each of its variables at a particular moment in time (Van geert, 1998). According to dynamical systems theory, movement arises due to a confluence of constraints: mover constraints (e.g., muscular, skeletal), environmental constraints (e.g., gravity, the stability of a surface, the social milieu), and task constraints (e.g., an object's speed, mass, weight, size) (Mullally \& Mullally, 2007). This notion implies a non-linear relationship between causes and consequences. For instance, it provides an explanation of developmental changes in movement that is not simply caused by maturation time, which is genetically programmed (Thelen, 1994). Instead, development changes arise within context as the product of multiple developmental elements. In support of this contention, Thelen (1995) asserted that "for infants as well as for adults, movements are always a product of not only the central nervous system but also of the biomechanical and energetic properties of the body, the environmental support, and the specific demands of the particular task" (p.81).

\section{Movement Studies in Ecological Psychology}

Research studies have tested various hypotheses from an ecological perspective on movement change. Numerous studies in the literature include those: (1) in the domain of movement coordination, as well as changes in movement patterns from instability to stability in coordination (Bernstein, 1967; Kugler, Kelso, \& Turvey, 1980; Kugler \& Turvey, 1987; Turvey \& Carello, 1996; Vereijken, Van Emmerik, Whiting, \& Newell, 
1992), (2) in motor development, including developmental changes in terms of a series of states of stability, instability, and transition under various constraints (Goldfield, Kay, \& Warren, 1993; Thelen, 1989, 1992; Thelen \& Fisher, 1982, 1983; Thelen, Kelso, \& Fogel, 1987), and (3) in developmental psychology, exploring perceptual information and judgment in the context of an ongoing activity (Adolph, Eppler, \& Gibson, 1993; Gibson, E. J., 1982, 1988; Gibson et al., 1987; Gibson, J. J., 1979). The premises of ETA were grounded on the findings from the movement studies in the ecological view. Specifically, the dynamic relationship between manipulation of task dimensions and the movement production to achieve functional goals were supported (Bingham, Schmidt, \& Rosenblum, 1989: Burton \& Welch, 1990; Saltzman \& Kelso, 1987; Warren, 1984). Research interest in the use of performer-scaled dimension (Kugler, 1986; Kugler \& Turvey, 1987; Warren, 1984), the consideration of a performer's body size relative to a task goal, arises in education and clinical fields and has attracted the attention of those interested in the development of interventions and instructional strategies.

\section{Research Hypotheses in ETA}

ETA theoretical tenets have led to the generation of hypotheses in movement study, which have been tested, anticipating the application of ETA to practice in clinical and educational settings. To test theoretical assumptions underlying ETA principles, studies have focused on: (1) identifying and ordering relevant task dimensions to reveal interacting variables in a task, (2) identifying optimal and critical points, which serve as constraints to confine redundant degrees of freedom, for movement change and the achievement of functional goals, and testing the invariance of these points across persons of different ages, physical sizes and/or developmental status (i.e., testing the reliability of 
movement changes by manipulating task variables), and (3) comparing individuals in terms of their perceptual judgment or sensitivity to environmental and task constraints relative to their own capabilities (i.e., justification of the theory of affordance, coupling action-perception; Whitall, Sanghvi \& Getchell, 2007). Movement solution of a task may be determined by function and intention and not by being a corrected variation of movement patterns. Physical dimensions of a task are defined in terms of essential and nonessential variables (Davis \& Broadhead, 2007).

\section{The Limitations of Previous Studies}

The effect of task and environmental variables in ballistic movement was examined by the studies on traditional task analysis approach. They indentified the variables, size of ball, changes in colors and patterns of background, which were hypothesized to affect on perception and performance of ballistic skill (Isaacs, 1972; Morris, 1976; Payne, 1982; Payne, \& Koslow, 1981; Ridenour, 1974, 1979). The findings from the studies, however, failed to lead to a consensus concerning the effects of physical dimensions (e.g., the ball size) on a task and assessment in changes in receiving patterns, the emergence of specific movements, in accordance with varying task dimensions (e.g., size of object, velocity of object, feeding an object from various distances). Payne and Koslow (1981) asserted that many studies have been based on casual observations or simple examinations of mean scores; therefore, they were of questionable scientific value in terms of their experimental procedures because they did not provide consistency in subjects with ball speed and trajectory. A suggestion made by the advocates of ETA was employing intrinsic measure to gauge performer characteristics. Then, information from the assessment may be taken in to consideration into defining physical dimensions of task 
and environment (Davis \& Burton, 1991). The studies did not produce enough information to understand the variables affecting on the nature of task and to hypothesize the orders of the critical elements leading a desirable changes that favor to a performer's skill acquisition (Burton \& Welch, 1990).

\section{The Problem}

\section{The Purpose of Study}

The purpose of the present study is to examine changes in throwing patterns and perceptual judgment as a function of task variation in specific throwing tasks. Each experiment identifies various task parameters (e.g., force, trajectory of throws) and attempts to adjust them to meet a task goal. The modifications of tasks include changes in distance from targets, size of ball in relation to target size, and height of target in relation to eye- height level of children. The intra-task variations were designed with the constraints imposed in order to produce changes in movement patterns on the given throwing tasks. However, the goal of tasks remained constant across variations in physical dimensions of the tasks, a functional goal, throwing ball and score. The study observed children's throwing patterns and analyzed the course of changes in response to the intra-task variations and examined perceptual judgments or strategic choices in relation to the success of tasks.

The premise of ETA addressed the interactions among the physical properties (e.g., size of ball) of the task that function as constraints, allowing children to employ different throwing patterns to achieve a task goal under each experimental condition. Each experiment was designed to identify critical points of an array of constraints, while 
imposing task variations, at which changes in throwing patterns (e.g., the transition from a one to a two-hand throwing, humerus movement, stepping, and trunk action in ongoing throwing action) emerge.

\section{Research Questions}

1) Do four-year old children respond to changes in the height of a target in relation to their eye height level and demonstrate throwing patterns (e.g., humerus movement) which may be effective to achieve a goal?

2) Does the size of the ball relative to the size of the hand influence the transition from one handed throwing to two handed throwing?

3) Do four-year old children perceive the absolute sizes of a ball and a hoop strategically? In other words, do they choose ball sizes suitable for relevant hoop sizes, so that they can score more successfully? Do they vary ball size choices as distance from a target increases? Do they perform some movements to produce forceful throwing like throwing at a distance?

\section{Scope of the Study}

Four-year-old children ( $n=5$; four boys and one girls) participated in this study. The investigator recruited the participants from among children in a local child care center in Morgantown, West Virginia.

Alternating treatment method and simultaneous treatment single case design were used to collect data. The independent variable in Experiment 1 is the relative height of a horizontal hoop target compared to 4 year-old children's eye-height. The dependent variables are; (1) the distinctive upper arm movement patterns (e.g., position of humerus 
in relation to height of target); and (2) the scores. In Experiment 2, independent variables are; (1) choice between two sized hoops; (2) choice between two sized balls, and (3) increments of distance from a throwing point to the targets. Dependent variables are: (1) the scores of each attempt to aim either the small ball or the bigger ball at the selected hoop; and (2) the movement components in forceful throwing as distance from the targets increase(e.g., trunk action, stepping).

To examine the changes in various movement patterns, the Dartfish program (SimulCam ${ }^{\mathrm{TM}}$ technology, 2007), a video analysis software, were used to aid to visual inspection on video clips. Descriptive statistics were used to examine if consistent pattern changes occurred in response to task variations. All conducts in experiments were videotaped and used to assess the degree of inter-observer agreement as well.

\section{Assumptions}

1. Perceptual information varies according to the perceiver's eye height level (Mark, 1987; Warren \& Whang, 1987).

2. Four year old children perceive the physical dimensions of objects in the task environment.

\section{Limitations of Study}

1. Since the children who participate in this study are enrolled in the Kinderskills Program in the Motor Development Center, it is highly possible that they have engaged in various types of motor activity more frequently than other children of their age. Moreover, the parents of these participants are aware of the value of motor activity in the development of children at this age. So, these parents may provide their children with an environment that facilitates their children being 
active. In these respects, the characteristics of the children in this study may be different from those of four year children who are outside the study.

2. The setting of each test in study will be recognizable to the participants as distinct from the normal play ground. This awareness of the test setting could influence their behaviors and performance. The level of reaction to the test setting may vary depending on the individual child.

3. The extent to which children are aware that their performance is being tested or observed can influence their performance. Using a video-camera in this study is a highly distinctive feature, which may arouse the children's awareness. Its presence will be desensitized by the attempt to hide it from the children's sight.

\section{Operational Definitions}

1. Horizontal hoop - A target consisting of a hoop, through which a ball may be thrown, is installed in an orientation within the environment, such that the plane created by the circumference of the hoop is parallel to the floor.

2. Vertical Hoop - A target consisting of a hoop through which a ball may be thrown is installed in an orientation within the environment, such that the plane created by the circumference of the hoop is perpendicular to the floor.

3. Hand size - The size of the participant's hand as measured, with fingers spread, span between thumb and $5^{\text {th }}$ digit.

4. Ball size - The size of a spherical ball as measured by the diameter of the circle on any plane passing through the center of the ball.

5. Hoops size - The size of a target hoop as measured by its diameter. 
6. Trunk action - " Upper trunk rotation or total trunk block rotation: the spine and pelvis both rotate away from the intended line of flight and then simultaneously begin forward rotation, acting as a unit or block" (Haywood \& Getchell, 2008, p.147).

7. Backswing - "Elbow and humeral flexion: the ball moves away from the intended line of flight to a position behind or alongside the head by upward flexion of the humerus and concomitant elbow flexion" (Haywood \& Getchell, 2008, p.147).

8. Stepping - "Homo-lateral step or contra-lateral step: the child steps with the foot on the same side as the throwing hand or the opposite side from the throwing hand" (Haywood \& Getchell, 2008, p.148).

\section{Significance of Study}

This study was designed to produce empirical evidence about ETA theoretical assumptions, which serve as a bridge for transforming theoretical concepts into practical applications in educational practice. The variations of throwing tasks in this study may encourage four-year old children to discover preferred movement patterns to achieve a goal. The information from children's performance will evaluate the physical dimensions in the task as a way of identifying conditions, which may acquire appropriate movement pattern in relation to children's capability to increase success. Achievement-based curricular models have been introduced (Davis \& Burton, 1991; Griffin et al., 1997; Mohr, Townsend \& Bulger, 2002; Siedentop, 1994; Thorpe \& Bunker, 1989), which have emphasized the assessment of student success in terms of functional skills or goals in the highest-level of functional context possible (e.g., game playing). In adapted physical education, teachers have incorporated intra-task variation into their instruction, in order 
to meet the challenge of creating optimal tasks, which are appropriate in terms of allowing students to acquire functional skills. However, dominance of the multi activity curricular model, which focuses on improving actual skills of performers, has been unchallenged in last decades (Alexander \& Penney, 2005; Hastie \& Curtner-Smith, 2006). Few studies have provided teachers with models of task variation based on a manipulation of the physical dimensions of objects and equipment in a manner that will provide insights useful in practical curriculum decision-making.

This study attempts to demonstrate that four-year-old children vary their movement patterns and perceptual decisions in accord with intra-task variations. Observations will be made for: (1) Specific skills and patterns in throwing used to carry out the tasks; (2) the absolute physical dimensions in a task at which skill or pattern changes; and (3) when preferred, the changes will be measured in relation to children's capability.

As this study attempts to reveal the relationship between contextual settings (e.g., multiple task variables), performers and outcomes, the descriptions of how young children end up finding their own solutions to task-problems in this study may provide additional evidence in support of the environmental premise in Piaget's approach (1981, 1985) to learning within the context of constructivism.

The theoretical propositions of ETA maintain that this fact does not indicate any lack of ability that children might have. From the ETA standpoint, constraints inherent in the environment and created by the children's own bodies are blamed for this incapability. Accordingly, there is no reason to conceive of, design educational settings in terms of what the learners can do, or what they cannot. As teachers, our mission is to 
create educational settings that feature minimal constraints on the parameters of tasks, allowing learners to discover more about what they can do, rather than about what they cannot.

The findings from this study may provide information leading to strategies in assessment of young children's throwing performance and efficient implementation of ETA. Pedagogical insights resulting from this study will be: (1) The conditions affording achievement of the throwing task efficiently; (2) the parameter values at which skill or movement patterns change; and (3) flexibility in application of movement solutions in accordance with various conditions. 


\section{CHAPTER TWO \\ Review of the Literature \\ Introduction}

ETA (Davis \& Burton, 1991) is the paradigm used in attempts to understand movement outcomes under circumstances that are dictated by environment and by attributes of individuals. Contemporary developmental psychologists have tended to take an inter-actionist, trans-actionist or system-theoretical approach to the problem, conceiving of developmental changes in terms of the reciprocal effects of organisms and their environments, while many have been holding the argument of the nurture versus nature as relevant to understanding the effects of developmental changes (Thelen, 2002). ETA model is one such approach that reveals the mechanisms that underlie movement changes and movement emergence in terms of the mutual or reciprocal interactions between the performer and his or her environment.

This study attempts to stratify the variables related to the task and the performer, using the task of throwing a ball at a target while manipulating the variables, in order to examine the blended effects of the interaction between the environment and the performer on the success in achieving the goal of the task. ETA model has practical implications for curriculum planning and related decision-making in physical education. These are important considerations in student-centered instruction that is part of an achievement-based curriculum. ETA study may assist teachers by relieving some of the overwhelming burden of implementing numerous task-varieties in their lessons by preferred conditions for carrying out the tasks for skill acquisition, depending on individual student capabilities. 
In this chapter, the theoretical assumptions in ecological psychology on which ETA is grounded will be introduced, which at the same time may be used in future ETA studies. The discussion includes a review of studies inspired by ETA as applied to research issues in movement assessment and instruction. This review of literature includes: (1) theories stemming from ETA, (2) applied research to test the theoretical assumptions in ecological task analysis, (3) research on throwing patterns, and (4) summary.

\section{Theories in Ecological Task Analysis}

\section{Dynamical Systems Theory}

Dynamical systems theory is a branch of mathematics that has been utilized in physics, chemistry, and biology and has alternatively been named non-linear dynamical systems theory, chaos theory, or self-organization theory (Barton, 1994). Motor developmentalists in human movement study are no longer content to accept that the origins of productions of new movements are merely a result of instructions stored in the genes; instead, they attempt to reveal the mechanism behind movement productions of organisms through an interactive or non-linear perspective approach (Thelen, 2002). That is, movement development as well as regression is a series of phases which an organism undergoes continuously to reorganize components (e.g., limbs, muscle contractions, joints, motivation, attention, etc.,) to respond to task and context parameters (e.g., task goal, equipment, space, people, etc.,) in the movement production. Organisms are often called a complicated system which is characterized by a "dynamically stable state" (p.350) as they produce certain movements. The system needs to coordinate all 
components and task or context parameters to achieve a task goal. To explain the hypothetical nature of "dynamic stability", a heuristic paradigm, "attractor" (p.343), helps to understand how movements can be observed as both consistent and identical, or universal within a species and unlike or variable as well. In dynamical systems theory terms, stability means a state where is it is easy not to get fluctuations by perturbations, depicted as a ball in a steep well. A world- class golfer produces almost identical golf swings every time he hits a ball. The conceptual attractor of his swing is steeper than one who begins to learn golf swing. Instability is more likely to be distracted by a minor change of component in a system and be transited to a different phase. Typical observations of a beginner's performance in motor learning may explain that there exists an unstable attractor, which requires more experiences in skill development. Therefore, instability means more possibilities to make developmental changes and transitional stages toward a stable attractor.

Dynamical systems approach to movement study understands the formation and change of movement. It deemphasizes the role of function of $\mathrm{CNS}$ while focusing on interactions among constraints imposed on task in terms of the conceptualization of movement production. The movements emerge from a confluence of constraints: mover constraints (e.g., muscular, skeletal), environmental constraints (e.g., gravity, the stability of a surface, the social milieu), and task constraints (e.g., an object's speed, mass, weight, size). The coordinate movements are dependent on reduction of degree of freedoms, the interaction of existing constraints as a way of enablement or limitation on movement (Mullally \& Mullally, 2007). For instance, the constraints from human body structure (e.g., muscular, skeletal, neural, cardiovascular, etc.,) considered to be one of the 
subsystems of organism on dynamic system approach, limit the size or the range of actions. Each sub-system such as task parameters, control parameter (e.g., force, speed, etc.), and organism (e.g., intention, ability, size of body, strength, etc.,) creates constraints on a particular moment or under specific conditions imposed by the environment and the task.

In the early years of developmental psychology, the motor developmentalists, Gesell (1929) and McGraw (1943) conducted descriptive studies with extensive observations and qusai-experimental studies and reported universal-sequential orders of ontogenties in the stage-like developmental changes. They concluded that the global regularities in early infancy were driven by instructions from maturational timetable. Maturation theory approach had been accepted to explain how infants produce the universal development changes in last 30 years (Thelen, 1995).

However, an alternative approach to motor development has made the claim that developmental changes are not determined by any biological timetable (i.e., maturational process) prescribed by DNA rather, it is a function of interactions among constraints imposed on a task (Newell, 1986). In contrast to the traditional approach to the ontogeny origins, the coordinative structure theory proposed that the milestone motor skills during early years emerges as the constraints changes, where organism attempts to achieve the coordination among a set of parameters as a series of adaptive solutions. That is, this position holds that the biological constraints (e.g., increase fat tissues in their legs) on infants, during any period, functions mutually in relation to the infant's social or physical environment, , and produce a developmental change in movement pattern (e.g., the shift from the appearance of a stepping reflex to the disappearance of a stepping reflex). 
Coordination is required to produce optimal movement pattern, which controls free variables in the emergence of a movement on the configuration of parameters, at every moment. Constraints that potentially impact coordination can be categorized into three domains: organism constraint, environment constraint, and task constraint (Newell, 1984).

According to Newell (1986) organism constraint is seen at the macro level (i.e., body structure) and at the micro level (i.e., neuro-synaptic structure). It is relatively easy to find the empirical evidence of the function of organism constraints at macro level than at the synaptic developmental changes. Newell (1986) exampled the findings from the early studies (Shirly, 1931), reporting the relationship between the onset of voluntary walking and the proportional changes in leg length. He asserted that not many study supported a direct relation between synaptic structure development and the emergence of certain movement patterns.

Environmental constraints may refer to gravity, temperature, atmosphere, and ambience of a place where an action takes place. Thelen's stepping reflex reappearance study (1986) gives an insight into the impact of environmental constraint on the emergence of a task specific movement pattern: submerging an infant reduces gravity and regenerates stepping action. Smith and Thelen (1993) maintained the significant role of contextual constraints on every type of movement we observe; milestone motor skills and other motor skills at the now and here. The mechanism of how both skills are acquired is not different and dependent on collective context specific knowledge from the perceptions of here and now, a task specific real-time knowledge. Walk is known as a typical milestone motor skill. They asserted that individual walks are not alike, even on 
the same surface, and with the same person, although it looks identical. Organism makes a movement and selects an adaptive solution every time he faces a context specific task.

Properties that are indigenous to a task, and limit the range of coordination called task constraints. Three categories of task constraints are (1) goal of the task; (2) rules; and (3) implements or machines constraining response dynamics. The Newell paradigm addresses that optimal coordination and control are determined by interaction of constraints in three categories. Perception of task and environment constraints imposed on a task may be different person to person, due to organism constraints (e.g., size of body, motivation, etc), resulting in different interpretations of task constraints, which were hypothetically depicted as a triangle with each of the three constraints at each end . A common research strategy in this line of research is the manipulation of constraints to compare the coordination outcome. The coordinative approach to motor development brought new insights of traditional distinctions between ontogenetic and phylogenetic skill developments, as well as the species-specific sequences of milestone motor skills during infancy.

Thelen and Fisher (1982) claimed that the increase of fat tissue in infants' legs prevents them from lifting their legs upright, causing the stepping reflex to disappear However, a series of studies succeeded in eliciting the stepping reflex in experiments that compensated for the biological demands of the heavy legs by manipulating contexts, such as placing the infants supine (Thelen \& Fisher, 1983), submerging the infants in upperbody deep warm water (Thelen \& Fisher, 1982) and placing the infants on treadmills (Thelen, 1986). This finding suggests that biological constraints from different levels of subsystems (e.g., the neural net, muscles, limbs, etc) in an organism in relation to a 
specific task context should be considered as the factor that accounts for developmental changes (e.g., the shift from stepping to non-stepping). This view is proposing that a universal milestone is learned through a process of tuning the constraints and creating a certain movement to fit a task (Thelen, 1995).

In short, Newell's paradigm incorporates the dynamical process of action, implying constraints in determining the development of coordination. This development refers to the propensity toward optimal self-organization by means of tuning two or more constraints on different levels (e.g., neural nets, muscles, limbs) in order to achieve coordination in a movement. Self-organization refers to the achievement of a configuration, order of elements in a system without any prescriptive directions. Despite infinite degrees of freedom a system eventually finds order in both space and time (Thelen, 2002). A famous chemical reaction, Belousov-Zhabotinskii reaction, is often represented as a heuristic example of self-organization, but there has had no iconic presentation at the behavioral level (Thelen, 2002).

Thelen (1995) recognized Bernstein's pioneer work of examination on the multicausal relationship in the process of movement production and first defined coordination as the reduction of any excessive degree of freedom by involving joint, segment, and muscle actions that serve as constraints from the biomechanical perspective. Bernstein's issue was how organism with infinite degree of freedom can figure out how tens of billions of body parts work together to achieve a task specific coordination. Thelen (1995) appreciates the Bernstein's inquiry in that it set the fundamental grounds of relativism and coordinative approach on motor development study. 
ETA grounds on Newell's paradigm and maintains the logical rationale underlying the coordinative theory approach on motor development study. It applied the constraint interaction hypothesis on the theoretical ground, creating a propensity to achieve the optimal coordination and control for a given movement. ETA states that the form of a movement is an outcome of constraints on the three major components of the system: the task goal, the environmental conditions, and the performer characteristics, in congruence with the logical paradigm of Newell's theory. Changes in relevant aspects of the environment and the task goal affect movement patterns, eliciting outcomes in terms of performance.

There is no one best movement pattern for all individuals. From an educational perspective, since action should be interpreted in light of coordinative theory structure (Burton \& Davis, 1992), optimal movement patterns through the process of discovery through comparison of task conditions (i.e., task goal, environment) with movement forms, ultimately arrive at optimal performance outcomes (Balan \& Davis, 1993).

\section{Theory of Affordance}

The term, affordance, coined by Gibson (Gibson, 1979) implies ecological meaning from task context, which is available for an organism, whose perceptual system is able to receive (Scarantino, 2003). More specifically, throughout its perceptual system, the organism senses, for instance, whether a staircase is low enough to step up, or to describe the question in the language of the theory, whether the staircase can afford stepping to the performer. This theoretical assumption refers to the unique relationship between the potential actions of an organism and some aspect of its environment, such as a place (e.g., a slope, water bed, rigid surface, or staircase), an object (e.g., a ball which 
may be grasped with one hand) or, an event. Those contextual conditions (i.e., a place, an object, an event) that support adaptive actions on the part of some organisms may not do so for others of different size, body structure, or organic requirements (Gibson et al., 1987), which implying the relation between organism and the ecological entities are reciprocal. The interpretation of an ecological condition may be different from one to another mover.

Organism is defined as one being open to its environment, exchanging both energy and matter in its evolutionary process. Hypothetically, when the organism produces a movement form, it places itself in the middle of an infinite energy field, which surrounds and continuously influences it. They view the ongoing procedure dealing with ecological information as how a mover functions as an open system in generating movements. Davis and Strand (2007) described the responsive nature of organisms toward their environment asserting that, "Living systems are learning systems because they have continual structural changes in response to their environment, which involves adaptation, learning and development."

Gibson's approach to conceptualizing the link between perception and action has inspired numerous studies of developmental change in individuals who are distinguished by having limited verbal communication skills (e.g., infants, in addition to autistic and mentally retarded children). These studies have examined how individuals perceive their environments, according to their perspective across chronological age and handicapping condition. Gibson characterized affordances as properties of objects and layouts that are specified by information in the array of energy available to an organism's perceptual systems (Greeno, 1994). Accordingly, this situation holds true regardless of whether the 
person is aware of the relationship between his or her leg length and the stair riser's height, which further suggests that meaning is not internally constructed and stored, but is rather inherent in the person-environment system (Jones, 2003). It is assumed that objects and events have inherent meaning, which is detected and exploited by individuals without mental calculation (i.e., the direct-perception view).

Neuropsychological developmental principle explains that perception and action process are functionally intertwined and do not develop separately, which rather do mutually as in action and perception are a means each of them reciprocally (Kugler, Kelso, \& Turvey, 1982). The action coupled action and perception system is the logic of nerve system advocates the holistic approach in developmental change in movement, maintaining of movement emerges when growth and activity related change in force occur not by the prescriptive plan of heredity (Davis \& van Emmerik, 1995). It is viewed that organism perceives so as to engage in movement (e.g., moving the head for looking and fingers for touching), and that such actions enable further perception in that the consequences of the actions give the perceiver additional information and guide his or her next moves (Gibson, 2000).

In a study of affordance in the context of stair-height and climbing, Warren (1984) concluded that the optimal stair-height must be detected by the perceiver or mover, who needs to pick up, not only information concerning the height of the stair, but also the constraints imposed by the perceiver's own stature (e.g., leg length). The study compared the leg height of both tall and short men to relative stair-height. The results indicated that both groups felt comfortable in climbing when the height of the stair was 
closely matched to their individual heights in terms of the ratio between stair height and leg length.

One of classic studies, the visual cliff experiment (Gibson \& Walk, 1960) has been quoted by many researchers as in the one study to support affordance framework, which demonstrated that crawlers avoided crossing a visual cliff covered with a safety glass or a transparent-ridge surface. The infants in the study showed their ability to perceive depth by avoiding the deep side of a visual cliff. The findings indicated that perception is an essentially adaptive process.

In addition to the visual cliff study, movement study with ecological view has conducted many studies with young children and attempted to investigate what young children respond to under a given novel task. The young children's responses were believed the products resulted from the cognitive function to decision making with incoming ecological information without knowledge built up by previous learning experiences. A series of studies testing infants' locomotor skills in various experimental settings and reported that infants were capable of adapting their locomotor skill patterns in coping with challenging contexts.

The study of walking in a waterbed and plywood is also most quoted for developmental psychologies with ecological view, conducted by E. J., Gibson and her colleagues (Gibson et al., 1987). They assessed latency to initiate locomotion, duration of visual and haptic exploration, and displacement action with two infant groups, crawlers and toddlers. They chose either a waterbed or a plywood surface to walk across. The observation of the study is that toddlers hesitated to cross the waterbed more so than crawlers, implying that infants perceive the surface properties differently in relation to 
the locomotor skills such as bipedal gait and crawling they have newly acquired. Moreover, both toddlers and crawlers preferred the rigid surface to the waterbed when they crossed the surface, suggesting that infants may detect information concerning surface rigidity, elasticity, or discontinuity visually and gather it haptically with their hands or feet. These results provide an indication that even at an early developmental stage, human beings may be sensitive to the contextual constraints affecting the way in which they move and may be able to make the perceptual judgments in coping with the constraints imposed on a task. The explanation from the coupled perception-action system may fit to what the perceptual judgment the infants made in relation to locomotor skill ability. They were capable to perceive whether a surface affords either bipedal gait or crawling

One group of researchers succeeded Gibson's approach to support the hypothesis on the perceptual decision mechanism (Adolph, 1995; Adolph, Eppler Marin, Weise, \& Clearfield, 2000; Adolph, Vereijken, \& Denny,1998; Adolph, Vereijken, \& Shrout, 2003;).They built slopes at various degrees of angle and put two groups of infants by locomotor skill patterns, either toddler or crawlers. The studies reported that both toddlers and crawlers chose a slope on which they could travel without falling, rather than a rigid but steep, downhill slope and also engaged in a variety of probing and exploring behaviors whenever faced a risky slope. The strategic variations in infants' locomotor skills were observed such as sliding in a sitting position, backing down feet first, crawling on hands and knees, and sliding head-first prone. The one of conclusions was what perceptual judgments infants made was right to travel safely downhill in accordance with changes to the angle of a slope (i.e., $10^{\circ}, 20^{\circ}, 30^{\circ}, 40^{\circ}$ ) (Eppler, Adolph \& Weiner, 1996). 
That is, the infants chose a locomotor skill in coping with traveling on a downhill slope in relation to their capability in that they act differently on each of the four different slopes. The implication of these studies is that infants may predict the potential consequences of locomotion based on the relationship between surface slant and their individual's level of walking proficiency.

Movement production may be either limited or allowed depending on perceived ecological meanings from environment. For example, walking is impossible unless the floor is appropriately stable, flat, rigid, wide, and with sufficient traction to support the movement required for balance and propulsion. (Adolph, 2002)

Consequently, in the generation of movement and its improvement may rely on an affordance, which is necessary to perform functional activities.

\section{Ecological Task Analysis as a Strategy of Assessment and Instruction}

Ecological task analysis is theoretically grounded on an ecological view of theories of motor development. ETA conceptual model is directly derived from Karl Newell's (1986) triangle of constraints model, and philosophical influence and research tool are linked with Gibson's (1979) theory of affordance; Bernstain's physiological and neurological approach; dynamical systems theory (Davis \& Broadhead, 2007). The tenets of ETA are (1) the product of movement or task is assessed rather than a particular movement pattern; (2) movement is defined as the relation between the task, mover, and environment, not by mechanism; (3) constraints imposed by the dynamics from the relation are examined by the use of performer-scaled or other intrinsic dimension (Davis \& Broadlead, 2007). ETA was developed as an applied model introducing an alternative strategy for traditional task analysis in movement assessment and instruction, which may 
be beneficial in a variety of educational settings. The applied model of ETA suggests the following specific steps to incorporate the theoretical tenets into practice.

The first step is identifying task goal on functional perspective, what is needed to accomplish in task. Task condition and rules are also specified along with what needs to be done. The speculation of rules and condition serve as a clear criterion for measuring performance outcome for students and instructor. Having clear expectation of task and assessment will benefit to students motivation. Instructor demonstrates and explains the task and presents more than one specific skill to achieve a functional goal. The ETA approach in educational settings advocates setting a goal from outcome based assessment and instruction on functional point of view so as not to focus on acquiring specific skill proficiency or competency. The identification of a task goal implies that the teacher is a careful observer.

The second step is providing students with choice in practice, choice of movement pattern or skill under existing condition and criteria. Davis and Strand (2007) defined this as a central value of ETA with tremendous implications for education settings in general. They discussed choice as constraints in physical, social, psychological realm of human behaviors, which either allows or limits action at the same time. Choice is also illustrated as meaning possession of skills, ability to use many resources, and as self-determined acts leading to intrinsic motivation. During given practice time, instructor assesses what outcome the students get and measure what choice they made. Information the teacher collects in the second step is used to identify task dimensions for task modification. 
The third step involves using task manipulation in a relevant dimension of the task in relation with learners' variables (i.e., attributes). In terms of ETA, since movement emerges from relationships among variables, the most relevant variables can be modified to make a task easier or more difficult. This manipulation is strategically implemented by allowing students to have choices, which results in the individual experiencing a level of success that motivates the individual to engage in physical activity (Bulger, Townsend, \& Carson, 2001). The term critical point refers to the value after scaling the relevant variables that cause a movement to change either up or down (Whitall, Sanghvi, \& Getchell, 2007). Likewise, optimal point refers to the values of variables at which the performer is most efficient in accordance with the achievement of a task goal (Whitall et al., 2007). The function of choice (e.g., participants selecting their own criteria for achieving a goal) works as a powerful motivator to hold students' interest in a task and is a key element in the effort to incorporate the student-centered approach into models of curriculum development.

The fourth strategy consists of requiring the teachers to continuously conduct assessment of performance in order to compare the performance outcomes with the task conditions. According to Burton and Davis (1996), the information from this assessment needs to include; (1) the context or conditions in which performers accomplish a task and how often they complete, or succeed in a task under those particular conditions and; (2) the system that links the performer with the environment, coupling action and perception (Gibson, 1979), which may either limit or allow the performer to produce a certain movement. Modification of task dimensions in the condition takes place in a systemic way based on the assessment, which may lead change in movement patterns. 
Applied Research to Test the Theoretical Assumptions in Ecological Task Analysis

The theoretical assumptions in ETA may be tested with the following steps; (1) identifying and ordering relevant task dimensions in order to reveal the interacting variables in a task; (2) identifying optimal and critical points which serve as constraints that confine redundant degrees of freedom for movement change and the achievement of functional goals; (3) testing the invariance of the critical or optimal point across persons of different ages, physical sizes and/or developmental status; and (4) comparing individuals in terms of their perceptual judgments or sensitivity to environmental and task constraints relative to their own capabilities (Davis \& Burton,1991).

To truly understand the critical point and optimal point for each of the relevant variables, the researcher, who is interested in the constraints placed on a performer by physical attributes (e.g., body size, body structure, motor ability), needs to discuss these two points in a way that converts the variance in the performers' physical attributes into the invariance of the dimensions. That is, the one's body size can be measured in relation to an apparatus of task, what we consider it as one of task dimensions. It is performerscaled or intrinsic measures (Kugler, 1986; Kugler, \& Turvey, 1987) referring to the absolute-extrinsic measures related to the task (e.g., the height of obstacle or a staircase); it is ratio between the relevant performer's body size to a task dimension or a task goal (e.g., leg length, eye height level) and the variance of a task dimension (Whitall et al., 2007). It differs from absolute- extrinsic measures attempting to gauge physical characteristics regardless of any task dimensions. The intrinsic measure accounts for the relativity in a performer's attributes, which is strongly associated with the individual perception-action system. Performer-scaled measurement was offered as an important 
way to establish direct links between a task goal and important task dimensions that constraints impose on the performer's action (Burton \& Davis, 1996).

A mover's physical properties may determine a particular array of information in the middle of energy field where a task is posited and completed. Young children perceive a hanging target's physical dimension, up in a wall, differently over what an adult with 6 feet height, does. Information of task properties such as sizes, distances, and surface height may be scaled depending on one's size of body. A study found that eyeheight level changed a mover's perceptional judgment in a task. It used $10 \mathrm{~cm}$ block to get raised a mover's eye-height level as having it attached on a mover's feet. The participants were asked to make perceptual decision to predict the maximum sitting height and climbing height each before they actually attempted to sit and climb up of an adjustable riser. The study reported while they were standing barefoot, they did an underestimation of the maximum sitting height, but while wearing the blocks, they did an overestimation of his or her predicted climbing height accordingly (Mark, 1987). Despite the fact that they misjudged the perceived height for sitting and climbing, over the course of six trials, the participants reduced their estimates of climbable height and of the maximum sitting height. There was a clear increase in perceived height by the end of the trials.

In a similar fashion, another perceptual judgment of whether an apparatus affords passing through action beforehand with attempting it (Warren \& Whang, 1987). The study examined participants' accuracy in judging whether the apparatus was passable without the shoulder rotation, using two groups of participants classified according their body sizes. They were actually asked to pass through the apparatus and were allowed to 
rotate their shoulders if necessary after making the judgment in whether the apparatus was passable or not individually. The findings from this study provided again empirical evidence of mover's responsive perceptual judgment concerning a task dimension, which may be deduced from the body-scaled information. In this study, participants with larger body sizes more frequently judged the apparatus to be impassable than did the smaller participants. The larger participants were observed emerging from the apparatus with greater angles of shoulder rotation, while at the same time they traveled at a faster speed.

Burton, Greer, \& Wiese-Bjornstal (1993) hypothesized ratio between size of ball and size of hand may be associated with the change in grasping and throwing patterns. The study results supported the hypothesis, as the diameter of a ball was scaled up, the transition from one-handed grasp to two-handed grasp occurred across five-different age groups, from kindergartners to young adults. The mean ratio was 0.99-1.20.that was believed to lead the changes in throwing and grasping actions. The results showed that the transition consistently occurred just as the ball's diameter began to exceed the participants' hand widths, at ratios from 0.99-1.20. An early study in throwing pattern found a similar finding with Burton et al.'s study (1993). The study reported the number of fingers used to grasp an object was similar for adults and children when the relative size of the object was the same (Rutter, 1987). In this study, grasping action was examined in relation to size of object across different-age groups, both children and adults, as they grasped different sized spheres ranging from $3 \mathrm{~mm}$ to $180 \mathrm{~mm}$ in diameter. Grasping actions were defined by using several categories such as immobilization, manipulation, displacement, or projection in attempt to grasping 14 spheres. The study identified the critical point at which the participants changed from using a one-handed 
grasp to a two-handed grasp, as well as the boundary point at which the participants were able to make a stable grasp, which were very similar for both adults and children, but were different for grasping actions in the category. Therefore, a task goal (i.e., what grasping action should be performed to achieve it) should be taken into consideration in understanding the mechanism underlying movement form in addition to information from body scaled measurement. Therefore, a task goal is one dimension of a task as a parameter to shift one movement to another.

Investigation of the perceptual judgments of individuals with mental or learning disabilities claimed that the perceptual judgments were as accurate as those of individuals without disability. Standing jump was to cross over at various levels of bars, performed by both children with and without learning disability (Burton, 1990). There were the locomotion patterns observed, including walking over, jumping over, and crawling under the bar. The one with a disability was the least efficient at negotiating the bars of each height. They simply took longer to judge the clearance height of the bars than it did for children without any disability prior to doing standing jumps. Also They chose a right locomotor skill other than standing jump when the height of bar was too high to jump over.

Block's (1993) selected long jump and conducted a perceptual judgment study with children with retardation. Similarly, children with and without mental retardation were first asked to judge whether they could jump over various lengths of mat using a standing long jump. Then, each child did long jump on the mat to assess his/her actual jumping ability. The finding from this assessment was that both groups of children with and without retardation were accurate in judging their jumping ability beforehand, 
although children with mental retardation could not jump long distance as the children without retardation.

Another study (Whitall et al., 2007) found results that are consistent with the above two studies. In this study, children with learning disabilities were asked to judge the clearance height of a bar located in front of them. After answering whether they could step over the bar without touching it, the participants were allowed to demonstrate the movement of stepping over it. The same experimental condition was applied to children with no learning disabilities. The study found that despite the fact that both groups of children were accurate in judging the actual clearance height at various height, children with learning disabilities displayed again poor motor ability and took longer to make the judgments.

Surprisingly, children with mental or learning disabilities had the same ability in the precision of their perceptual judgments with the ones with non-mental and learning challenge. It appears that the challenge does not degrade the ability of using information from a task condition as a reference to decide what to do and how to do to achieve goal. The consensual findings may support the existence of holistic-interrelated the perceptionaction system being stored in the child's mind, as the theory affordance claims.

\section{Research on Throwing Patterns}

Over hand throwing has been studied most widely, which attempted to investigate developmental sequences in throwing and also the developmental components described in both quantitative and qualitative respects (Halverson, Roberton, \& Langendorfer, 1982; Langendorfer \& Roberton, 2002; Nelson, Thomas, \& Nelson, 1991; Roberton, 1978; Roberton \& Halverson, 1984; Roberton, Halverson, \& Erbaugh ,1981; Roberton 
\& Konczak, 2001; Roberton \& Langendorfer, 1980; Runion, Roberton, \& Langendorfer, 2003; Thomas \& French, 1985; Yan, Payne, \& Thomas, 2000). They examined the action components of over hand throwing such as the actions of forearm, trunk, foot-stepping and joint (Yan et al., 2000) and used process assessment to measure the proficiency level of throwing rather than using product assessment (e.g., distance, accuracy, \& ball velocity). The issues of using outcome measure such as accuracy test is, when it comes to interpret the data, the lack of consistency in task dimensions in target, ball, distance from target and consideration in individual's characteristics (e.g., muscle strength) (Haywood \& Getchell, 2008). The stage-like developmental sequence framework has been developed by the research endeavors and has been applied comprehensively to the practitioners. The developmental components, humerus, forearm, and trunk action at each developmental stage, were believed in the correlation to the changes, proficiency and outcomes in over arm throwing (e.g., throwing velocity, accuracy, distance) but there should be consideration of a set of constraints, which may be imposed on a task condition, age, gender, body size, and target and apparatus's properties to account for the outcome measure (Haywood \& Getchell, 2008). However, the related studies to the developmental sequence found the progressive orders of the developmental components weren't observed as in parallel with the sequence. The meaning of that is what throwing skill a child has a different component sequence from one whose is at the same age group as each child advances through the developmental sequences.

Roberton's early research (1978) collected progressive changes in throwing from kindergarten to $2^{\text {nd }}$ grade and measured changes in the action of humerus, forearm and trunk. She found that only $6 \%$ of children progressed in all three actions, while $20 \%$ of 
them did progressive changes in two actions and $39 \%$ of them changed in one action component. She claimed that "the issue of stage must be confined to the ordering within the components rather than to the total body configuration, although the latter has been a traditional practice in motor development" (p.174).

Gender difference seems be more common characteristics than other motor skills (Halverson, Roberton, \& Langendorfer, 1982; Nelson, Thomas, Nelson, \& Abraham, 1986; Thomas \& French, 1985). Heredity was claimed as an attribution to the gender difference in throwing performance. Physical characteristics of five year-old girls was measured and the difference from boys' was adjusted for boys' to estimate girls' performance what if they would have the same physical properties with what boys had (Nelson et al., 1986). It still showed the girls' performance just reached $67 \%$, from $57 \%$ originally, despite of the adjustment estimation. Culture of boys in favor to throwing activity may be another attribution to the gender difference. William, Haywood and Painter (1996) reported ball velocity difference between girls and boys significantly decreased as they were tested with a non-dominated hand.

Some findings might not be explainable on component approach in the developmental sequence. The underlying rationale of this approach should be confined to the ordering within the component categorization rather than total body configuration, the coordination among multiple dimensions of body actions (Roberton, 1978). Burton, Greer and Wiese (1992) also pointed out that changes in one-hand over handed throwing have, however, always been examined as a function of chronological age, even though every component in one-handed throwing pattern is not developed in parallel. A unified theory of movement change in throwing might be drawn from a compressive 
understanding of the relationship between outcomes, coordination and control among the action components (Roberton\& Konczak, 2001) not by the sense of maturational or chronological orders. Newell (1986) expanded the component approach to coordinated approach by including interaction within thrower's environmental components and asserted that the developmental feature in fundamental skills like one-handed over-hand throwing was coordinated movement that emerged due to the similarity of constraints imposed on young children.

The ball release velocity, the timing peak velocity relative to ball release, and joint kinematic measures were significantly different among the age groups, 3, 4, \& 6 year-old girls (Yan, Payne, \& Thomas, 2000). They concluded that the older children were better in joint coordination and supported the finding of Roberton et al.'s (1981) study, which concluded that contribution joint peak velocity to ball release velocity was an essential element in children's over arm throwing skills. Roberton et al. (1981) found that the action of forearm, humerus, trunk and forward step contributed to $75 \%$ increase in throwing velocity of older children.

A similar study, longitudinal ball velocity study, found that the developmental sequence of action accounted for $69-85 \%$ of the total velocity variance each year; although, the forearm or humerus action of the sequence accounted for considerable variances that best accounted for a large proportion of variance in ball velocity (Roberton \& Konczak, 2001). Roberton and Langendorfer (2002) reported that there was a certain invariant pathway for developmental changes in throwing patterns too.

Langendorfer (1987) conducted the study concerned with task constraints that hypothesized a function of changes in throwing according to task goals. The study found 
that in forceful throwing conditions male children increased higher mean levels in 4 out of 5 components, while female children showed significant increase in mean level in stepping component. However, children from 3 to 8 years didn't change any components like humerus, forearm, trunk and stepping under the four-target conditions: (1) no target; (2) a stationary target; (3) a stationary target changing location between trials;(4) a stationary target changing location within a trial (Roberton, 1987).

Burton et al. (1992, 1993) adopted intrinsic-measure strategy to gauge task dimension and physical property of performer that may lead variance of movement changes in throwing. They hypothesized that size of ball related to size of hand might be a critical variable changing from one movement to another, supported by their research. As increasing the size of ball, the changes from one-hand to two-hand grasp and in the same way one-hand to two-hand throw were occurred. Adult participants did not change to two-hand throw pattern with a larger ball as young girls do in the study. Older participants might be aware of their ability in controlling a larger ball with in one hand, which is certainly believed more efficient way of throwing. The increment of size of ball changed the quality of throwing forms. The study (Burton et al., 1992) assessed throwing by using a developmental component category and found back-swing, humerus, \& forearm action displayed with lower level of movement components based on the category system. That is, using larger ball, the size defined by intrinsic measure (i.e., ratio to hand width), downgraded throwing skills in some aspects.

Researchers investigated ball velocity as one of the control parameters, the factor for the development of throwing patterns (Southard, 1998) in that when ball velocity was scaled up, lower skilled throwing pattern changed and progressed toward an optimal state 
(Southard 2002). He reported that the throwing patterns develop into advance patterns, changes in patterns of distal lag and velocity differences between adjoining segments solely function as increases in the velocity of throwing under practice conditions (Southard 2007). Interestingly, when the thrower practiced at scaling up the velocity of throwing they changed their throwing patterns earlier, with no instruction other than what they practiced at a constant throwing velocity. He concluded that the increase in throwing velocity assisted the learner in moving toward optimal performance. This result supported his previous work (Southard, 1998, 2002), which reported that throwing patterns of less skilled throwers resembled those of skilled throwers at higher velocity throws.

\section{Summary}

The ETA model is a contemporary approach to revealing the mechanisms that underlie movement changes and movement emergence in terms of mutual or reciprocal interactions between the performer and his or her environment. This model has been inspired by the multi-causal, contextual, and self-organizing nature of the contemporary works in developmental psychology (Thelen, 1995). Since Bernstein (1967) has defined movement outcome as resulting from coordinative interactions with many body parts and process, developmental psychologists shifted to non-linear paradigms, from linear model, in developmental skill acquisition, addressing a dyadic relationship between the central nervous system and body.

One of theoretical grounds of ETA is Newell's (1986) categories of constraints. His paradigm represents an outcome of movement provided by coordination of 
movement control, imposed constraints on the three major components of the system: (1) the task goal, (2) the environmental conditions, and (3) the characteristics of the performer.

The self-organizing nature of development is supported by the theory of affordance (Gibson, 1979), which defines an organism as an open system, particularly as a system very responsive to its environment so that the nature of the environment propels the organism in its evolutionary process. Perception and action coupled in the theory expanded the role of discovery and choice in ETA. The empirical evidences from the studies with young children supported the assumption of links between performer and environment throughout the perceptual system and led to the insight that, even at an early developmental stage, human beings may be sensitive to the contextual constraints affecting the way in which they move and may be able to make perceptual judgments when coping with the constraints imposed on a task.

With broad-based theoretical support, ETA was developed to utilize assessment, instruction, and research on motor skill acquisition and development. Burton and Davis (1991, 1992, 1996) proposed the applied model, which included four stages of its application on clinical and educational settings. Identification of task goal under the specific conditions of task is assumed to direct action towards achieving the goal. The second stage is creating student-centered environment in terms of achieving a task goal. Having choices in solving kinematic and strategic problems of a movement task give them the chance to tune various constraints around the task. This is called selfdetermination or self-organization. Based on the teacher's observation of the student performance at stage two, the teacher identifies critical skills necessary for the successful 
performance of the task under natural setting. Then, he or she manipulates the task in relation to the students' capability. This manipulation focuses on functional attention to achieve a goal, followed by assessment and evaluation of movement and form in the outcome stage on both qualitative and quantitative approaches.

Grounded in the ETA model, this study uses the task of throwing a ball at a target and attempts to stratify the variables relating to the task and the performer. In this investigation, the study manipulates these variables in order to examine the blended effects created by the interaction between environment and performer on the success in achieving the goal of the task. 


\section{CHAPTER THREE}

\section{Method}

The purpose of this study was to measure children's movement patterns and perceptual judgments in various throwing tasks. The study included two experiments in throwing task in which constraints were imposed by manipulating task parameters with intratask variations on the given tasks, in order to assess and analyze changes in the movement patterns and perceptual judgments of four-year-old children. The participants were asked to achieve a functional goal (e.g., throwing a ball at a target hoop to score). The experimental conditions included changes in distance from targets, size of ball in relation to target size aiming to, and height of target in relation to eye- height level of children, which were believed to challenge them to achieve the task goal.

The research hypotheses, in Experiment 1, are: to make a goal: (1) four-year-old children will produce different movement patterns as the height of target, relative to children's eye-height level, varies; and (2) four-year-old children will produce distinctive throwing patterns that are more successful at each target height accordingly and gradually increase the use of the successful patterns. A set of hula-hoops horizontally mounted created the unique layout of target according to the level of height of the standing targets. The impression of the target at above eye-height level differed from what was at below eye-height level. Even though both had the same absolute quality of the size, the layout of the target is perceived differently in that the space available for aiming at looks smaller than what it should be looked, which depends on a person's eye-height level. The horizontal hoop offers the distinct optical perception according to the standing height of 
the target in relation to a thrower's eye-height level in the line of sight. Using the horizontal hoop over a hoop hung in vertically was hypothesized for a thrower to offer sharp difference in terms of the physical property of target according to increment of height of target.

Experimental condition 2 hypothesized that: (1) four-year old children produce throwing patterns that contain backswings, stepping, and trunk action for forceful throws as the distance from a target increases; (2) as the distance from a target increases they will choose more small balls, instead of big balls, to produce one-handed throws; and (3) four-year old children perceive the absolute sizes of the balls and hoops strategically for more successful scoring.

The method used in this study is described in the following sections: (1) participants; (2) research design; (3) apparatus; (4) procedures; (4) instruments; (5) data analysis; and (6) pilot study.

\section{Participants}

Four-year-old children ( $n=5$; four boys and one girl) participated in this study. The investigator recruited the participants from among children from a local childcare center. The participants were assessed their fundamental motor skill developmental to verify their age-appropriate motor development (Appendix H). Test of gross motor development (TGMD) is known as a popular developmental change instrument designed to evaluate the gross motor skill development of children from ages 3 to 10 (Burton \& Miller, 1998).

In this convenience sample, the investigator solicited voluntary participation from the parents of all those children who met participant requirements, in order to ensure a 
prospective participant list, in case a child drops out of the study. Three prospective female participants were ruled out because they failed to meet participant requirements with regard to attendance, lower gross motor skill level than age appropriate level. Participants received T-shirts as souvenirs for participating in the study. Approval was obtained from the Institutional Review Board for the Protection of Human Subjects (Appendix C).

\section{Research Design}

Experiment 1 was designed to measure the extent to which throwing patterns change in accordance with variations in height of target, examine observable throwing patterns and measure the changes in humurus angle toward trunk. The participants were asked to throw a ball at a hoop, horizontally mounted on poles (Figure 1). The height of the target changed in the experiment so that the participants threw at both 22 inches (i.e. below the children's eye height level) and 60 inches (i.e. above their eye height level) from the ground.

In the same line of studies, the upper-arm actions, positioning the humerus above the shoulder, was observed as aiming at a high target in two-different target orientations: vertical and horizontal, and 2 levels, at below and above eye-height (Choi, Hawkins, \& Langley, 2008). The finding from a similar study with more target orientations supported the change in positioning the humerus at higher target (Choi, Hawkins, \& Langley, 2009). As presenting the target orientations in the study: vertical and horizontal, angle toward, angle away (i.e., 45 degree angles tilted toward and away from the throwers), observable change in throwing pattern were not founded in response to the variation in orientations but did in accordance with the height of target. The horizontal target orientation was 
created with a hula-hoop mounted on two poles. The higher horizontal target was the most challenging target among all eight targets from 4 orientations. The participants, a boy and a girl, who scored less than others were less likely to elevate their humurus position when a high horizontal target was presented right after the lower horizontal target (Choi et al., 2008). The limitation of the previous studies was the assessment in change of humerus action merely relying on direct observation with the discrete categories, the occurrence of positioning humerus high action or not. The subtle change in humerus action was not able to assess, which might be still the meaningful action to create the higher trajectory of ball flight to score. The perception led by the increment height of target might be less discernable for the children with horizontal orientations over other orientations used.

Unlike previous studies, this study measured and compared the humerus angle toward trunk when participants released a projectile aimed between low and high levels of target. Horizontal target might be less available to four-year old children than vertical orientation. Therefore, it was believed that the horizontal target might be considered a novel task that provides a 'now and here experience' for participants, suitable for increasing sensibility in the perception of affordance.

Experiment 2 was designed to test the perceptual judgment of four-year-old children in seeking strategic solutions relative to the physical dimensions of balls and hoops, in the context of goal-scoring tasks. The participants threw a ball at a set of targets, a big target, a 47-inch diameter hoop; and a small target, a 16-inch diameter hoop, mounted next to each other and aimed at the target from two spots, 75 and 150 inches from the target (Figure 2). Also, they chose a ball out of two different-sized balls, 2.5 
inch diameter and 12 inch diameter each in Figure 3, and threw one to make a goal at either a small target or a big target, at 75 inches and 150 inches in each trial.

Table1

Description of the Throwing Tasks

\begin{tabular}{|c|c|c|c|c|}
\hline & Ball & Target & $\begin{array}{c}\text { Target } \\
\text { Orientation }\end{array}$ & Changes in Distance \\
\hline Experiment 1 & $\begin{array}{c}\text { One size ball } \\
2.5 \text { inch diameter }\end{array}$ & $\begin{array}{l}\text { Two target heights } \\
22 \text { /60inches } \\
\text { One size target } 25 \\
\text { inch diameter }\end{array}$ & Horizontal & $\begin{array}{l}\text { Change of distance } \\
\text { from the ground to } \\
\text { a target }\end{array}$ \\
\hline Experiment 2 & $\begin{array}{c}\text { Two sized balls } \\
2.5 / 12 \text { inch diameter }\end{array}$ & $\begin{array}{l}\text { Two sized targets } \\
16 / 47 \text { inch diameter }\end{array}$ & Vertical & $\begin{array}{l}\text { Change of distance } \\
\text { from the target to a } \\
\text { thrower } \\
75 / 150 \text { inches }\end{array}$ \\
\hline
\end{tabular}

Both experimental conditions were designed by single case design method. Experiment 1 used an alternating treatment design (Kazdin, 1982) in which two or more treatments (i.e., independent variables) were implemented to affect a single target behavior (e.g., throwing pattern) (Cooper, Heron, \& Heward, 1987). The two task conditions of the experiment 1 , aiming at low-horizontal target and aiming at highhorizontal target, were alternated in a random order and administered an equal number of times across each of the conditions, so that each child had different task conditions each day.

Simultaneous treatment design was used to construct the experiment 2 , which is also referred to by some as an alternating treatment design (Kazdin, 1982). However, according to Cooper et al., (1987) any design that presents the participants with two or more treatments simultaneously and induces them, by their behaviors to choose between treatments should be termed a simultaneous treatment design. The experiment condition 
provided all task variations, two- size balls and two-size targets at each distance from targets during the entire experiment sessions. The choices of ball and target at each trial were recorded.

\section{Apparatus}

\section{Experiment 1}

The primary purpose of planning experimental conditions was creating the constraints imposing on the tasks so as to produce observable movement changes over time. Four- year old children used over-hand throwing in most trials, regardless of target orientations (Choi et al., 2008; 2009). Over-hand throwing might be a pattern used most in throwing for young children, who are less likely to be exposed to contexts where under-hand throwing would be needed. They didn't seem to differentiate the classes of physical properties of each orientation of vertical and horizontal, angle toward, angle away (i.e., 45 degree angles tilted toward and away from the throwers). It would be efficient in attempt to score as producing under-hand throws with horizontal, slanted tilted away orientations, which are believed to bring more success at both height levels. However, just few under-hand throws were observed in the end of the courses in the study from the ones whose were less competent scored less in the task.

ETA predicts that a child's throwing movements may vary according to the size of the ball the child chooses and the variations presented in the task (e.g., varying the height of a target in relation to a child's eye height level). In Experiment 1 it is assumed that different constraints are imposed in accordance with the height level change in the same target orientation. The children were asked to throw a ball, small enough to be able to be thrown with one hand. Making a goal at a horizontal target was a relatively novel 
task for 4-year-old children facing imposing constraints and could produce alternative movement patterns over over-arm throwing in terms of a specific task goal.

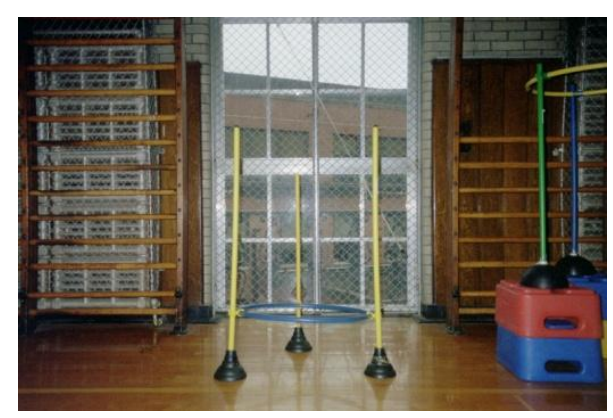

Figure1. Low horizontal orientation target (lower than children's eye-height level)

This experiment attempts to determine whether and to what extent children' throwing patterns change in accordance with novel target orientation. Presumably, overhand throw might not be compatible if the goal is a horizontal hoop. Moreover, over-hand throw might not be very successful in making a goal at a target higher than a child's eye height. Small ball tends to limit shooting with two hands, and encourage one-handed throws, instead. Burton et al. (1993) found that one-handed throwing works when using balls with relative sizes of less than 1.00 (i.e., the ratio of ball size to hand size) and twohanded throwing works when using balls with relative sizes of more than 1.50 . This experiment investigated the ETA premise that individual perception varies because performers recognize existing sources of size, distance, and surface height in terms of some dimension of their body (Mark, 1987). Accordingly, eye-height levels in relation to different body sizes determine intrinsic information, which a performer needs to make perceptual judgments. The children might perceive the physical dimensions (e.g., ball size, height of target, target orientation) in relation to task goal and produce distinctive throws that are likely to be successful. Therefore, relevant variation of tasks, designed 
with pedagogical considerations, may increase chances of the children acquiring a particular movement.

For Experiment 1, the participants were asked to throw balls one at a time at a 47inch target; they did so 75 inches from the target. This set of tests used one sized ball and a hoop attached horizontally at poles (Figure 1). The task goal was to throw the ball so that it came through the hoop. Each child was assigned to throw at both lower and higher than eye-height level in a random order, each day, for 14 days. An instructor handed one ball at a time to a child for each attempt for $3 \mathrm{~min}$. No instruction in throwing was given. Performance cues were restricted during the experiment as well. During the experiment, an instructor supervised a child's throwing according to preplanned protocol (Appendix I). However, positive feedback and encouragement were used as they were needed.

The independent variables in Experiment 1 were the relative height of a horizontal hoop target compared to 4 year-old children's eye-height. The dependent variables were the distinctive throwing patterns (e.g., over and under hand throwing) and the score.

\section{Table 2}

\section{Recording Sheet in Experiment 1}

\begin{tabular}{|c|c|c|c|c|c|c|c|c|c|c|c|c|}
\hline \multicolumn{13}{|c|}{ Under eye-height level } \\
\hline & $1^{\text {st }}$ & $2^{\text {nd }}$. & $3^{\text {rd }}$. & $4^{\text {th }}$. & $5^{\text {th }}$ & $6^{\text {th }}$. & $7^{\text {th }}$. & $8^{\text {th }}$ & $9^{\text {th }}$. & $10^{\text {th }}$ & $11^{\text {th }}$. & $12^{\text {th }}$. \\
\hline One-hand overhand & $\mathrm{F}$ & $\mathrm{S}$ & & $\mathrm{F}$ & $\mathrm{S}$ & $\mathrm{F}$ & $\mathrm{F}$ & $\mathrm{S}$ & & $\mathrm{S}$ & & \\
\hline One-hand underhand & & & $\mathrm{S}$ & & & & & & $\mathrm{S}$ & & $\mathrm{S}$ & $\mathrm{S}$ \\
\hline \multicolumn{13}{|l|}{ Over eye-height level } \\
\hline & & & & & & & & & & & & \\
\hline \multicolumn{13}{|l|}{ One-hand overhand } \\
\hline One-hand underhand & & & & & & & & & & & & \\
\hline
\end{tabular}

Note. Each trial is coded as success, $\mathrm{S}$ (making score) or failure, F (no goal). 


\section{Experiment 2}

The hypothesis in experimental condition 2 was that children may perceive the physical dimensions of the balls and hoops and attempt solutions according to scoring goals. Experimental condition 2 was designed to examine whether four year old children perceive the size of the balls as relative to the size of the hoops by strategically choosing a ball and a hoop that makes it easier to throw the ball through the hoop, thus scoring a goal.

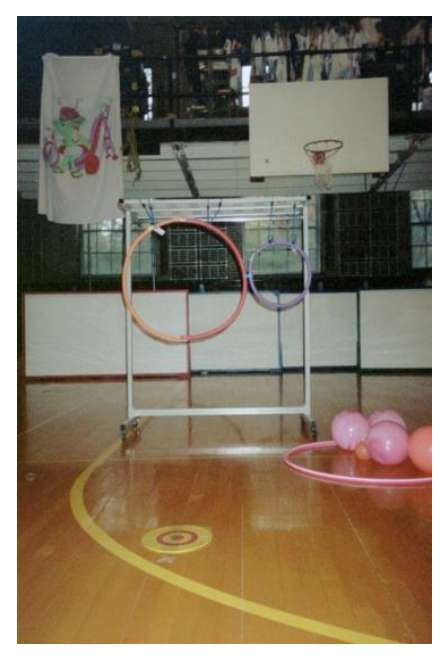

Figure 2. Example of the Target in Experiment 2

For Experiment 2, the participants were repeatedly asked to select a ball of their choices and attempted to throw it through a hoop of their choices. The participants were asked to throw the ball at one of two different sized hoops. Two balls, sized 2.5 inches and 12 inches in diameter were provided in the same color. The target hoops had diameter of 16 and 47 inches respectively and were placed 75 inches apart in the actual experiment (unlike the adjacent positioning in Figure 2). The sizes of the balls in this experiment have been chosen by the investigator for their absolute dimensions, not relative to the size of the children's hands. The hoops were vertically mounted on a stand and were facing a thrower at distances of 75 and 150 inches. 


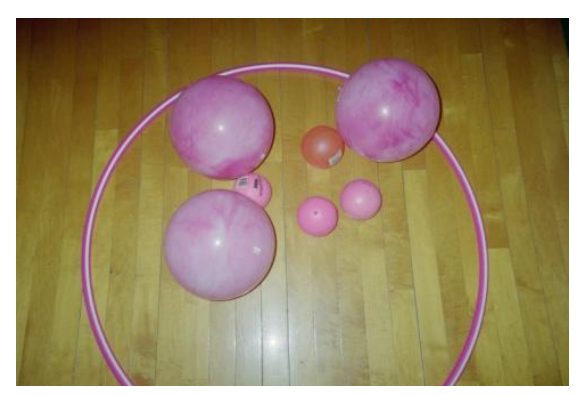

Figure 3. Balls in Experiment 2

The children in this study might engage in trunk action, backswings and stepping as an over-hand throw is used because the distance from the thrower to the target increased. Trunk action, backswings and stepping are considered to be some of the skill components that determine an advanced throwing pattern (Haywood \& Getchell, 2008). Pedagogical consideration of physical dimensions in throwing tasks might encourage more mature patterns in throwing skill acquisition.

The children attempted to score as many goals as they did for $3 \mathrm{~min}$, at each distance from the targets. In this experiment, an instructor supervised a child's attempt according to an experimental protocol (Appendix I). He or she did not provide any instruction in throwing and controls the experimental setting, but tried to maintain a positive atmosphere during the experiment.

Independent variables are: (1) choice between two sized hoops, (2) choice between two sized balls, and (3) increments of distance from a throwing point to targets. Dependent variables are: (1) successful throws with balls in selected hoop and balls; and (2) the movement components in forceful throwing as distance from the target increases (e.g., backswing, trunk action, stepping). 
Table 3

Recording Sheet in Experiment 2

\begin{tabular}{|c|c|c|c|c|c|c|c|c|c|c|c|c|c|c|}
\hline \multirow{2}{*}{$\begin{array}{l}\text { Attempts } \\
\text { Balls } \\
\text { Hoops }\end{array}$} & \multicolumn{2}{|l|}{$1^{\text {st }}$} & \multicolumn{2}{|l|}{$2^{\text {nd }}}$. & \multicolumn{2}{|l|}{$3^{\text {rd }}$. } & \multicolumn{2}{|l|}{$4^{\text {th }}}$. & \multicolumn{2}{|l|}{$5^{\text {th }}$. } & \multicolumn{2}{|l|}{$6^{\text {th }}$} & \multicolumn{2}{|l|}{$8^{\text {th }}}$. \\
\hline & Small & Big & Small & Big & Small & Big & Small & Big & Small & Big & Small & Big & Small & Big \\
\hline \multicolumn{15}{|c|}{ From 75 inches } \\
\hline $\begin{array}{l}\text { Small } \\
\text { hoop }\end{array}$ & & $\mathrm{S}$ & & $\mathrm{S}$ & & & $\mathrm{S}$ & & & $\mathrm{F}$ & $\mathrm{S}$ & & $\mathrm{S}$ & \\
\hline $\begin{array}{l}\text { Big } \\
\text { hoop }\end{array}$ & & & & & $\mathrm{F}$ & & & $\mathrm{F}$ & & & & $\mathrm{S}$ & & \\
\hline \multicolumn{15}{|c|}{ From 150 inches } \\
\hline $\begin{array}{l}\text { Small } \\
\text { hoop }\end{array}$ & & & & & & & & & & & $\mathrm{F}$ & & & \\
\hline $\begin{array}{l}\text { Big } \\
\text { hoop }\end{array}$ & & & & & & & & & & & & & & \\
\hline
\end{tabular}

Note. Each trial is coded as a success, $\mathrm{S}$ (scoring a goal) or failure, F (no goal).

\section{Procedure}

Approval was obtained from the director of the Motor Development Center for the use of equipment and the recruiting of participants. Approval of Co-director of the local childcare center was obtained for the use of space and the children's participation (Appendix D). Approval was obtained from the Institutional Review Board for the Protection of Human Subjects (Appendix C).

Over 14 days, the participants were asked to perform the tasks of the two experiments. For Experiment 1, horizontal hoops at two different heights were applied in random order on each day for 14 days. This scheduling was intended to alternate the conditions in order to achieve an equal number of exposures to each condition per participant throughout the course of Experiment 1. In Experiment 2, the participants chose two targets and two balls of different sizes, which were aimed at the target from two different distances. Each day children was given the same condition. 
Two stations were set on a playground at a local childcare center in Morgantown West Virginia. Some equipments belonging to the Motor Development Center at West Virginia University was used to build the stations for the experiments. During data collection the investigator visited the child care center and built the stations for a day of experiment. A camcorder was set in an outdoor toy house, which helped in desensitizing the presence of videotaping procedure. It was placed at a spot that made it possible to shoot a child from the front diagonally. It was mounted on a tripod to ensure the quality of video clips. An instructor wore a wireless microphone for audio recording while conducting the experiments.

When the experimental setting was ready, an instructor came into the classroom and took a child at one time to the experiment-setting outside. Play ground was the only open space big enough to build the station, which allowed the investigator to collect data only when they had a class. After completing the experimental tasks, a child came back to the classroom.

In Experiment 1, the instructor guided a child to stand behind a spot to keep them 75 inches away from the targets. However, there was no physically taped line or spot on the ground. The instructor recognized the spot and kept children staying at the spot without a physical mark. A physical mark may restrict stepping action while trying not to cross any physical mark or line. The instructor did not any instructional interventions or provides any performance cues in throwing but did organizational cues and demonstrations such as how a ball passes through a hoop to make a goal by releasing a ball from the top of horizontal hoop and where they stand and pick up the balls. In the pilot study, the investigator discovered that sometimes four-year old children could not 
understand verbal instruction such as 'throw this ball to the target and make a goal'. The instructor could not provide any instruction in throwing but provided the instruction of how the task works, what 'making a goal' meant, demonstrated passing a ball through the hoop.

The instructor gave a child a prompt like 'ready, throw the ball'. If he or she made a goal, positive feedback was given. If a child didn't make a goal after several consecutive attempts the instructor prompts, 'can you show me a different way to throw the ball?' as well as encouragements. The prompt may facilitate producing an alternative throwing pattern and convince a child to make a choice in terms of being able to use a different way to achieve a goal.

A child throws a ball handed by the instructor to a target. The instructor made sure that he throws a ball behind the line at each attempt and at a proper tempo. The observation from the pilot study was that at times children were very excited about getting picked to participate in the throwing tasks, or for no reason at all. When that happened they tended to throw balls too quickly, and needed to be controlled by the instructor. The instructor sets a routine, throwing a ball at the prompt, 'ready, throw a ball'. A child throws balls as many times as possible during the experiment. The investigator videotapes every attempt and times the session to ask the instructor every 3 min to end each session.

Experiment 2 was conducted according to the same protocol as Experiment 1. After completing Experiment 1, a child moved to the experimental setting for Experiment 2 and faced the targets. Each attempt began with the instructor's prompt. A child threw balls at each distance for $3 \mathrm{~min}$ (i.e., 75 and 150 inches from the targets). The instructor 
put balls back into a hoop on the ground and lets a child had an equal chance to choose between small and big balls. The small and big balls were made of the same materials, and colors. As Experiment 1, the instructor refrained verbal instruction cues and demonstration in throwing during Experiment 2 as well.

\section{Instruments}

The investigator analyzed the children's throws by using Dartfish 4.5., a videoanalysis software (SimulCam ${ }^{\mathrm{TM}}$ technology, 2007), which compared and captured a movement. This video analysis software broke down the video clips of the children's throws and measured some changes in throwing patterns over time. Elbow and arm movement, and trunk action was captured to see some changes in continuous throwing movement.

Video clips from the pilot study, done in spring 2007, were used for training in observation and analysis in this study. A graduate student practiced identifying the responses of children in each experiment and recorded them too. His analysis was used to check the reliability of this analysis.

The Test of Gross Motor Development (TGMD; Ulrich, 1985) was used to verify if participants were functioning at an age-appropriate level in gross motor skill development. Burton and Miller (1998) cited studies reporting the reliability level of the test (Ulrich, Riggen, Ozmun, Screws, \& Cleland, 1989), which resulted in the high level of reliability of the TGMD. Ulrich (1985) claimed to establish content validity with agreements among motor development experts. 


\section{Data Analyses}

Observation was made with video clips by using the Dartfish Pro 4.5, a video analysis program (SimulCam ${ }^{\mathrm{TM}}$ technology, 2007). Changes in choice and throwing movements were recorded. To analyze data from observation descriptive statistics were used. To assess changes in throwing patterns, the investigator used a sequence of throwing development, describing the hierarchical order in the development of throwing, examined by Carson (1985), and Haywood and Getchell (2008) as criterion for reference. Change in trends and level on graphs were examined on graphs by visual inspection to see if task variations in experimental settings might be responsible for observable changes in throwing patterns.

\section{Pilot Study}

The investigator conducted a pilot study, in spring 2007, consisting of the modified experiments with 4 year-old children from a local child care center, in Morgantown, West Virginia. A throwing task was designed to assess changes in throwing patterns as a function of variation in target orientations and height. Targets were created by using hoops ( 25 inches in diameter) set in vertical, horizontal, and slanting orientations. The target's height was adjusted in relation to the children's eye height level. Each orientation of target was presented at two levels, both lower and higher than eye-height (22 and 60 inches from the ground respectively). Four children enrolled in KinderSkills, a preschool motor skill program at a large state university, participated in this study. During the experimental sessions, instruction in throwing skill was restricted. Throwing patterns were categorized in terms of developmental stages to measure 
variations in throwing. The checklist included the position of the throwing hand and elbow, forearm action, foot position, and stepping in early over-arm throwing (Carson, 1985; Haywood \& Getchell, 2008). Data was collected once a week for a seven-week period and all sessions were videotaped.
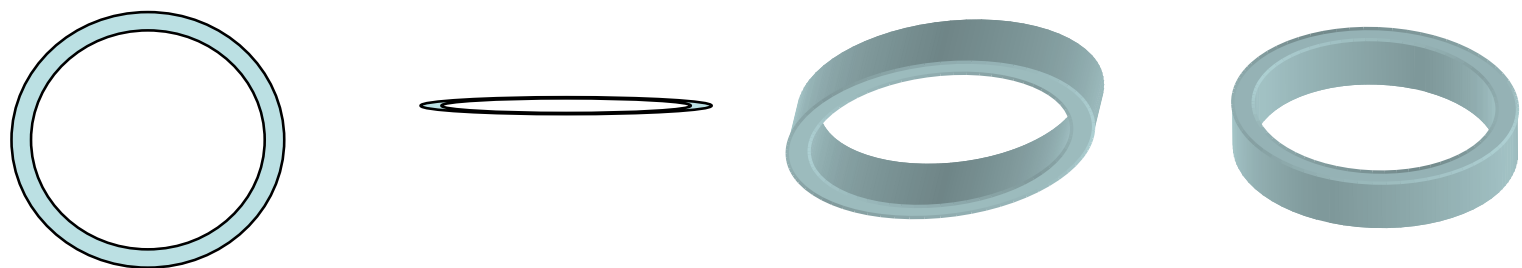

Figure 4. Four Different Orientations of the targets in the study (Choi et al., 2008): Vertical, Horizontal, Slanted Hoop \#1 and Slanted Hoop \#2

Results found that more mature developmental components were observed in the throwing hand and elbow positioning when children attempted to hit high level targets. Homo-lateral stepping was performed in throwing at both high and low level targets. The subjects jumped and stood on their toes when throwing to a high target, instead of stepping. Those actions might produce what the subjects perceived as a more appropriate trajectory relative to the higher target, but they may also hinder the development of more mature throwing patterns. Future research may investigate whether target heights between the two used in this study (slightly higher than eye-height level) may facilitate more advanced throwing patterns. The results from the pilot study provided justification for some changes in the full study. 
Over-hand throwing was a dominant pattern for children with all types of hoop orientation; even though, two children produced under-hand throwing patterns when they attempted to do the horizontal hoop in both heights. They did not retain the under-hand throwing pattern for the horizontal hoop for the remaining sessions after it had been performed. A boy used the under-hand throwing in an early experimental session and a girl used it in the very last session. The children's throws did not appear to differ a lot for the horizontal and vertical hoops from those for the two slanted hoops. It might be because of very similar constraints imposed by horizontal hoops and slanted hoops \#2 (i.e., a 45 degree angle sloping downwards, away from a thrower), and vertical hoops and slanted hoops \#1 (i.e., a 45 degree angle sloping downward toward a thrower). 4 year-old children might not detect the affordances of each hoop's properties as they produce a throwing pattern. Accordingly, it seemed that the orientations of hoop failed to present distinctive constraints that children may perceive. The results from the differentiation of height level of hoops in relation to children's eye level produced some implications for predictions of changes in throwing pattern. The height level might be a relatively perceivable constraint for the children.

The observations from the pilot study reveal that a study needs more sessions and, often, more tries to expose a task constraint and to change a functional movement pattern in throwing. Also, the horizontal hoop might be one of the novel tasks, which may help to explain the demand affordance of task achievement and, may distinguish from the physical properties of the other hoops. It is expected that change from over-hand throwing to under hand-throwing will be possible by imposing the task constraint of horizontal hoop on the children for a longer period of examination. 


\section{CHAPTER FOUR}

Results

The purpose of this study is to answer three questions: (1) Do four-year old children respond to changes in the height of a target in relation to their eye height level and demonstrate throwing patterns (e.g., humerus movement), which may be effective to achieve a goal? (2) Does the size of the ball relative to the size of the hand influence the transition from one-handed throwing to two-handed throwing? (3) Do four-year old children perceive the absolute sizes of a ball and a hoop strategically? In other words, do they choose ball sizes suitable for relevant hoop sizes, so that they can score more successfully? Do they vary ball size choices as distance from a target increases? Do they perform some movements to produce forceful throwing like throwing at a distance?

The participants were tested to verify age-appropriate object manipulation skill development by using TGMD, the Object Control subtest. In the result of the test, the participants were rated neither very superior and superior, nor poor and very poor. The evaluation from the test result verified that the participants fell within either average or proximity of average level in the object manipulation of skill development in comparison with the same age group. 
Table 4

TGMD Object Control Test Result

\begin{tabular}{ccccc}
\hline & \multicolumn{4}{c}{ Object Control Subtest } \\
\cline { 2 - 5 } & Raw score & Standard score & $\begin{array}{c}\text { Percentage } \\
\text { Included }\end{array}$ & Rating \\
\hline Jonah & 33 & 13 & $16.12 \%$ & Above average \\
Oloe & 13 & 6 & $16.12 \%$ & Below average \\
Trever & 21 & 9 & $49.51 \%$ & Average \\
Zack & 26 & 10 & $49.51 \%$ & Average \\
Payton & 20 & 8 & $49.51 \%$ & Average \\
\hline
\end{tabular}

Experiment 1

Experiment 1 was designed to attempt to answer the research question, 'Do four-year old children respond to changes in the height of a target in relation to their eye height level and demonstrate throwing patterns (e.g., humerus movement) which may be effective to achieve a goal?' The participants were asked to throw a ball at a hoop, horizontally mounted on poles (Figure.1). The video clips were analyzed to examine the extent to which throwing patterns change in accordance with variations in the height of the target, which were observable throwing patterns and the changes in humurus angle in relation to trunk. The height of the target changed in the experiment so that the participants threw at both 22 inches (i.e. below the children's eye height level) and 60 inches (i.e. above their eye height level) from the ground.

Data from Figures 5 to 8 present the changes in humerus angle in relation to trunk over the entire trials during Experiment1. The numbers of attempts at throwing varied each day since individuals were asked to throw balls at their own pace. 


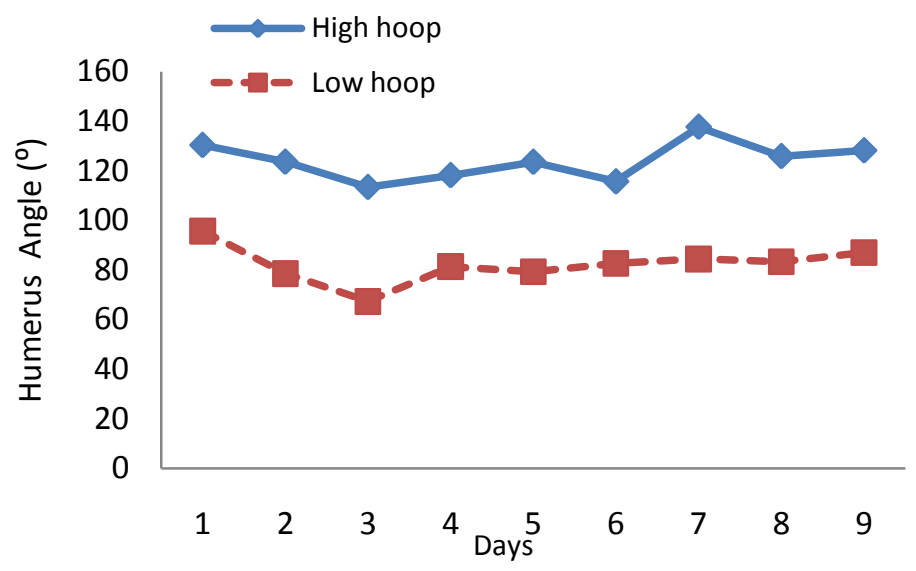

Figure 5. Jonah's mean humerus angle according to target heights

$\left(\right.$ Note . range $($ high target $)=56.4019^{\circ}$ Max: $147.308^{\circ}$ Min: $83.4558^{\circ}$; range $($ low target $)=60.2541^{\circ}$ Max:

$116.2581^{\circ}$ Min: $\left.57.0004^{\circ}\right)$

Jonah's humerus angles measured in each day trials distributes from Max:

$147.308^{\circ}$ to Min: $83.4558^{\circ}$ with a high target in Figure 5. The range of changes in angle is from Max: $116.2581^{\circ}$ to Min: $57.0004^{\circ}$ in attempts to score at low target. Humerus angles shifted from large angles to smaller angles as the height of the target decreased. The distribution of humerus angles at each height of the target is reflected in relative large angle's distribution with high target and small angle's distribution at low target in Figure 5 .

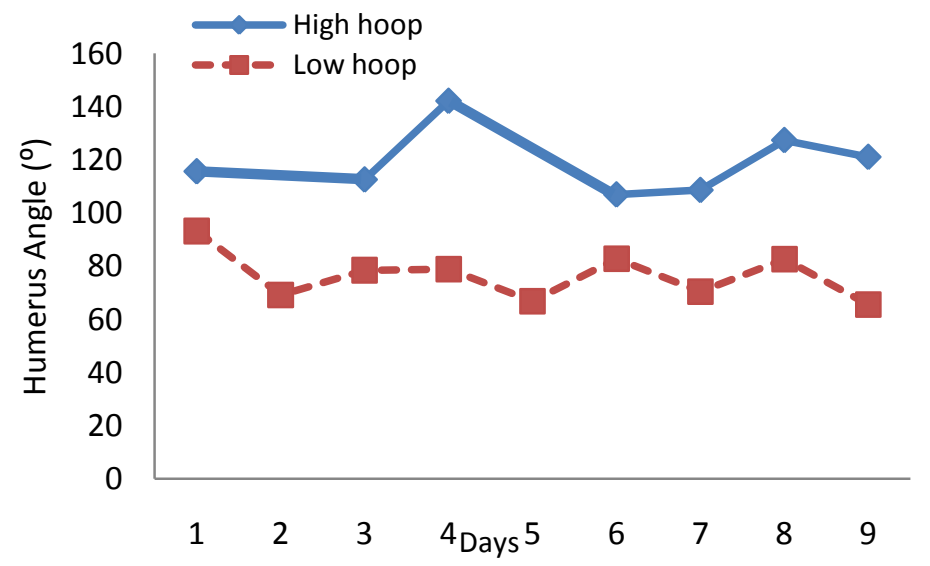


Figure 6. Oloe's mean humerus angle according to target heights

$\left(\right.$ Note range $($ high target $)=52.8897^{\circ}$ Max: $145.7089^{\circ}$ Min: $93.8192^{\circ}$; range $($ low target $)=51.4402^{\circ}$ Max: $104.2511^{\circ}$ Min: $\left.53.8109^{\circ}\right)$

Oloe's data in Figure 6 present the changes in the degree of humerus angle in accordance with changes in target height. The changes in angle distribute from Max $145.7089^{\circ}$ and Min: $93.8192^{\circ}$ to Max: $104.2511^{\circ}$ and Min: $53.8109^{\circ}$ as the target moved down from 60 inches to 22 inches from the ground accordingly. As reported with Jonah's data in Figure 5, the shift from large angles to small angles distribution is shown in Figure 6. The pattern has not changed during the entire 9 day- sessions.

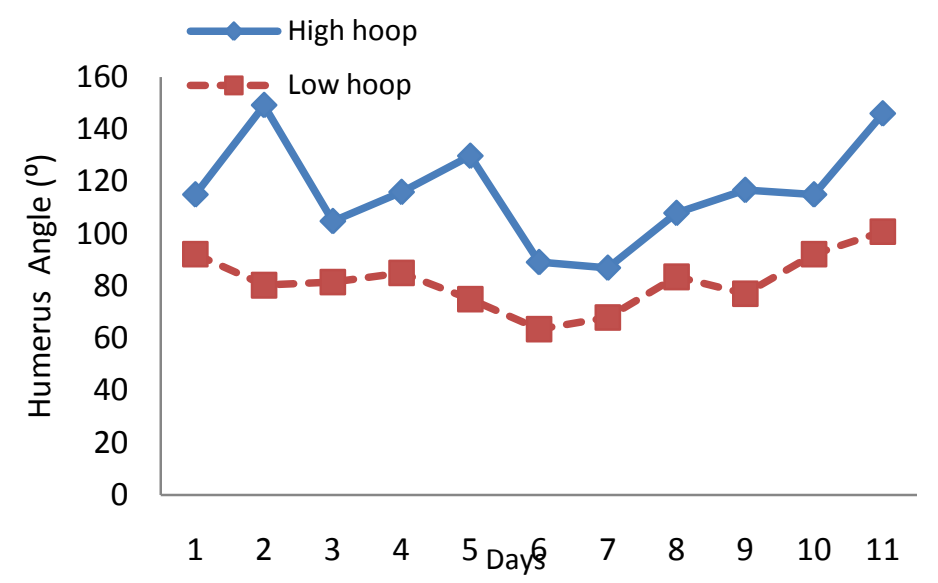

Figure 7. Trever's mean humerus angle according to target heights

$\left(\right.$ Note . range $($ high target $)=118.105^{\circ}$ Max: $177.1966^{\circ}$ Min: $60.0916^{\circ}$; range $($ low target $)=76.7635^{\circ}$ Max:

$133.1563^{\circ} \quad$ Min: $\left.56.3928^{\circ}\right)$

In Figure 7 Trever's humerus angle changes from Max:177.1966º and Min: $60.0916^{\circ}$ at high target to Max: $133.1563^{\circ}$ and Min: $56.3928^{\circ}$ at low target, in accordance with the changes in target height as well. The humerus angle distribution is more highly 
variable at high target in Figure 7, but the distribution for low target is shown as a collected pattern (i.e., less variable) as in Jonah's and Oloe's.

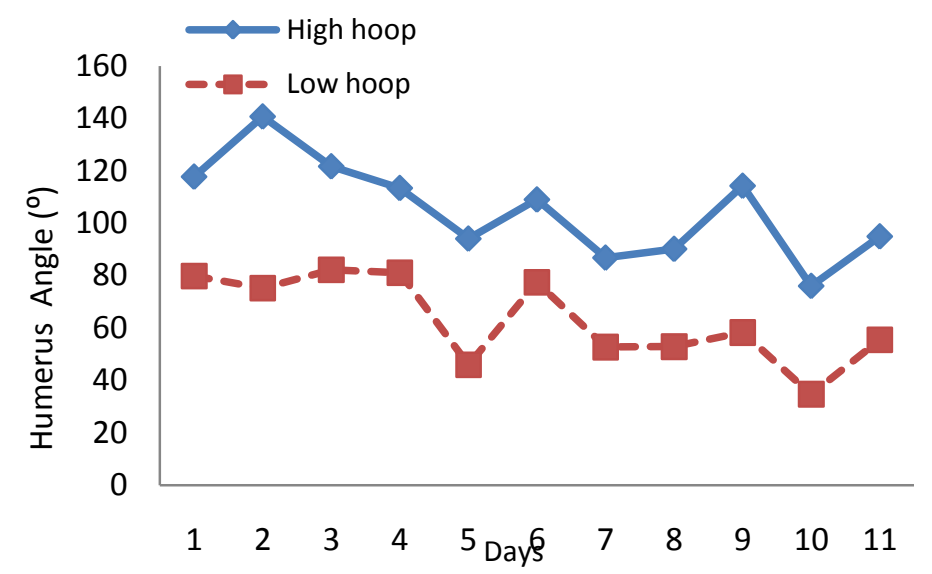

Figure 8. Payton's mean humerus angle according to target heights

$\left(\right.$ Note . range $($ high target $)=107.1347^{\circ}$ Max: $170.2358^{\circ}$ Min: $64.1011^{\circ}$; range $=72.9054^{\circ}$ Max: $96.2146^{\circ}$

$\left.\operatorname{Min}: 24.3092^{\circ}\right)$

As Figure 8 is seen Payton also produced a bigger humerus lift in throwing action when aiming at a high target. The humerus angle distributions indicate that the degree of humerus angle varied over the course of experiemntal sessions with the high target. However, the upper arm movements still respond to the disparity in the targets heights, from 60 inches to 22 inches, differently. Aiming at high target produced larger humerus lifting action and at low target produced relatively small actions before releasing a ball. 
Table 5

Range of Humerus Angle

\begin{tabular}{ccccc}
\hline & \multicolumn{2}{c}{ Low target } & \multicolumn{2}{c}{ High target } \\
\cline { 2 - 5 } & Max & Min & Max & Min \\
\hline Jonah & $116.2581^{\circ}$ & $57.0004^{\circ}$ & $147.308^{\circ}$ & $83.4558^{\circ}$ \\
Oloe & $104.2511^{\circ}$ & $53.8109^{\circ}$ & $145.7089^{\circ}$ & $93.8192^{\circ}$ \\
Trever & $133.1563^{\circ}$ & $56.3928^{\circ}$ & $177.1966^{\circ}$ & $60.0916^{\circ}$ \\
Payton & $96.2146^{\circ}$ & $24.3092^{\circ}$ & $170.2358^{\circ}$ & $64.1011^{\circ}$ \\
\hline
\end{tabular}
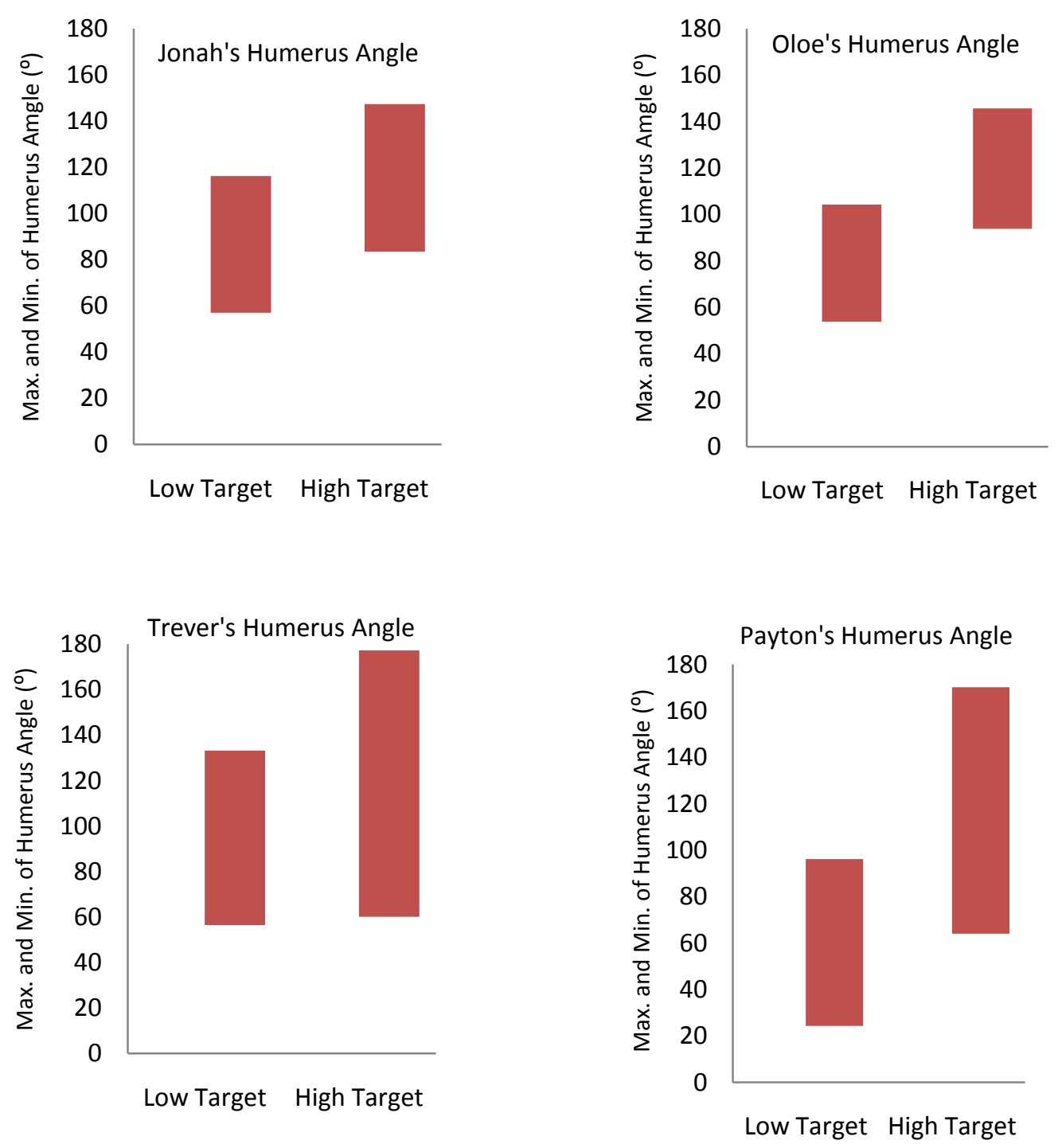

Figure 9. Maximum and minimum of humerus angle according to target heights 
Table 6.

Score Rate and Rank at the Horizontal Hoop and Range of Humerus Angle

\begin{tabular}{ccccc}
\hline & \multicolumn{2}{c}{ Low target } & \multicolumn{2}{c}{ High target } \\
\cline { 2 - 5 } & Score rates & Ranges & Score rates & Ranges \\
\hline Jonah & $0.58(1)$ & $60.2541(3)$ & $0.32(1)$ & $56.4019(3)$ \\
Oloe & $0.58(1)$ & $51.4402(4)$ & $0.26(2)$ & $52.8897(4)$ \\
Trever & $0.47(4)$ & $76.7635(1)$ & $0.25(4)$ & $118.105(1)$ \\
Payton & $0.55(3)$ & $72.9054(2)$ & $0.26(2)$ & $107.1347(2)$ \\
\hline
\end{tabular}

Note. Number in parenthesis refers to rank. Low target is a horizontal hoop with 22 inches of height (i.e. below the children's eye height level) from the ground. High target is a horizontal hoop with 60 inches of height (i.e. above their eye height level) from the ground.

All participants produced large humerus angles when aiming at a high target compared to the angle at low target. The range of motion in the humerus angle responded to changes in the target height. However, the range of variation in the humerus angle of individuals varied in Table 6 and Figure 9. Trever and Payton produced wider ranges of motion in humerus angle than Jonah and Zack.. The maximum angle of Trever and Payton were $177.1966^{\circ}$ and $170.2358^{\circ}$ each at the high target and the minimum angles were $60.0916^{\circ}$ and $64.1011^{\circ}$ each. In comparison to the angels of Jack and Jonah they appeared to produce a relatively bigger rotation of upper arm joint. Trever changed humerus angle, over the course of the experiment, the most at high target (range $=76.7635)$ and at low target (range $=118.105)$ among the participants in Table $6 . \mathrm{He}$ produced a score rate of 0.47 at the high target and 0.25 at the low target,which was the least successful among the participants. Jonah and Oloe's humerus lifting action were seen to have produced rather stable performances over the course of the experiment. They 
scored the most. Jonah had a score rate of 0.58 and 0.32 at high and low targets and Oloe had 0.58 and 0.26 at both high and low targets each.

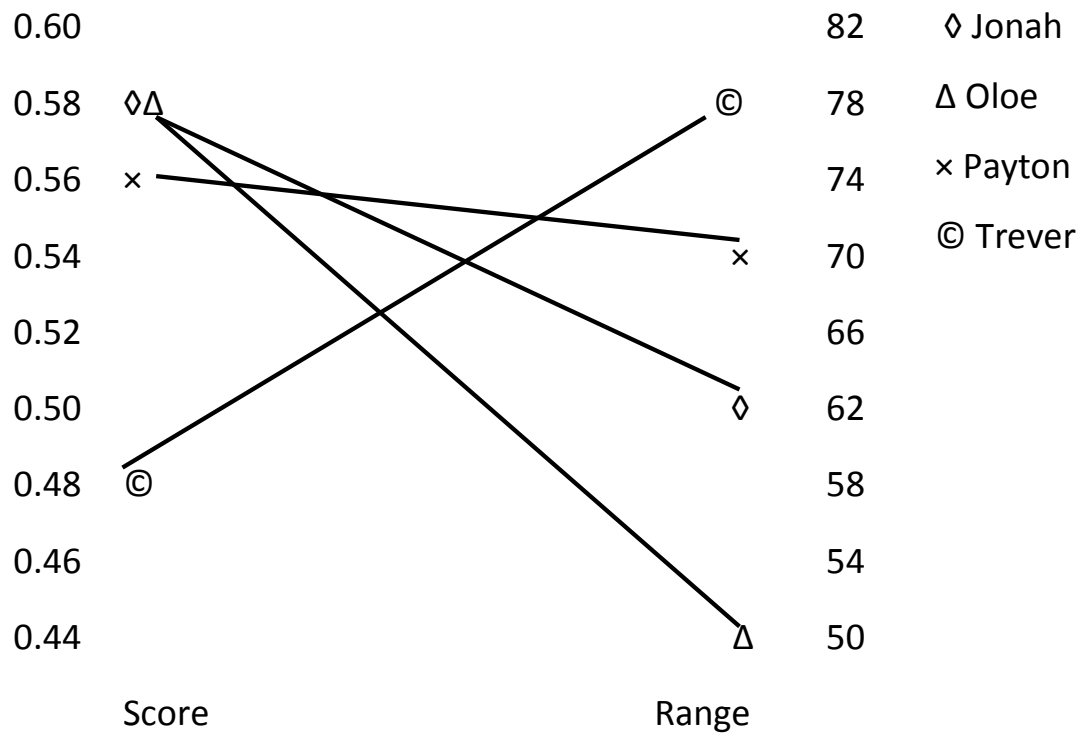

Figure 10. Relation between score rates and ranges of humerus angle at the low target in Experiment 1

Data presented in Figures 10 and11 show the implication of the relationship between score rates and range of angle. In the attempts of scoring with a low target only Trever's data displays a positive relation with his score rate and range of humerus angle. Data of Jonah, Oloe, and Payton, whose score rates were relatively higher than Trever's and whose humerus angles appeared smaller than Trever's, showed a negative relation between higher score rate and lower range change of humerus angle. 


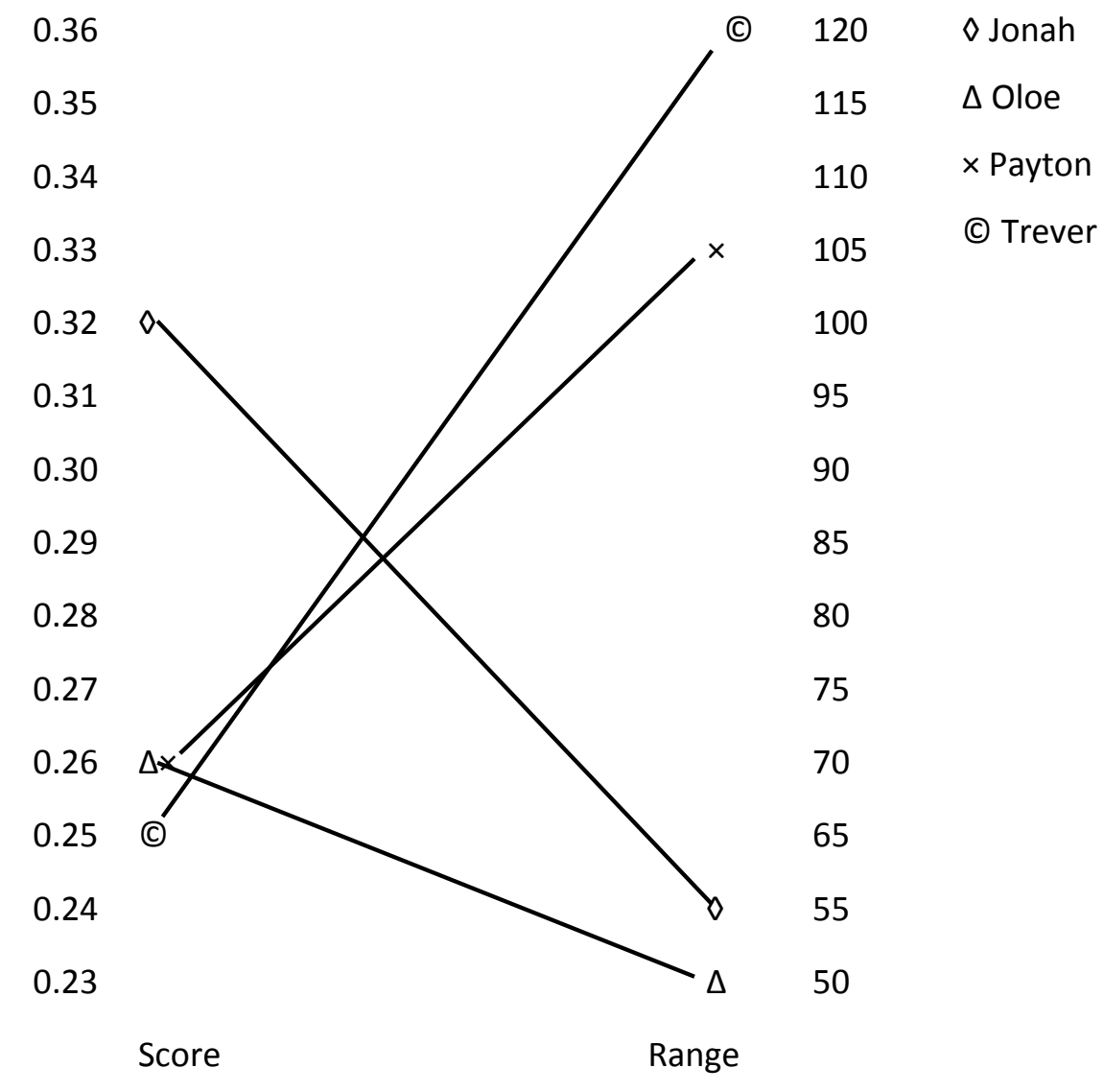

Figure 11. Relation between score rates and ranges of humerus angle at the high target in Experiment 1

In the attempt to score a high target Trever's data maintain the positive relation between the score rate and the humerus angle. His score rate was the least and his changes in the humerus angle were largest. Trever and Payton share the same relation between score rate and humerus angle in Figure 11.

\section{Experiment 2}

Experiment 2 was designed to test the perceptual judgment of four-year-old children in seeking strategic solutions relative to the physical dimensions of balls and hoops, in the context of goal-scoring tasks. Data were analyzed to answer the research 
questions 'Does the size of the ball relative to the size of the hand influence the transition from one handed throwing to two handed throwing?' 'Do four-year old children perceive the absolute sizes of a ball and a hoop strategically?' Corollary to the second question were, 'Do they choose ball sizes suitable for relevant hoop sizes, so that they can score more successfully?'; 'Do they vary ball size choices as distance from a target increases? Do they perform some movements to produce forceful throwing like throwing at a distance?'

The participants threw a ball at a set of targets, a big target, a 47-inch diameter hoop, and a small target, a 16-inch diameter hoop, mounted next to each other and aimed at the target from two spots, 75 inches and 150 inches from the targets (Figure 2). Also, they chose a ball from two different sizes, 2.5 inch diameter and 12 inch diameter each, and threw one to make a goal at either a small target or a big target, at 75 inches and 150 inches, in each trial. They attempted to score first at the targets with small and big hoops at a distance of 75 inches from then moved back to the targets from at a distance of 150 inches.
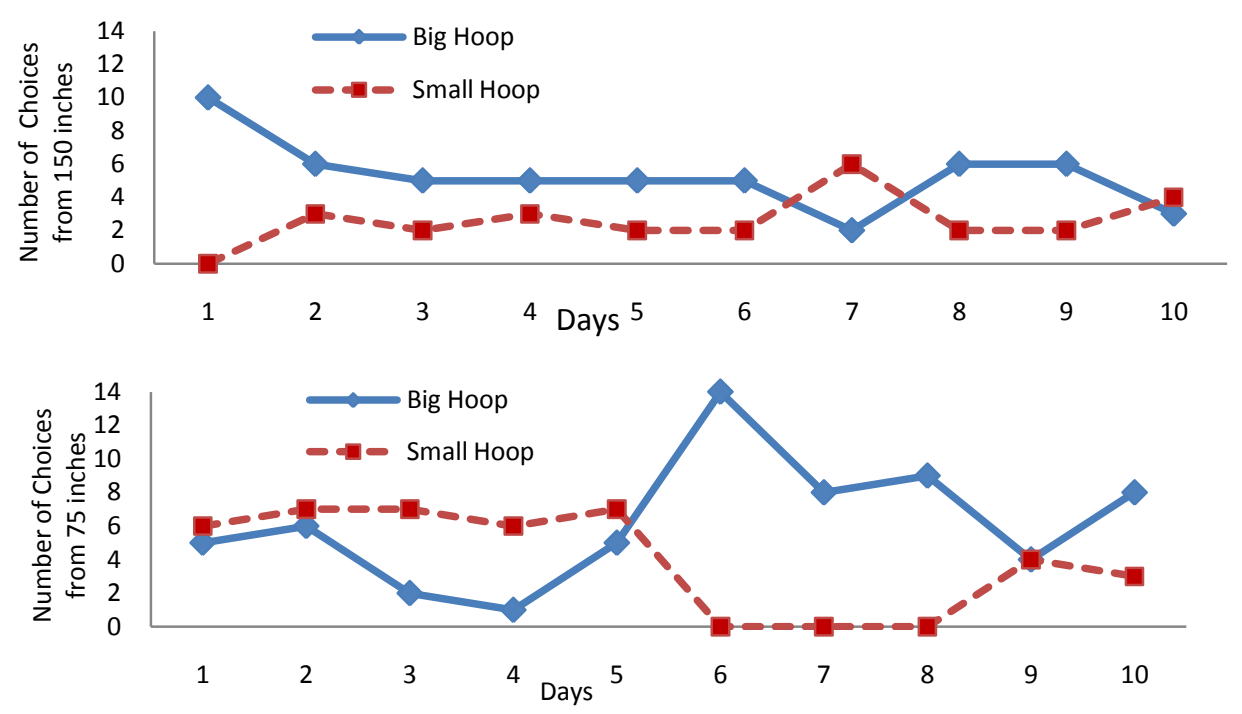

Figure 12. Jonah's choices of hoops aiming from 75 inches and 150 inches 

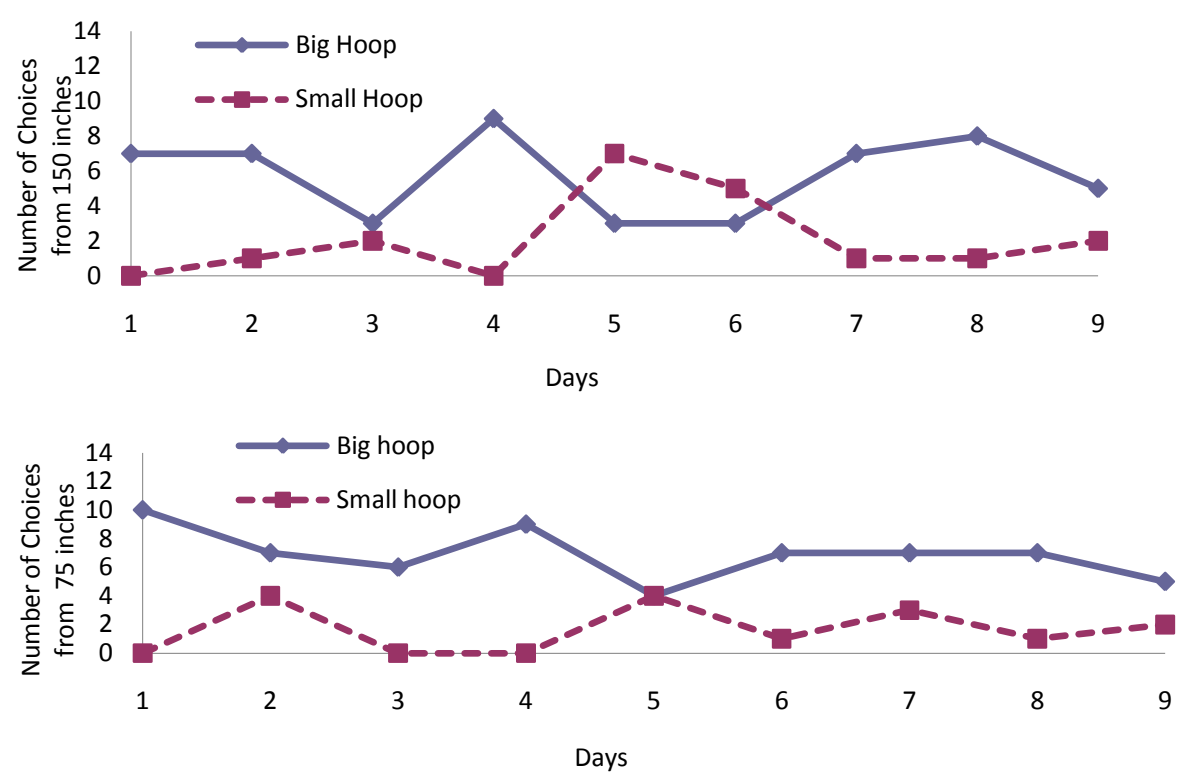

Figure 13. Oloe's choices of hoops aiming from 75 inches and 150 inches

The number of choices of either big hoop or small is presented in Figures 12 and 13. The data on these figures show the difference in the hoop choice pattern as the distance from the target hoop increases. In Figure12 Jonah attempted to score both small and big hoops in the short distance, 75 inches from the targets but chose the big hoop target more ( $M=6.2$ big hoop; $M=4$ small hoop). On Day 6 he changed his choice, aiming at the big hoop more until the end of sessions. From the longer distance, 150 inches from the target, the choice was observed to be stable in favor of choosing the big hoop target ( $M=5.3$ big hoop; $M=2.6$ small hoop). Choice of the big hoop target was observed with Oloe's data in Figure 2 ( $M=6.8$ big hoop; $M=1.6$ small hoop) from 150 inches and ( $M=5.7 \mathrm{big}$ hoop; $M=2.1$ small hoop) from 75 inches. 

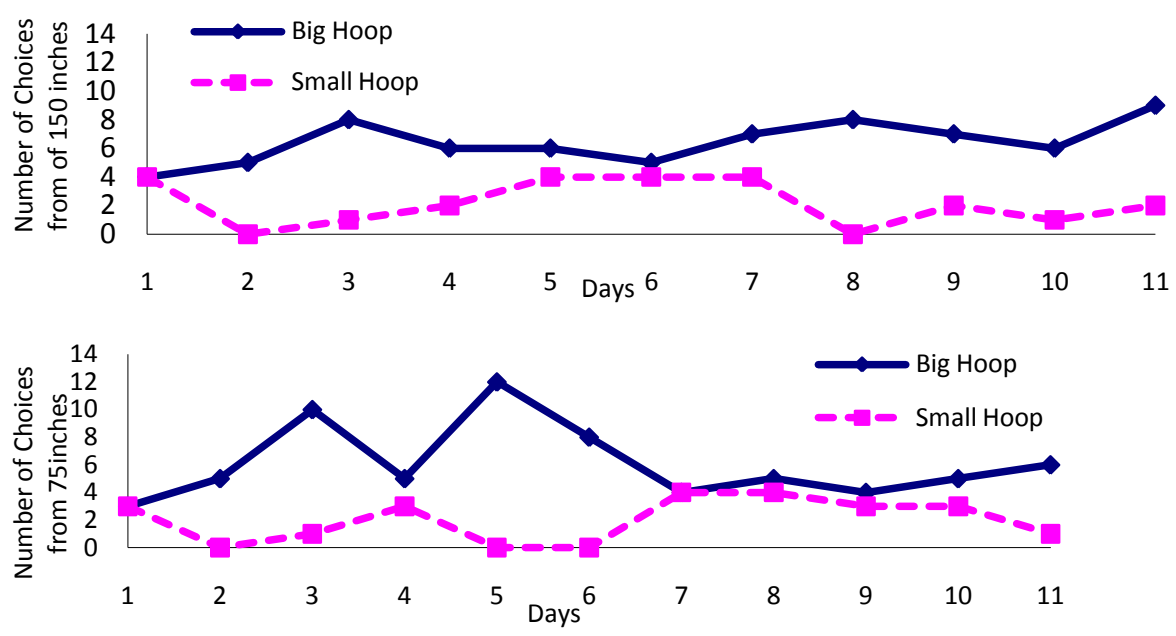

Figure 14. Trever's choices of hoops aiming from 75 inches and 150 inches
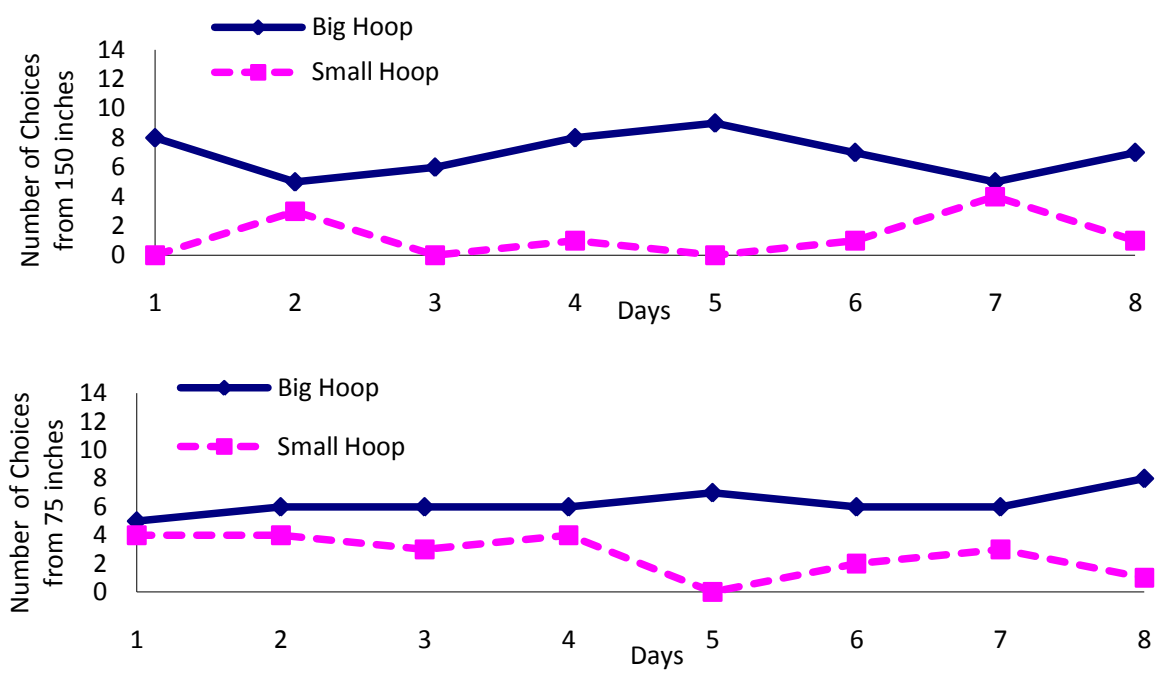

Figure 15. Zack's choices of hoops aiming from 75 inches and 150 inches 

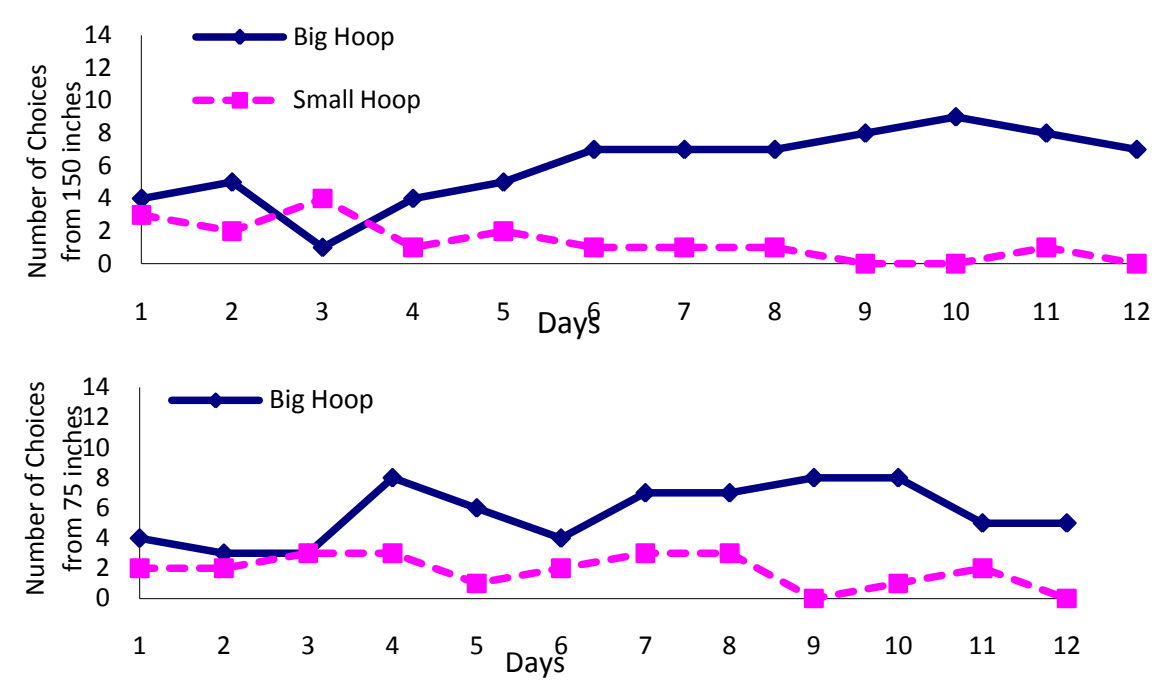

Figure 16. Payton's choices of hoops aiming from 75 inches and 150 inches

Trever (Figure 14), Zack (Figure 15), and Payton (Figure 16) chose the big hoops over the small hoops to aim regradless of the distance from the target. Data for Payton's hoop choices presented gradually increased preference for aiming a big hoop over time in Figure. 16. The extent to which she had a preference for aiming a big hoop appears growing in the throws from 150 inches. The mean number of choices for all participants in each distance is presented in Table 7.

Table 7

Mean Numbers of Hoop Choices

\begin{tabular}{ccccc}
\hline & \multicolumn{2}{c}{150 inches } & \multicolumn{2}{c}{75 inches } \\
\cline { 2 - 5 } & Big hoop & Small hoop & Big hoop & Small hoop \\
\hline Jonah & 5.3 & 2.6 & 6.2 & 4 \\
Oloe & 6.8 & 1.6 & 5.7 & 2.1 \\
Trever & 6.4 & 2.1 & 6 & 2 \\
Zack & 6.8 & 1.2 & 6.2 & 2.6 \\
Payton & 6 & 1.3 & 5.6 & 1.8 \\
\hline
\end{tabular}



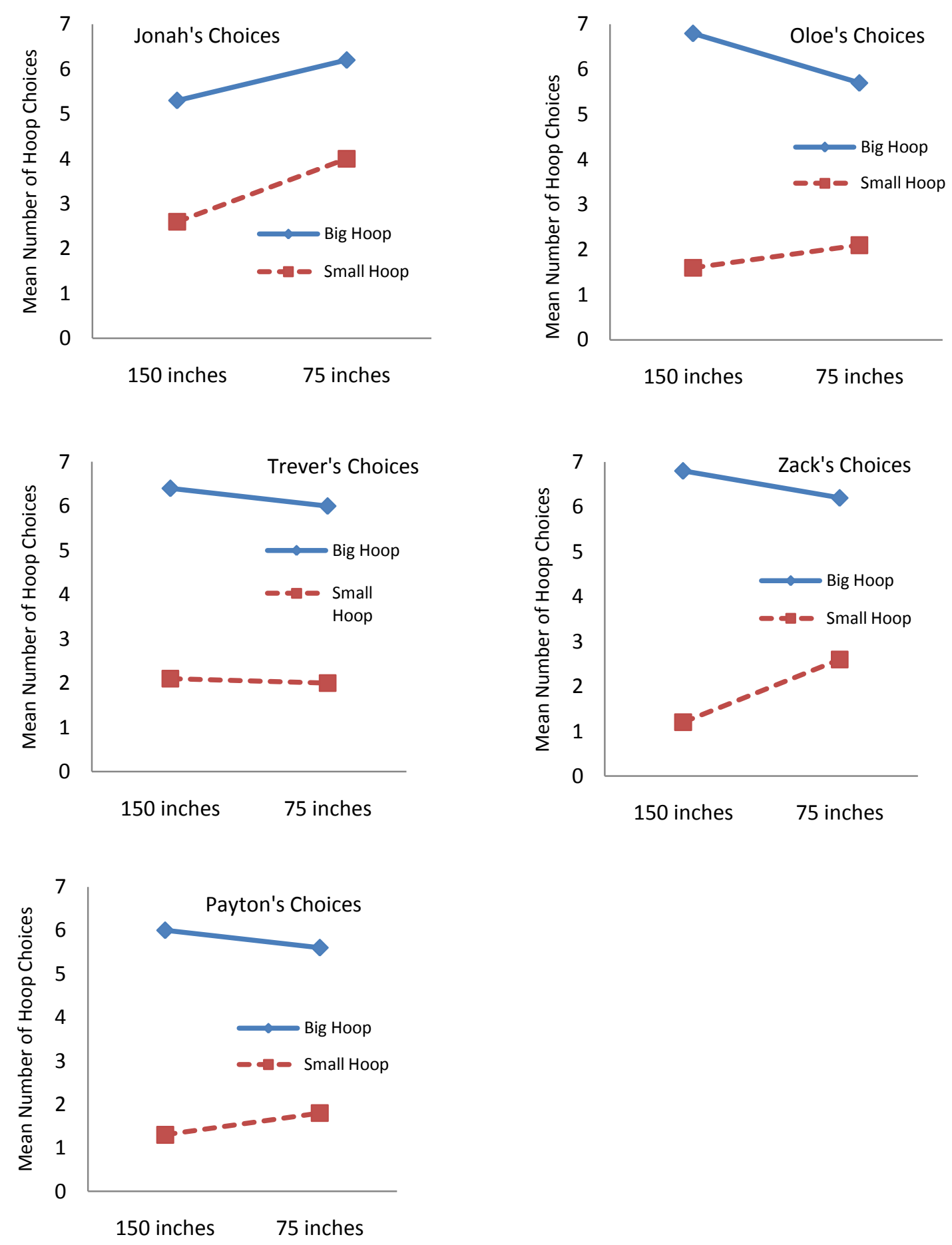

Figure 17. Changes in mean number of hoop choices in relation to distances in Experiment 2

Apparently the participants frequently preferred big hoops over small hoops. As shown in Figure 17, choice of the small hoop target increases when the target is closer for all except Trevor. For him they go down slightly for short distance throws. Conversely, 
the trends in choice of the big hoop target decreases for the shorter distance except for Jonah.

In additon to choice of hoop, choices of ball sizes made by the participants were observed. Two -sized balls, 2.5 and 12 inches in diameter each, were placed on the ground and they chose one to aim at a target. Figures 18 to 27 present the number of attempts to score at both targets in multiple trials and the number of ball choices in long and short distances from where the participants aimed.
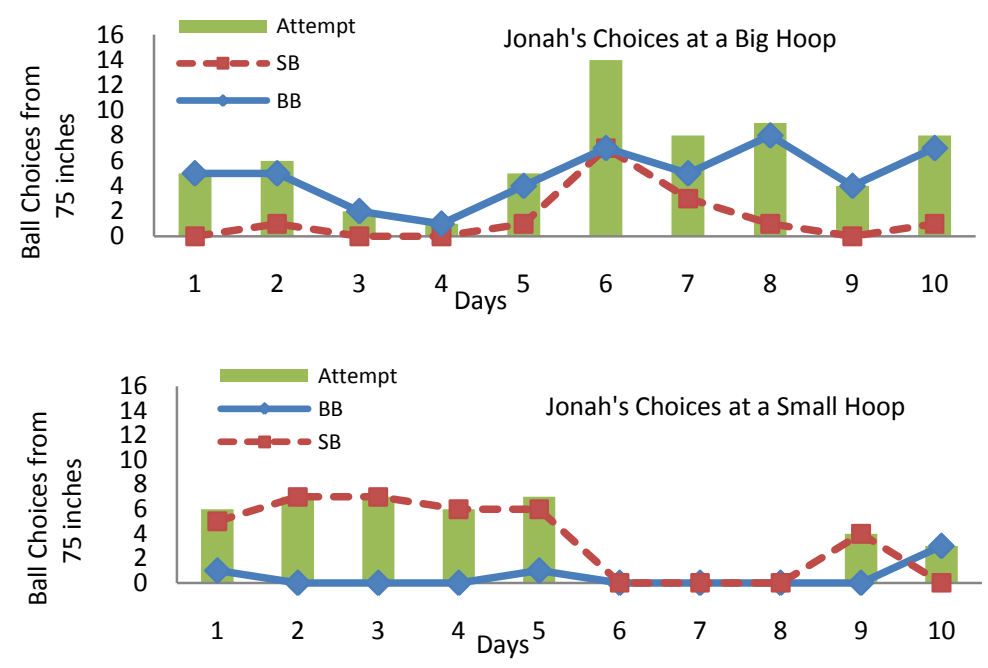

Figure 18. Jonah's choices of balls aiming at a big hoop and small hoop from 75 inches

(Note. Attempt $=$ Number of hoop choices $\mathrm{SB}=$ Number of small ball choices $\mathrm{BB}=$ Number of big ball choices)
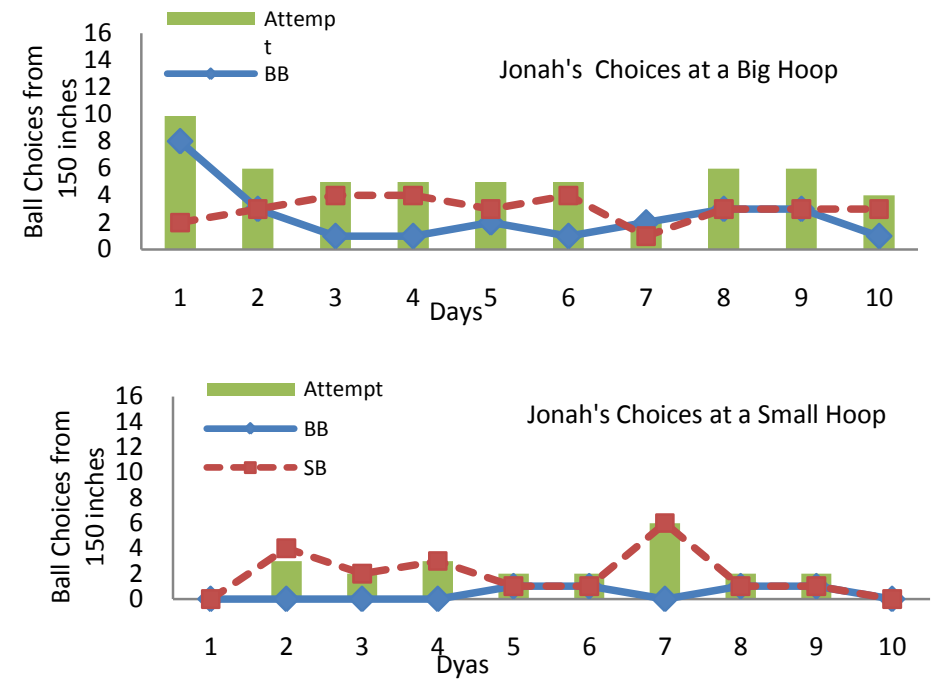
Figure 19. Jonah's choices of balls aiming at a big hoop and small hoop from 150 inches

(Note. Attempt $=$ Number of hoop choices $\mathrm{SB}=$ Number of small ball choices $\mathrm{BB}=$ Number of big ball choices)

Jonah's preference of a big ball for a big hoop when shooting from a short

distance is clear in Figure 18. When he threw at targets 150 inches away, it was observed that he uses a combination of big ball and small ball for big hoops ( $M=2.5$ big ball; $M=3$ small ball). However, he contantly used the small ball when aiming at small hoops regardless of the distance from targets.

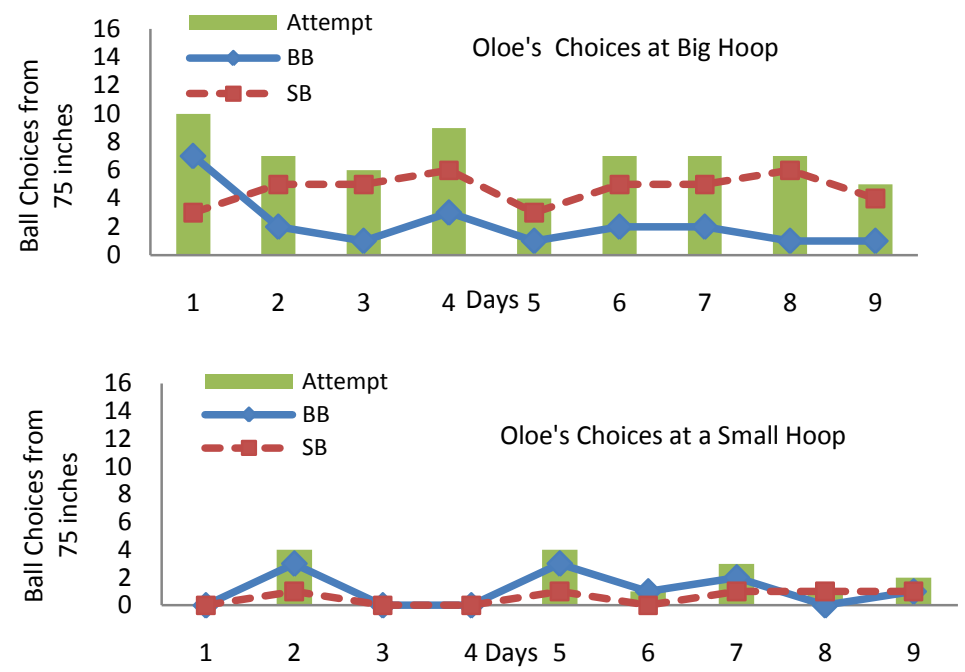

Figure 20. Oloe's choices of balls aiming at a big hoop and small hoop from 75 inches

(Note. Attempt $=$ Number of hoop choices $\mathrm{SB}=$ Number of small ball choices $\mathrm{BB}=$ Number of big ball choices)
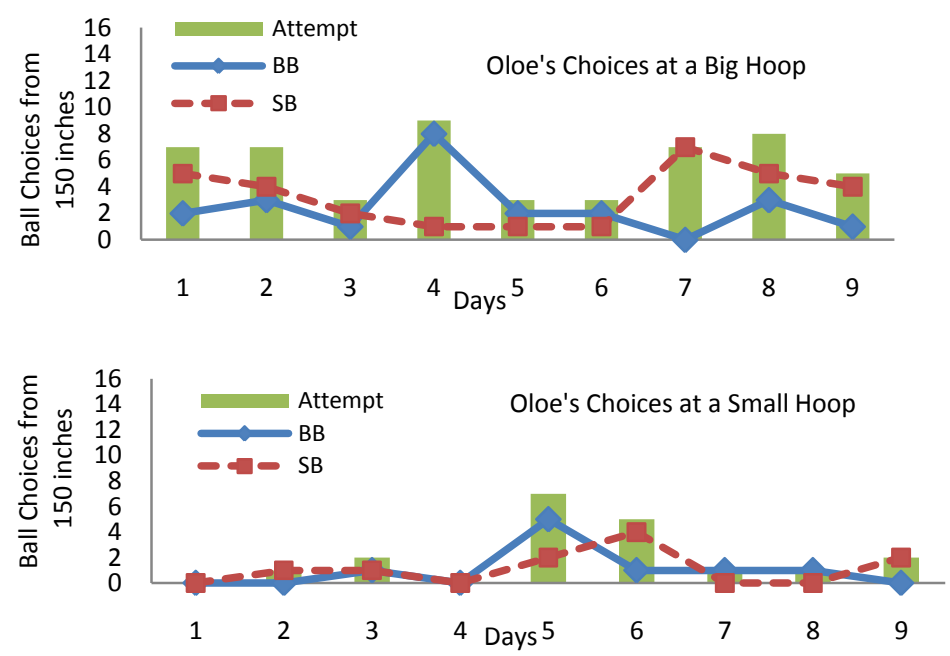

Figure 21. Oloe's choices of balls aiming at a big hoop and small hoop from 150 inches 
(Note. Attempt $=$ Number of hoop choices $\mathrm{SB}=$ Number of small ball choices $\mathrm{BB}=$ Number of big ball choices)

Data in Figures 20 and 21 indicate that Oloe used more small balls when aiming at the big hoop at a distance of 75 inches. The preference for small balls for big hoops was observed on Days 7, 8, and 9.

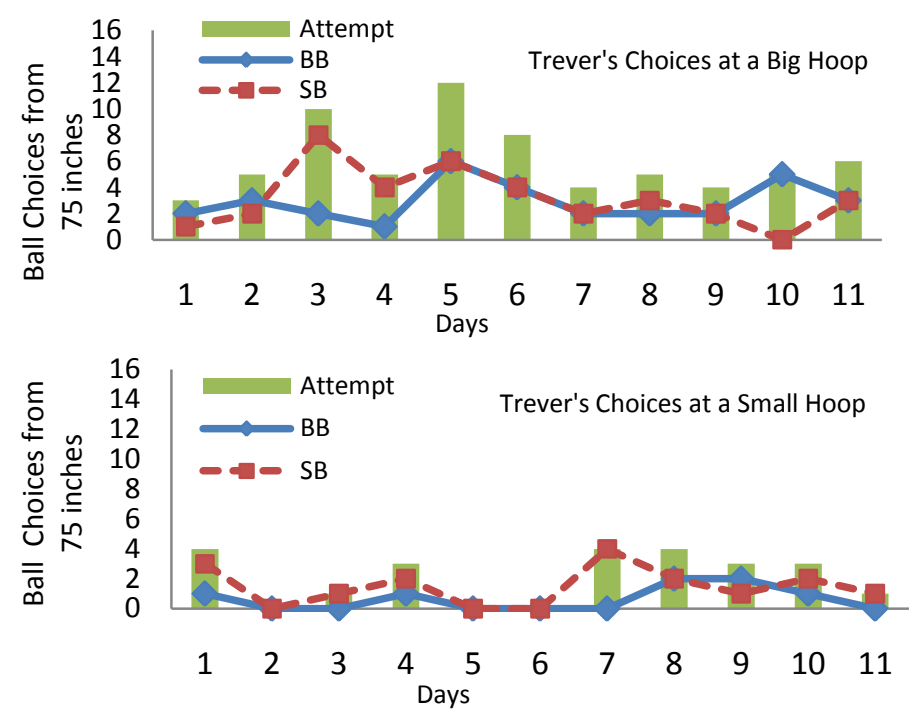

Figure 22. Trever's choices of balls aiming at a big hoop and small hoop from 75 inches

(Note. Attempt $=$ Number of hoop choices $\mathrm{SB}=$ Number of small ball choices $\mathrm{BB}=$ Number of big ball choices)
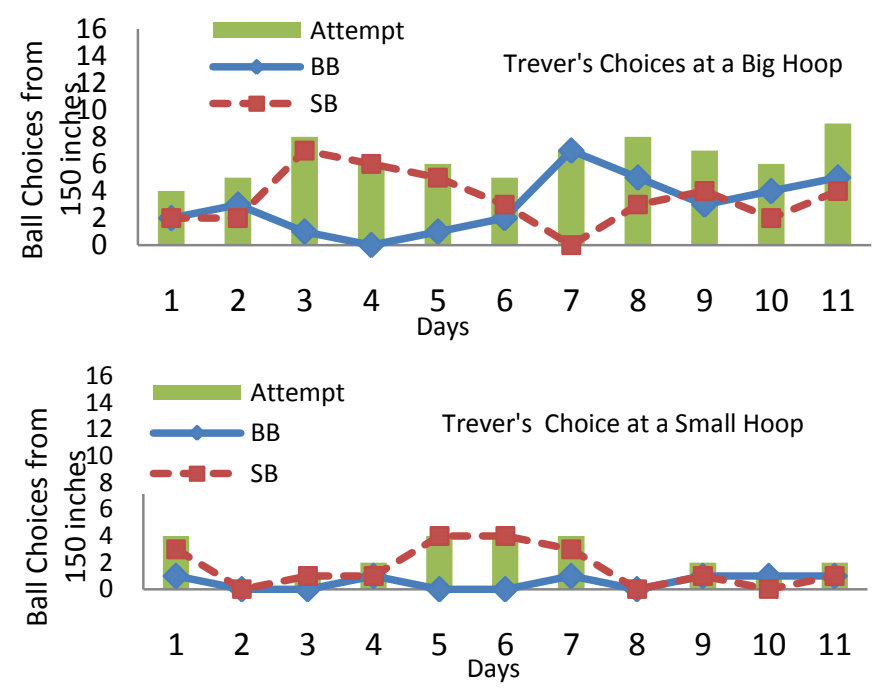

Figure 23. Trever's choices of balls aiming at a big hoop and small hoop from 150 inches

(Note. Attempt $=$ Number of hoop choices $\mathrm{SB}=$ Number of small ball choices $\mathrm{BB}=$ Number of big ball choices) 
In Figures $22 \& 23$ Trever chose the mixed uses of the big ball and the small ball in the attempt at a big hoop. In spite of a few attempts in scoring at the small hoop, Trever chose smaller balls for both 150 inches $(M=0.54$ big ball; $M=1.63$ small ball $)$ and 75 inches ( $M=0.63$ big ball; $M=1.45$ small ball). Over the course of the attempts at the small hoop, either mixed uses with two balls or preference for a small ball was recorded except for a few days.

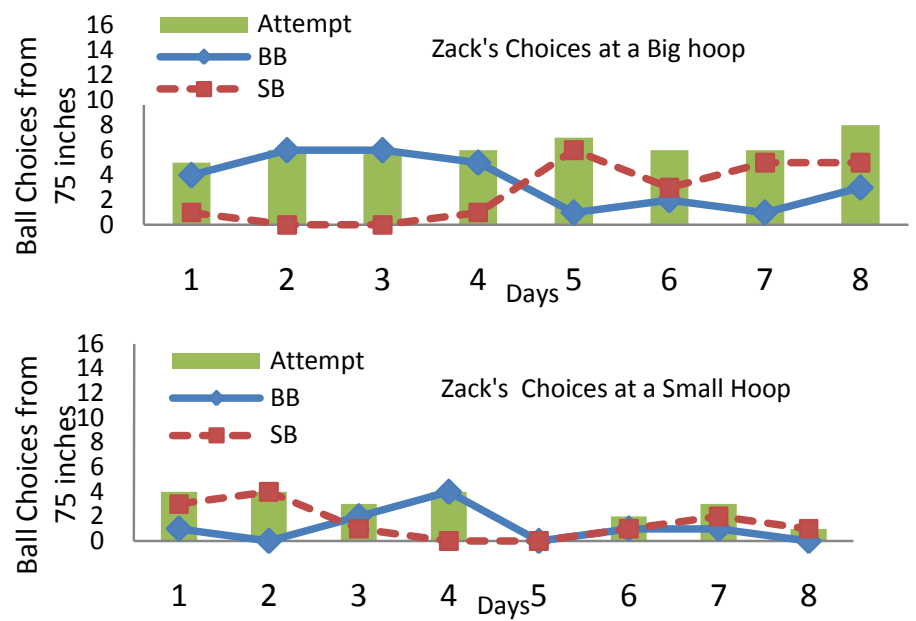

Figure 24. Zack's choices of balls aiming at a big hoop and small hoop from 75 inches

(Note. Attempt $=$ Number of hoop choices $\mathrm{SB}=$ Number of small ball choices $\mathrm{BB}=$ Number of big ball choices)
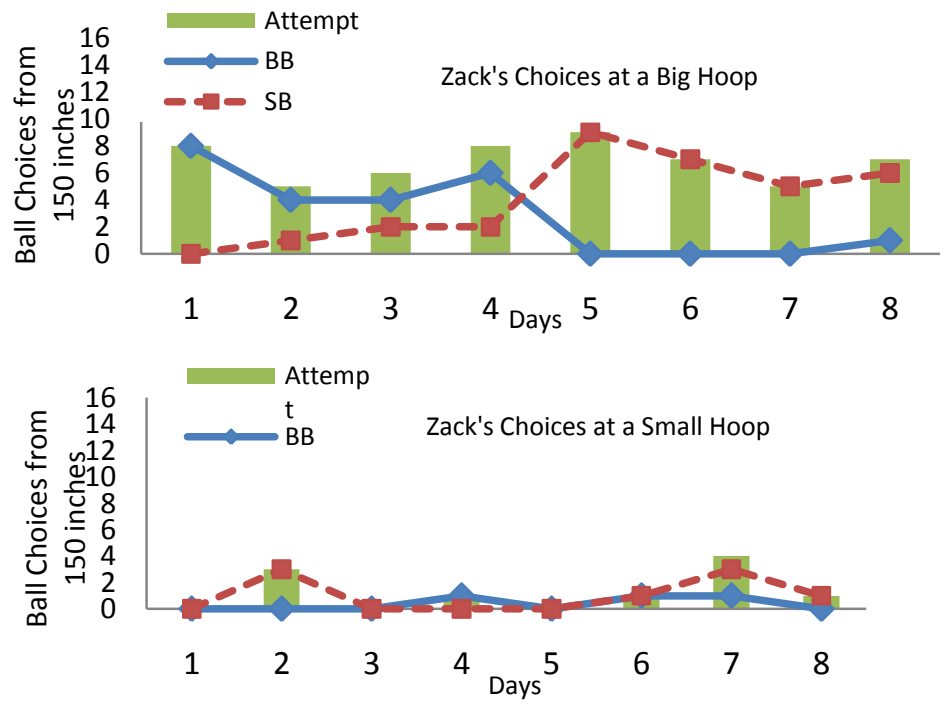

Figure 25. Zack's choices of balls aiming at a big hoop and small hoop from 150 inches

(Note. Attemp $=$ Number of hoop choices $\mathrm{SB}=$ Number of small ball choices $\mathrm{BB}=$ Number of big ball choices) 
In Figures 24 \& 25 mixed uses with the two sized balls were displayed in Zack's throws. However, a change in his preference for using a ball was seen during the experiment. When aiming at big hoops, he chose the big balls to score in the beginning, but from Day 5 he switched to small balls and persisted with that choice until the end of the experimental sessions. No big ball was used on Day 5, Day 6, and Day7 at a distance of 150 inches and one big ball was used on Day 8. As shown in Trever's data, despite only a few throws at the small hoop in the long distance choosing small balls were observed when aiming at a small hoop overall in Zack's data of Figures 24 and 25.
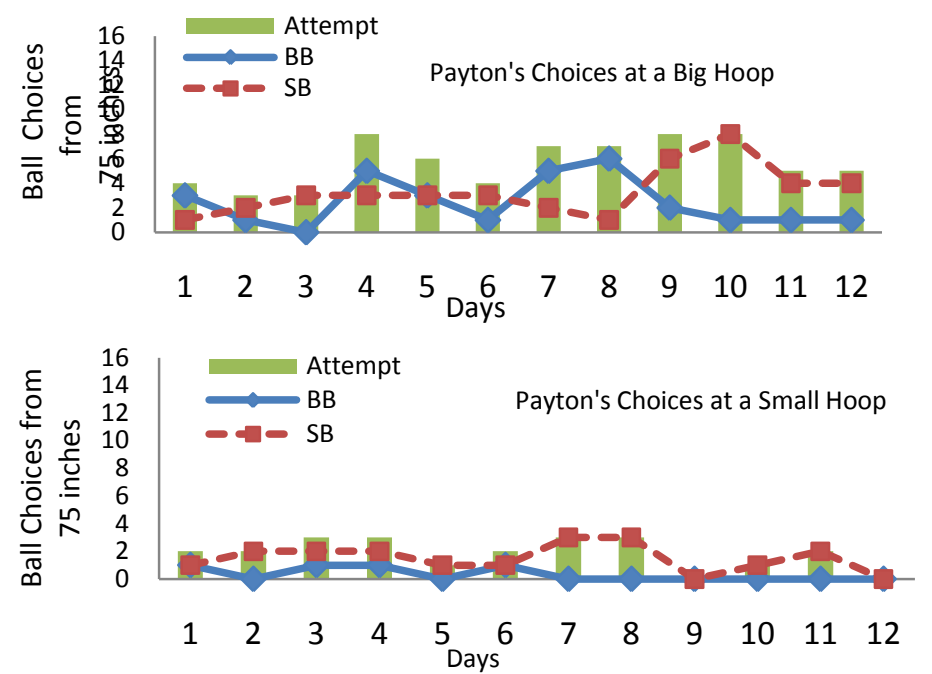

Figure 26. Payton's choices of balls aiming at a big hoop and small hoop from 75 inches (Note. Attempt $=$ Number of hoop choices $\mathrm{SB}=$ Number of small ball choices $\mathrm{BB}=$ Number of big ball choices) 

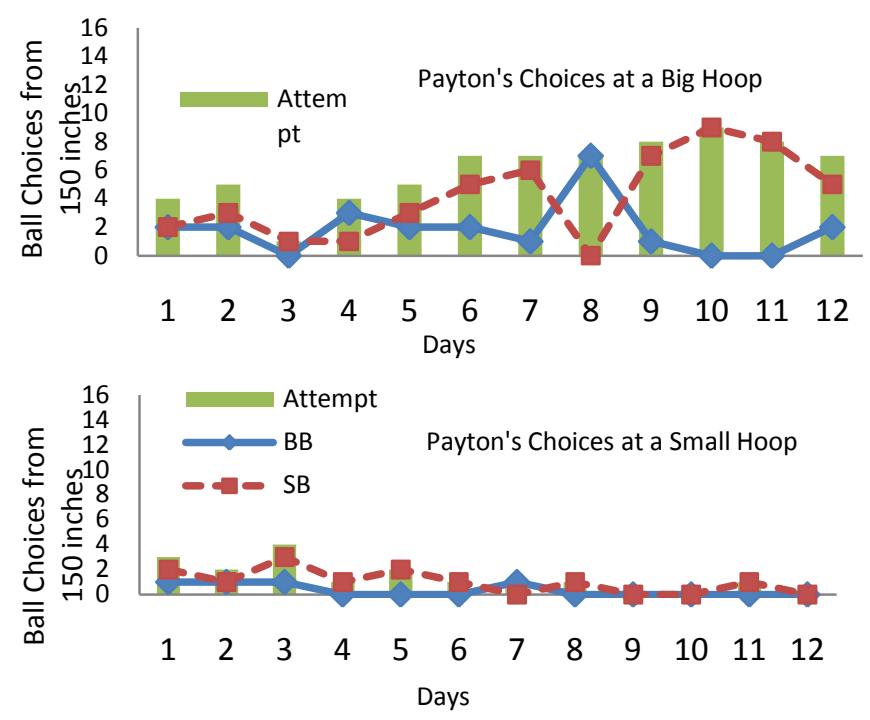

Figure 27. Payton's choices of balls aiming at a big hoop and small hoop from 75 inches (Note. Attempt $=$ Number of hoop choices $\mathrm{SB}=$ Number of small ball choices $\mathrm{BB}=$ Number of big ball choices)

In Figures $26 \& 27$ combined use of small and large balls were observed during all sessions in Payton's throws. In the last days of the sessions she started to choose small balls over big balls and persisted with the choice until the end of experimental sessions when aiming at the big hoop from both distances. The choices of small balls in the few attempts of scoring at the small hoop were observed in both distances as well.

Table 8

Mean Numbers of Ball Choice at a Distance 75 inches

\begin{tabular}{ccccc}
\hline & \multicolumn{2}{c}{ Big hoop } & \multicolumn{2}{c}{ Small hoop } \\
\cline { 2 - 5 } & Big ball & Small ball & Big ball & Small ball \\
\hline Jonah & 4.8 & 1.4 & 0.5 & 3.5 \\
Oloe & 2.22 & 4.66 & 1.11 & 0.55 \\
Trever & 2.90 & 3.18 & 0.63 & 1.45 \\
Zack & 3.5 & 2.62 & 1.12 & 1.5 \\
Payton & 2.41 & 2.62 & 0.33 & 1.5 \\
\hline
\end{tabular}


Table 9

Mean Numbers of Ball Choice at a Distance of 150 inches

Big hoop Small hoop

\begin{tabular}{ccccc} 
& Big ball & Small ball & Big ball & Small ball \\
\hline Jonah & 2.5 & 3 & 0.4 & 1.9 \\
Oloe & 2.44 & 3.33 & 1 & 1.11 \\
Trever & 3 & 3.45 & 0.54 & 1.63 \\
Zack & 2.87 & 4 & 0.37 & 1 \\
Payton & 1.83 & 4.16 & 0.33 & 1
\end{tabular}
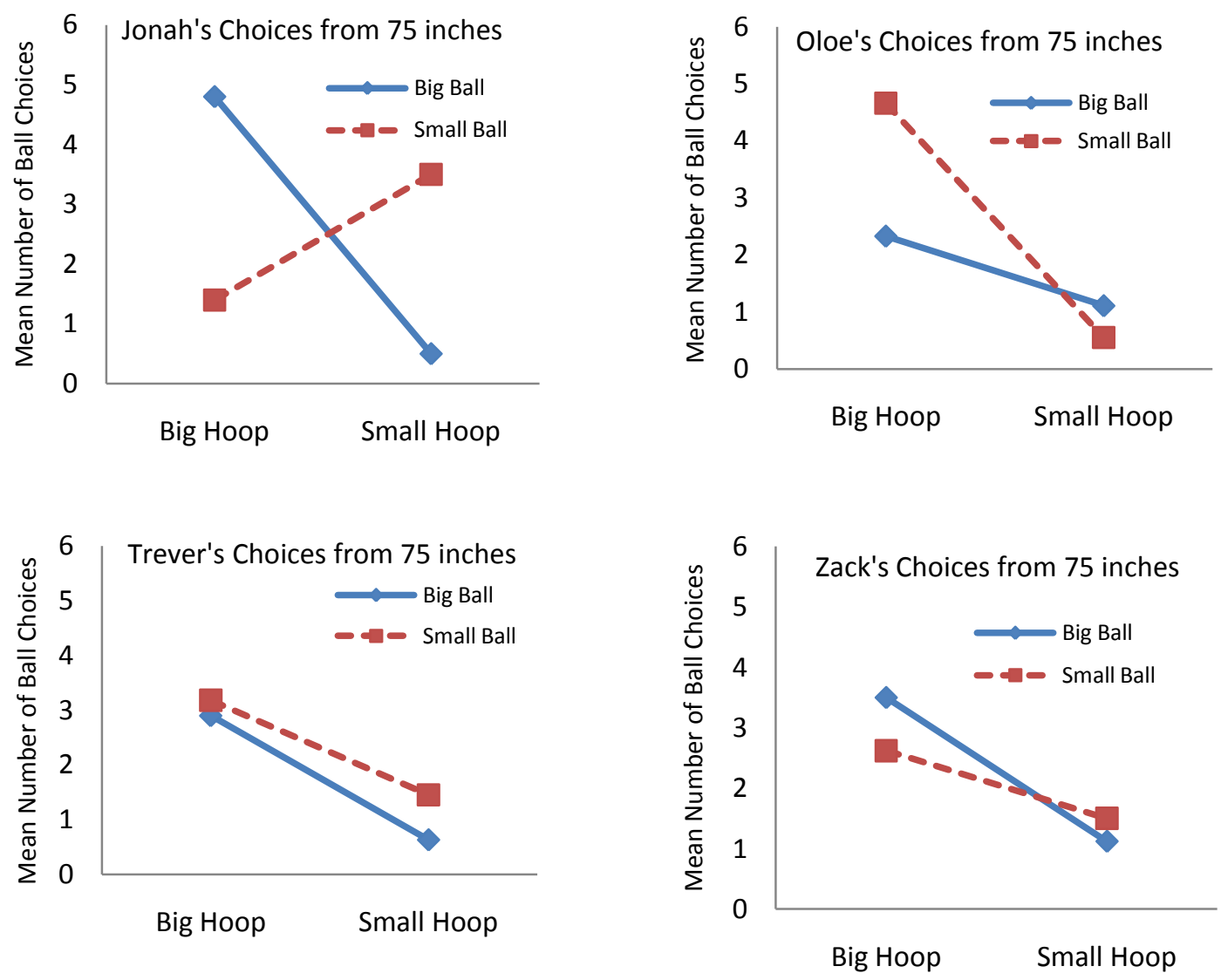


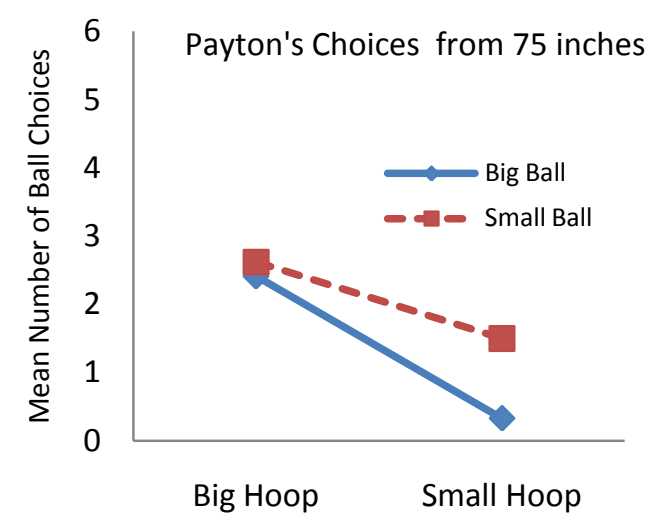

Figure 28. Changes in mean number of ball choices in relation to size of targets from 75 inches in Experiment 2

Figure 28 presents three types of trends in ball choice from the 75 -inch throws, in relation with change in size of target. Trever and Payton used small ball more regardless of size of target. Jonah and Zack switched the choice pattern when aiming at small hoop to more uses of small ball. Only Oloe chose more uses of the big ball at the small target.
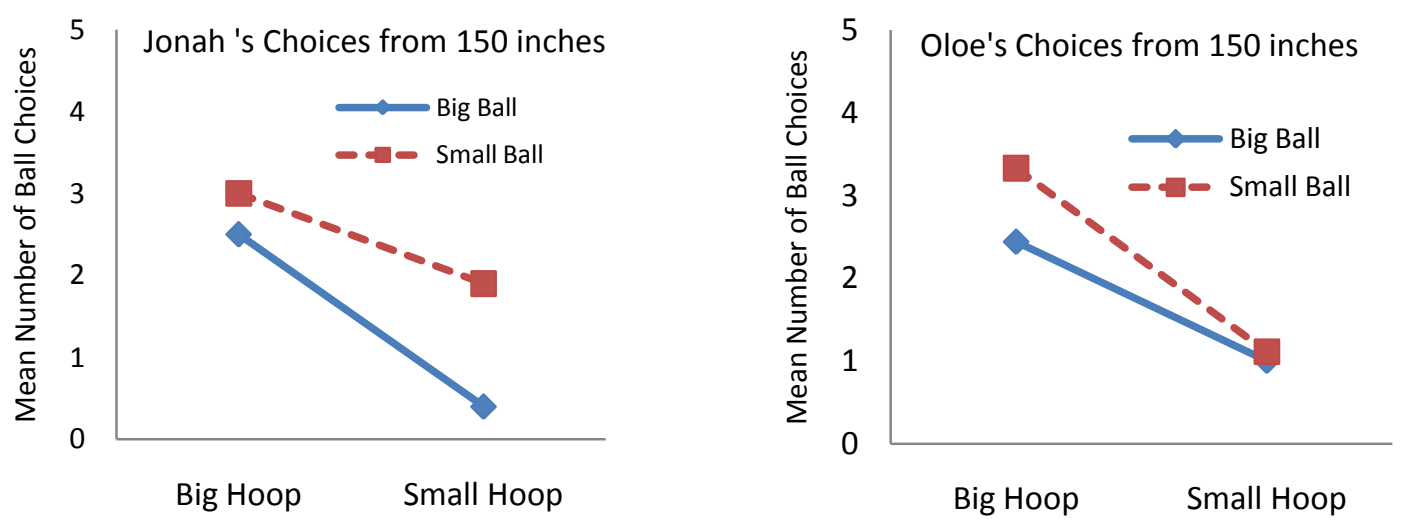

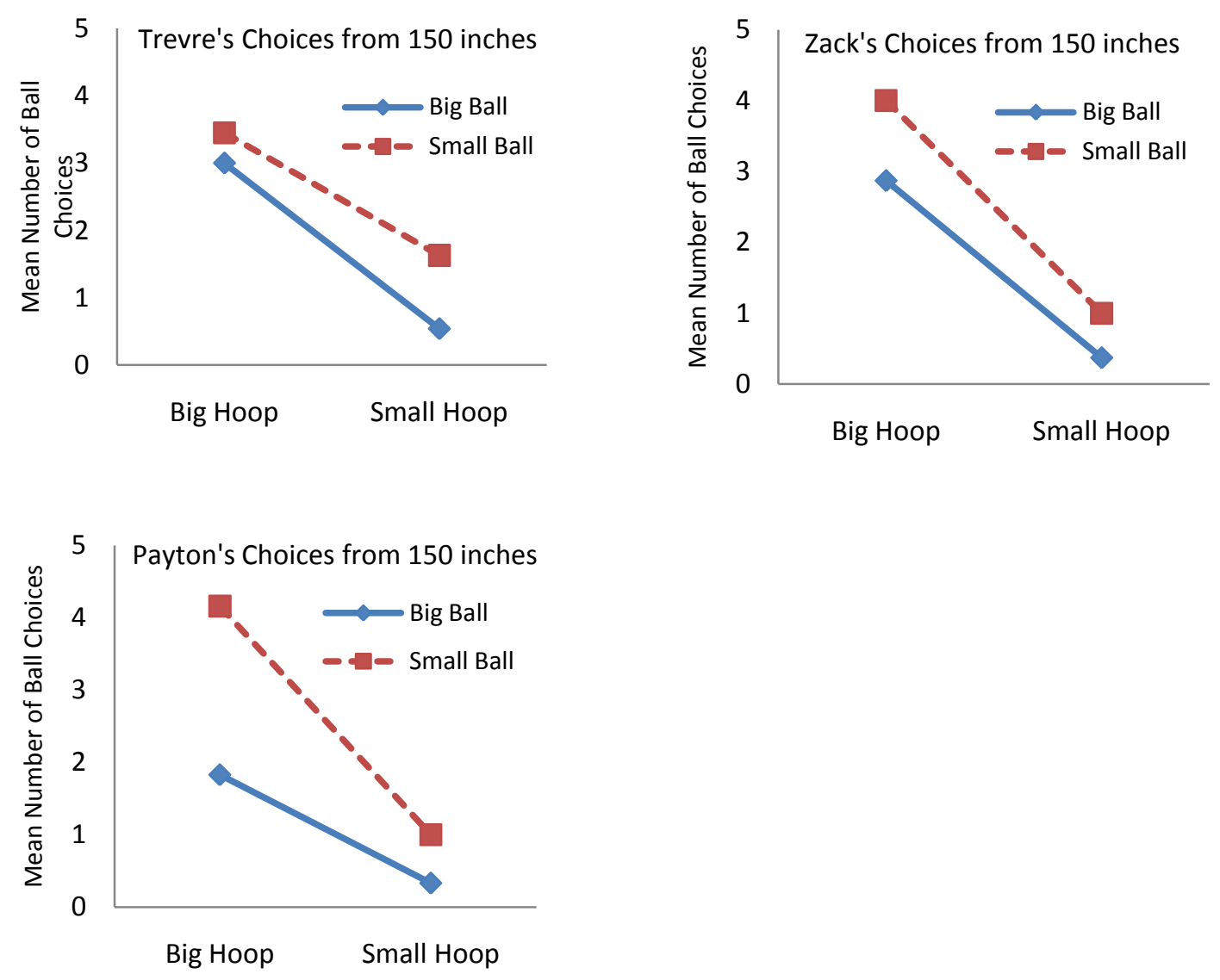

Figure 29. Changes in mean number of ball choices in relation to size of targets from 150 inches in Experiment 2

The pattern of ball choice at 150 inches from target appears identical for all participants. They all used more small balls over big ball for long distance throws. Since the participants were asked to throw a ball at their own pace, the total number of attempts at the targets on each day differed from thrower to thrower. In addition to the actual number of attempts, the ratios were examined between the number of the type of ball choices and the total number of attempts made at each hoop from Figures 30 to 34 . 

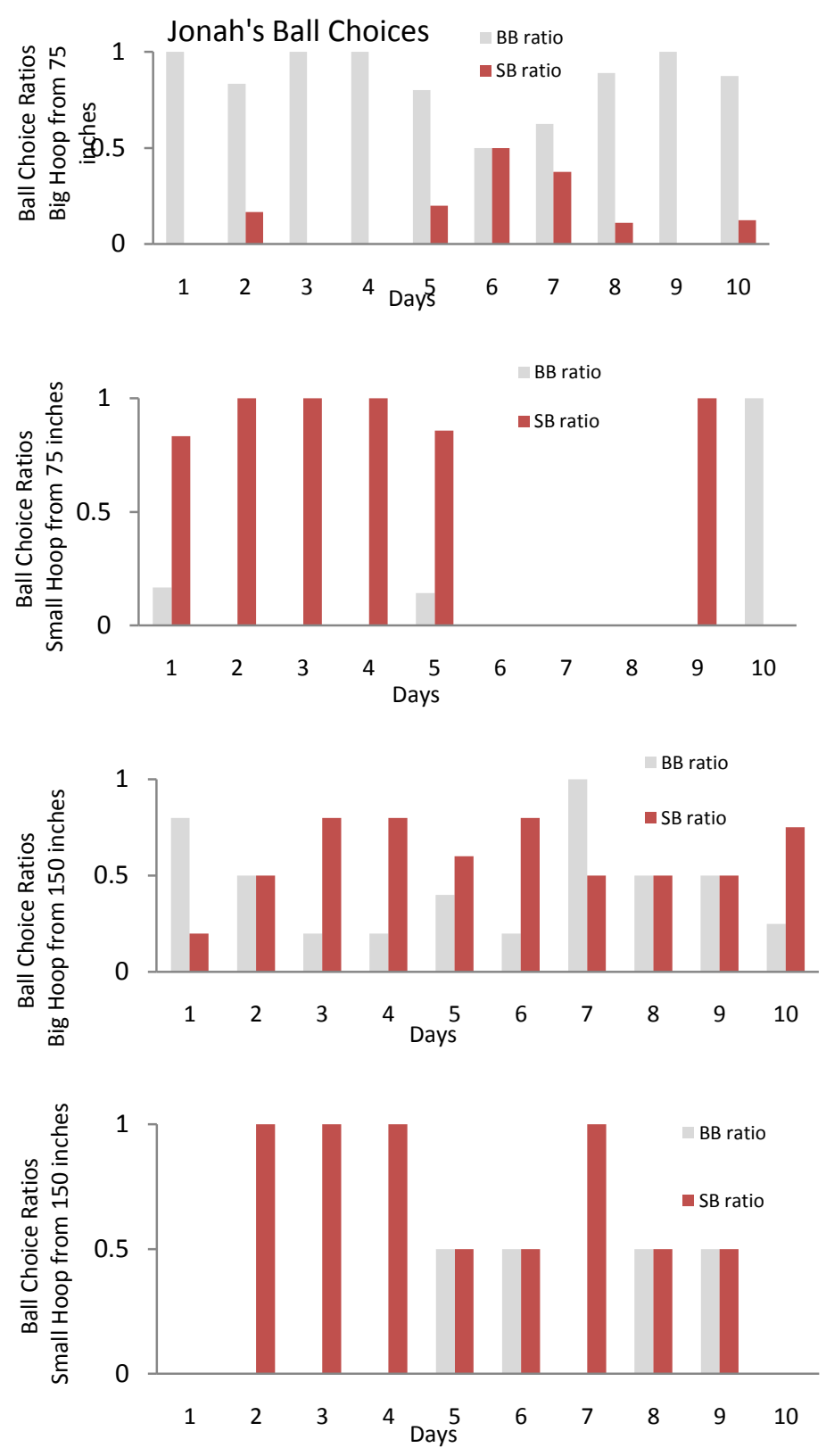

Figure 30. Jonah's ratios of ball choices to number of attempts to score at distances of 75 inches and 150 inches. The ratios were calculated with the total number of attempts scoring at each hoop divided by the total number of ball choices when aiming a hoop. BB ratio indicates the ratio between the number of big ball choices and the number of total attempts at a hoop. SB ratio indicates the ratio between the number of small ball choices and the number of total attempts at a hoop

Overall, Jonah threw the small balls more during the entire experimental sessions, except for the attempts to score at a big hoop from a short distance. Even with a 
few attempts made at a small hoop from a distance of 150 inches Figure 34 shows he preferred to use small ball for the distant throw attempts.
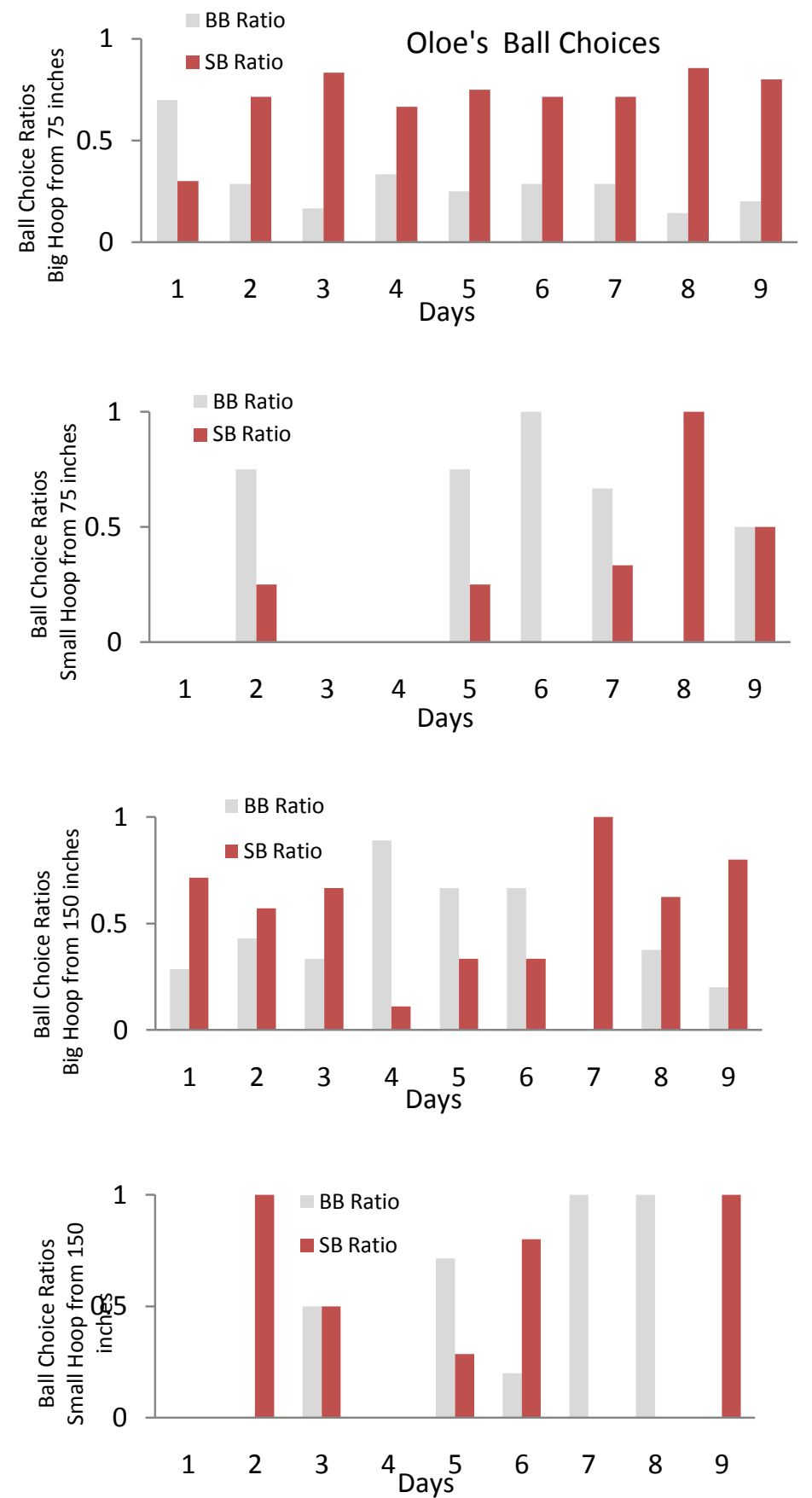

Figure 31. Oloe's ratios of ball choices to number of attempts to score at distances of 75 inches and 150 inches. The ratios were calculated with the total number of attempts scoring at each hoop divided by the total number of ball choices when aiming a hoop. BB ratio indicates the ratio between the number of big ball choices and the number of 
total attempts at a hoop. SB ratio indicates the ratio between the number of small ball choices and the number of total attempts at a hoop

In the use of balls Oloe's data show a unique trend in the throws at a small hoop from 75 inches. He chose the big ball more frequently than the small ball in the beginning but the use of small balls appeared gradually increased on Day 7, Day 8, and Day 9.

However, it seems hard to see a consistent way of the choice of ball at a small hoop from 150 inches.
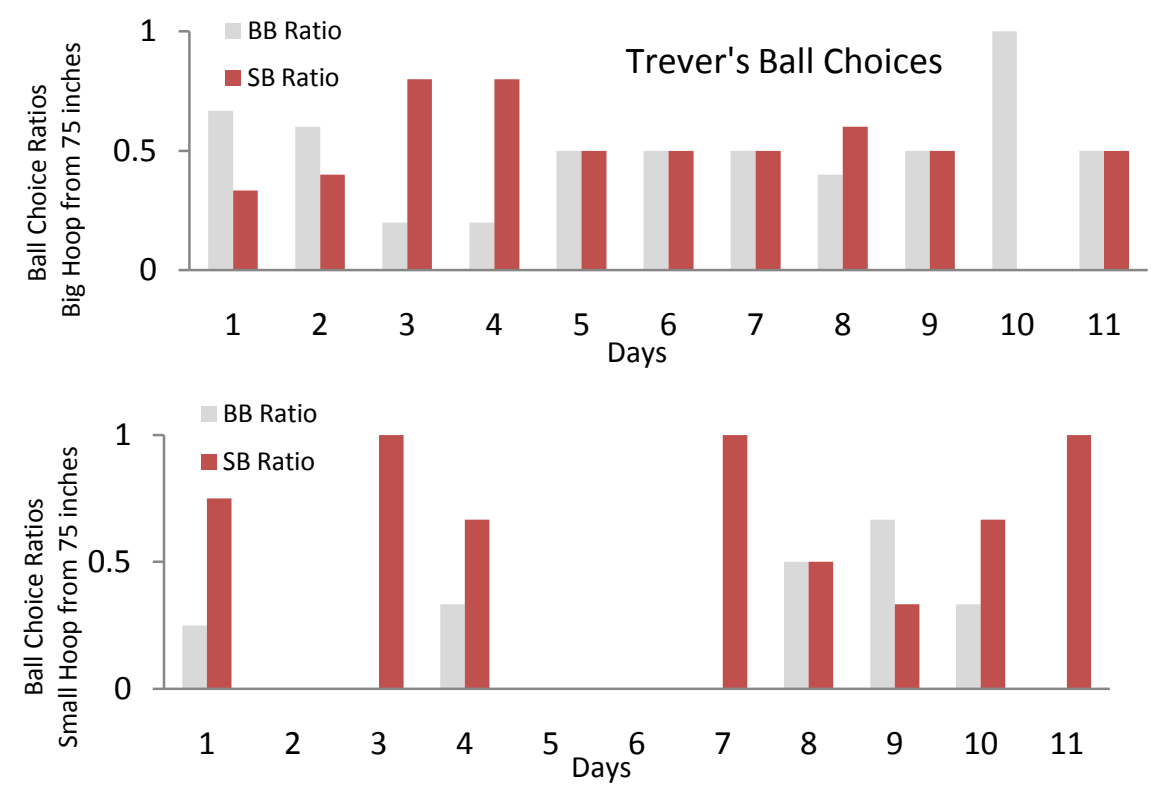

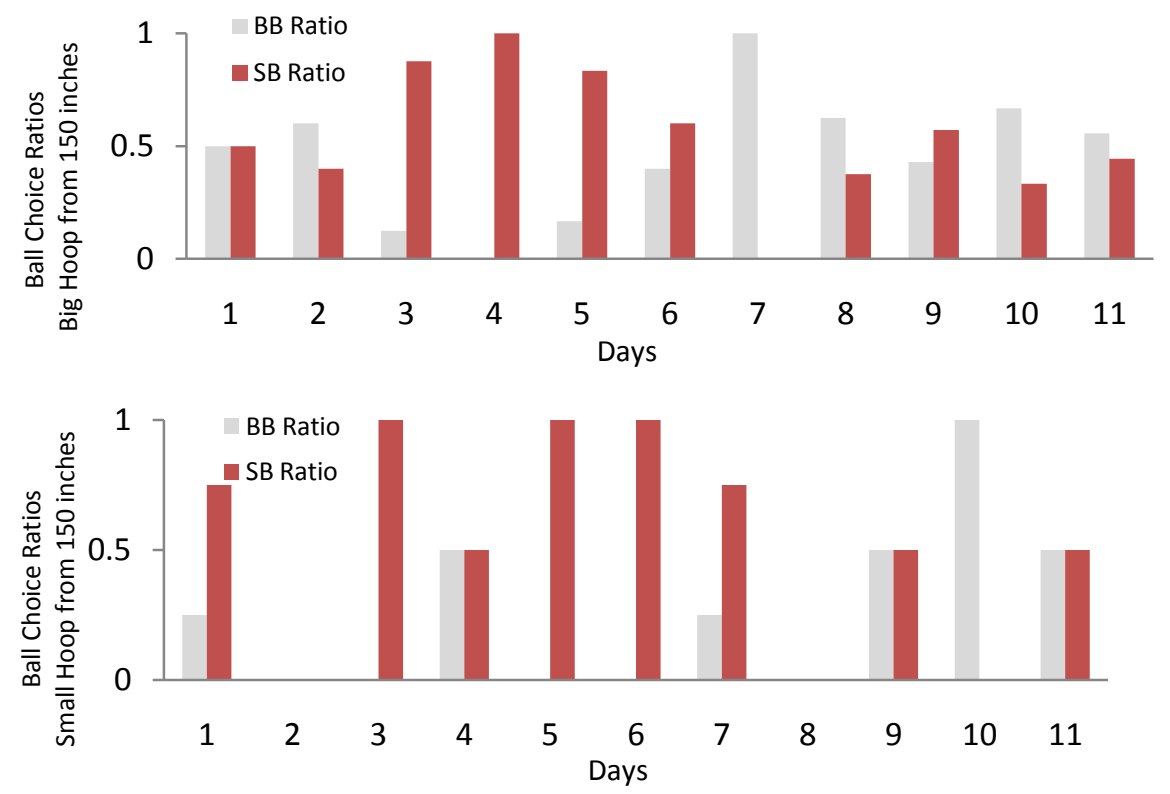

Figure 32. Trever's ratios of ball choices to number of attempts to score at distances of 75 inches and 150 inches. The ratios were calculated with the total number of attempts scoring at each hoop divided by the total number of ball choices when aiming a hoop. BB ratio indicates the ratio between the number of big ball choices and the number of total attempts at a hoop. SB ratio indicates the ratio between the number of small ball choices and the number of total attempts at a hoop

Trever's preference for a small ball was generally displayed in the throwing attempts regardless of the targets. When aiming at a big hoop from the both distances, the ratio of use of big ball seems higher than when aiming at a small hoop. 

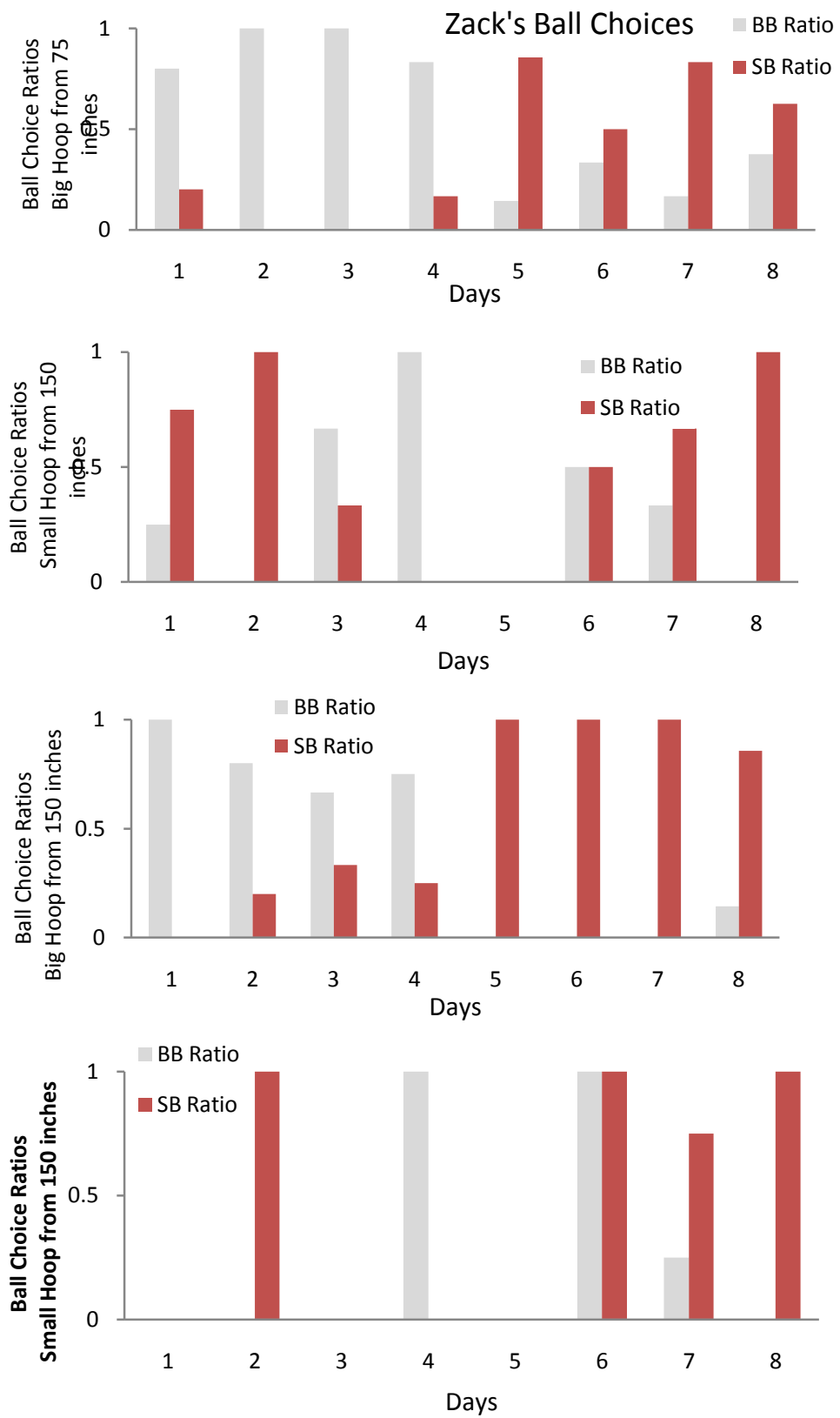

Figure 33. Zack's ratios of ball choices to number of attempts to score at distances of 75 inches and 150 inches. The ratios were calculated with the total number of attempts scoring at each hoop divided by the total number of ball choices when aiming a hoop. BB ratio indicates the ratio between the number of big ball choices and the number of total attempts at a hoop. SB ratio indicates the ratio between the number of small ball choices and the number of total attempts at a hoop 
Zack chose the both sizes of balls in the beginning of the experiment but changed it to frequent uses of a small ball toward the end of experiment on Day 6, Day 7, and Day 8.
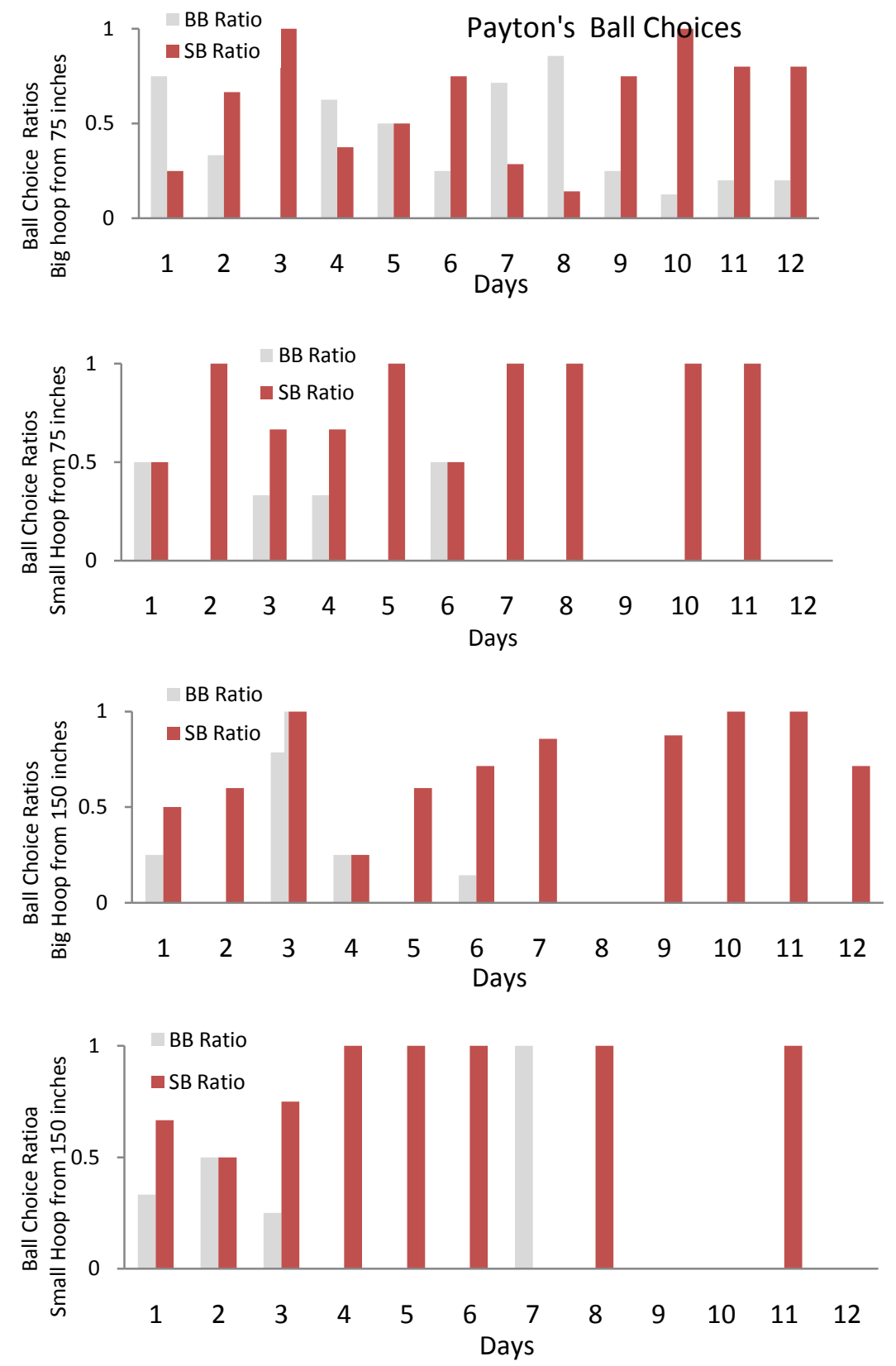

Figure 34. Payton's ratios of ball choices to number of attempts to score at distances of 75 inches and 150 inches. The ratios were calculated with the total number of attempts scoring at each hoop divided by the total number of ball choices when aiming a hoop. BB ratio indicates the ratio between the number of big ball choices and the number of 
total attempts at a hoop. SB ratio indicates the ratio between the number of small ball choices and the number of total attempts at a hoop

Payton's choice pattern of ball is similar to that of Trever's in Figure 34. Use of big balls was seen often in the throwing attempts of scoring at a large hoop from 150 inches. However, in the rest of the throwing conditions use of small balls seemed prevalent during the experiment.

Figures 35 to 42 show movements in response to change in distance from throwing target. It is hypothesized that a thrower produces movement patterns for a more forceful throw as distance from throwing targets increases. The participants generated the movement elements believed to be responsible for force production in throwing: homolateral stepping, contra -lateral stepping, block rotation, and flexion.
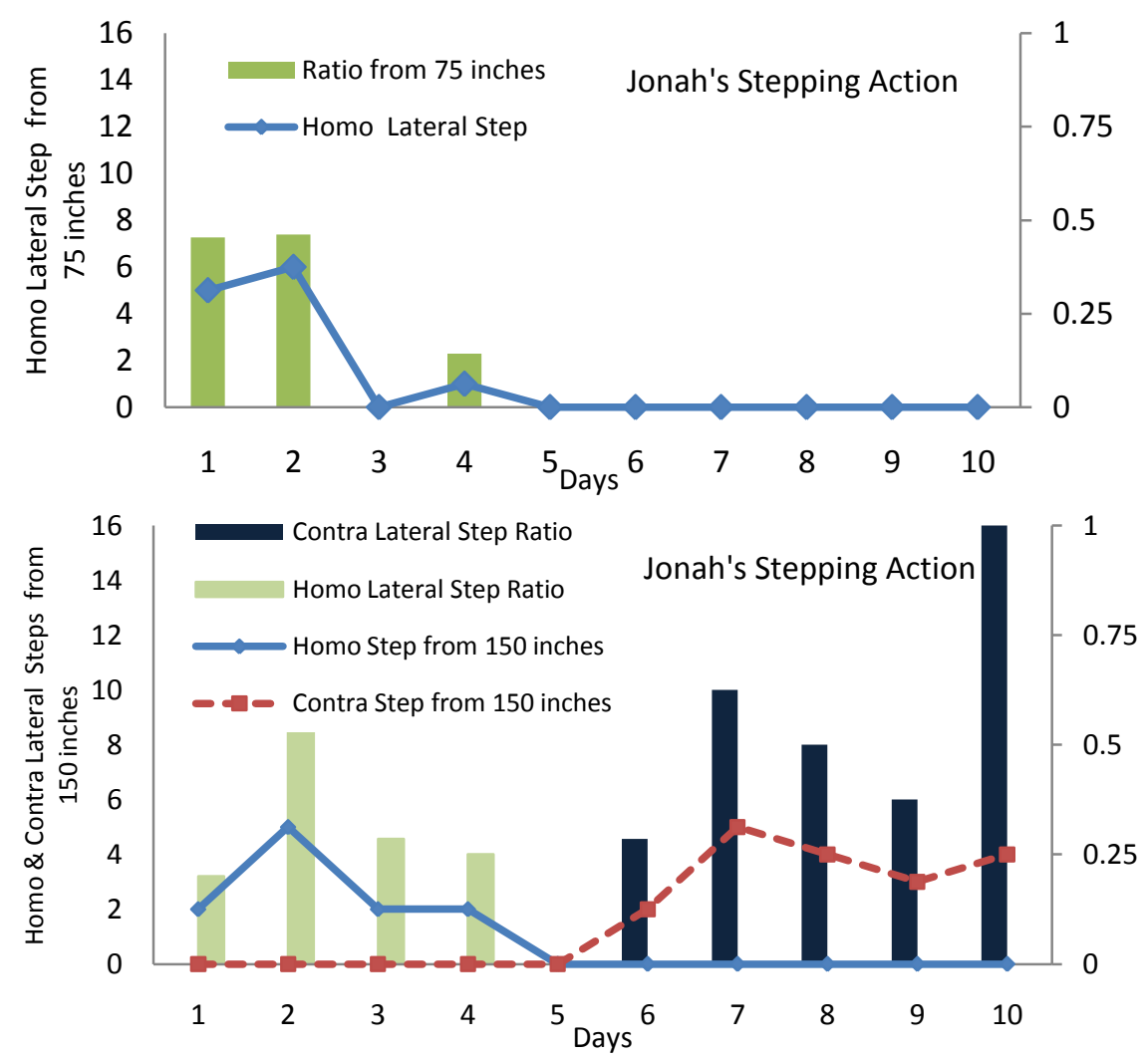
Figure 35. Homo-lateral stepping and contra-lateral stepping were observed in Jonah's stepping action. Ratios of steppings were calculated with number of stepping actions (i.e., either homo-lateral or contra-lateral stepping) divided by the total numbers of attempts scoring at distances of 75 inches and 150 inches.

Jonah used homo lateral steps only in the first few days of experiemental sessions at a distance of 75 inches, but it was diminished quickly in Figure 35. Conversely, throwing attempts from long distance, 150 inches, were executed with stepping actions in some cases. Both homo lateral and contra lateral stepping actions were obseved. The stepping pattern shifted from homo lateral action to contra lateral action from Day 6 . The use of contra lateral stepping action lasted until the end of the remaining experimental sessions.
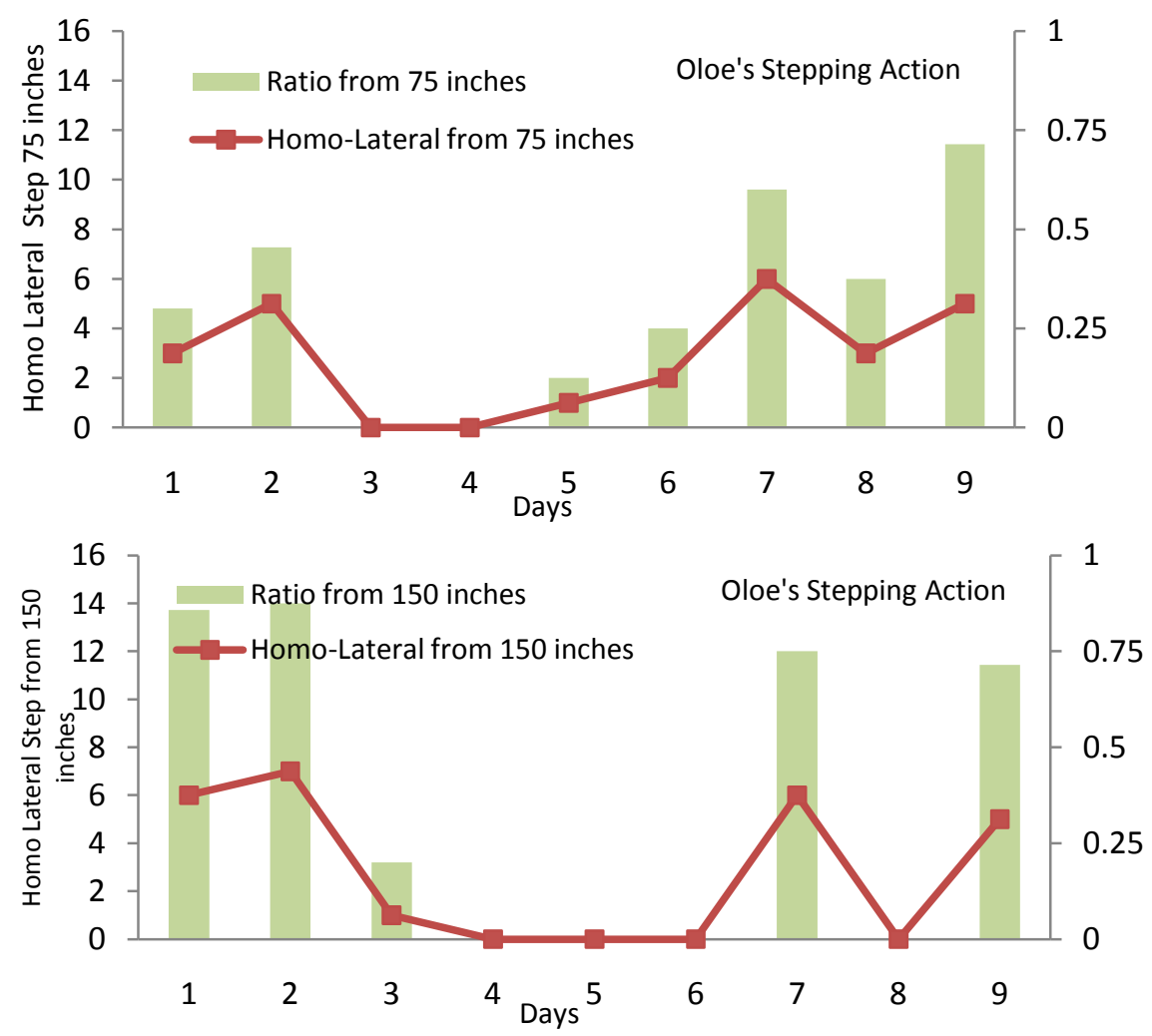

Figure 36. Homo-lateral steppings were presented in Oloe's stepping action. Ratios of steppings were calculated with number of stepping actions divided by the total numbers of attempts scoring at distances of 75 inches and 150 inches. 
Homo lateral stepping action was a stepping action for Oloe observed from both distances in Figure 36. The number of the stepping actions increased when throwing a ball from 150 inches in the beginning then they disappeared for a while in the middle of the experiment to come back in the end. There was no consistency in using homo lateral steps and no increament of its uses according to the increment of the distance from the taregts.
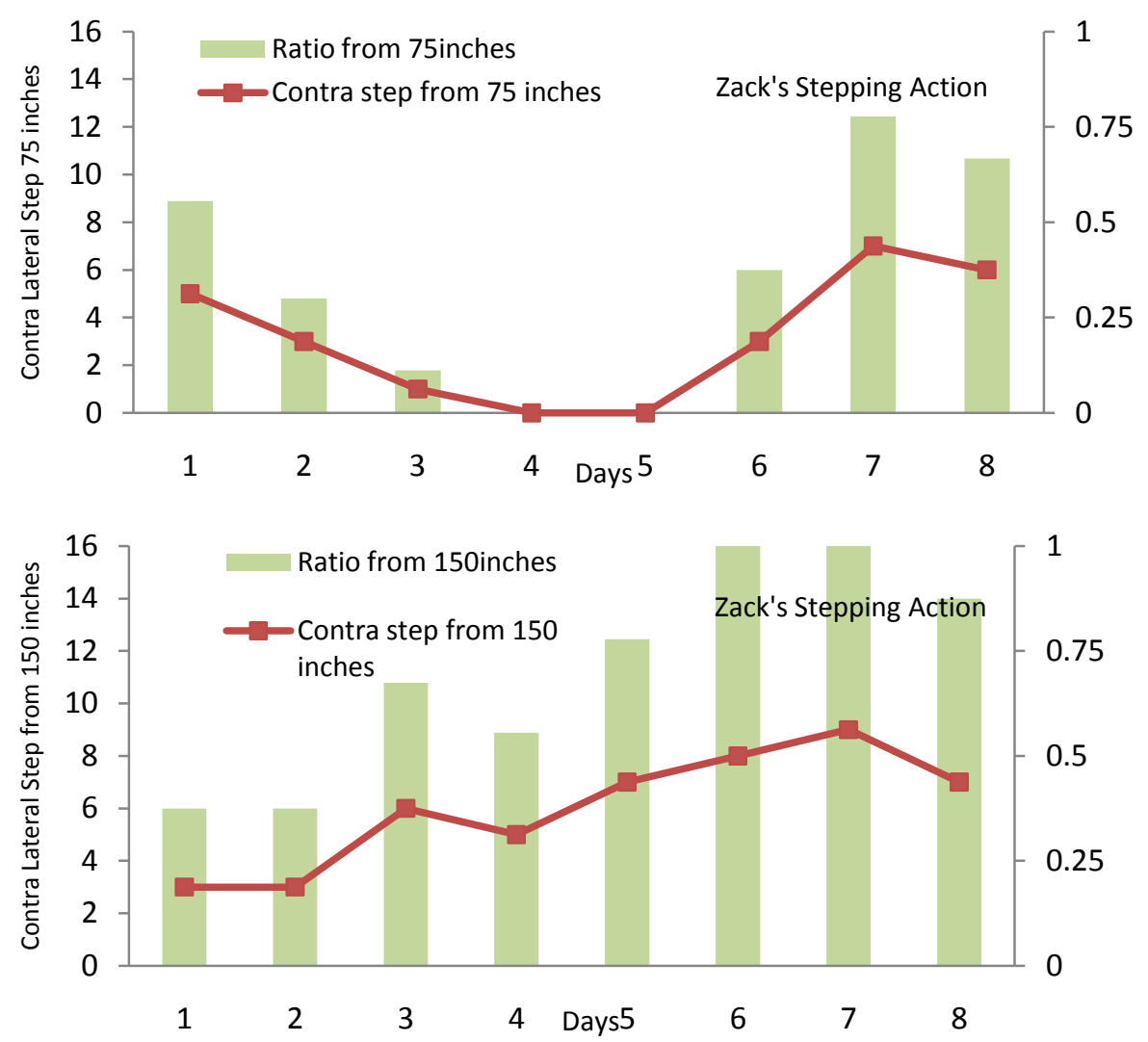

Figure 37. Contra-lateral steppings were observed in Zack's stepping action. Ratios of steppings were calculated with number of stepping actions (i.e., either homo-lateral or contra-lateral stepping) divided by the total numbers of attempts scoring at distances of 75 inches and 150 inches.

Zack used only contra lateral stepping in Figure 37 unlike Oloe in Figure 36. Even with the different type of stepping action the trend of Zack's with the throws from 
75 inches seems similar with Oloe's ones. Contra lateral stepping actions in Zack's data never went away and increased its uses over time with the throws from 150 inches while homo lateral steeping took place dispersedly in Oloe's data Figure 36 presented.
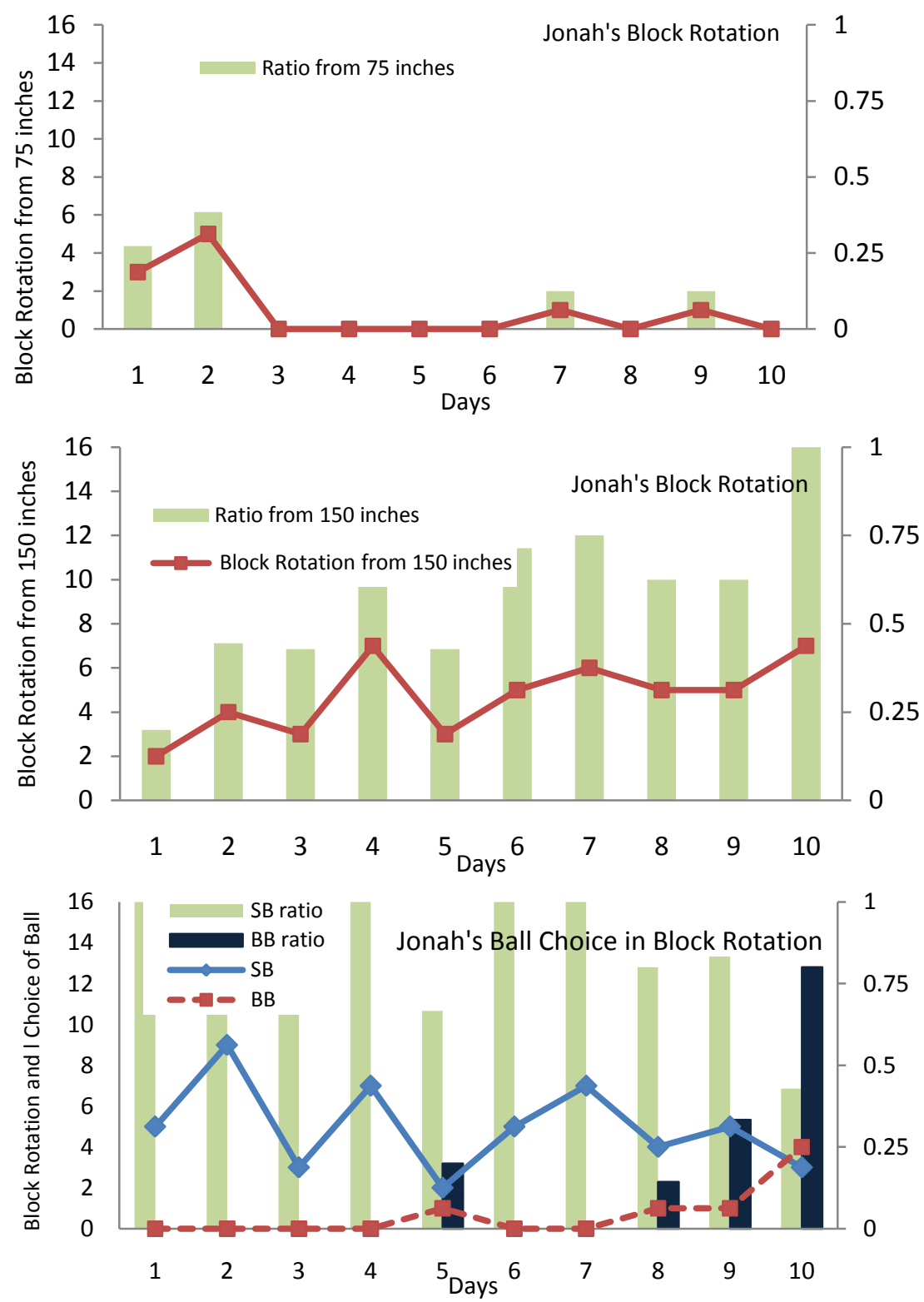

Figure 38. Jonah's ratios of block rotations were calculated with number of block rotation actions divided by the total numbers of attempts scoring at distances of 75 inch and 150 inch. SB indicates number of small ball choices and BB indicates number of big ball choices when block rotation was observed. SB ratio is a ratio of use of small balls with 
block rotation to total number of block rotations observed on each day trial. BB ratio is a ratio of use of big balls with block rotation to total number of block rotations observed on each day trial.

Jonah's block trunk rotation was observed on two days in the beginning of the experiment with short distance throws and disappeared afterward in Figure 38. However, in the throwing attempts from a long distance, Jonah's block rotation was consistently observed in the entirely of experimental sessions. The trunk actions were frequently observed in use for small balls. On the last few days, Day 8, Day 9, and Day 10, block rotation was observed with use of a big ball in throwing as well, On Day 10, eventually the trunk action occurred more with the use of big balls instead of with the use of small balls. 

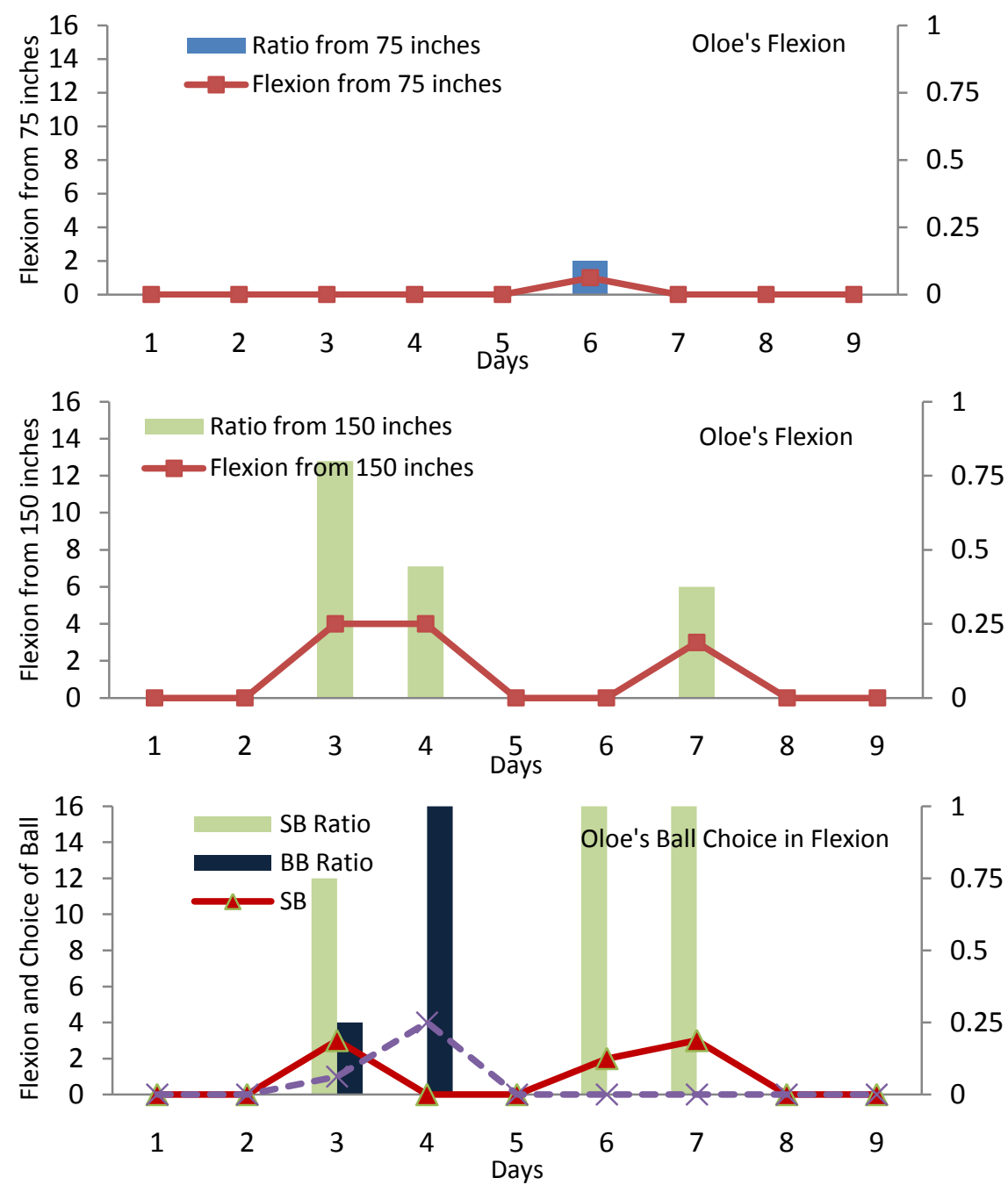

Figure 39. Oloe's ratios of flexion were calculated with number of flexion actions divided by the total numbers of attempts scoring at distances of 75 inch and 150 inch. SB indicates number of small ball choices and BB indicates number of big ball choices when flexion was observed. SB ratio is a ratio of use of small balls with flexion to total number of flexion observed on each day trial. BB ratio is a ratio of use of big balls with flexion to total number of flexion observed on each day trial.

In Figure 39 flexion action as in a trunk action was observed in Oloe's throws. However, the action was performed sporadically regardless of distance change. There was no consistency of occurrence of flexion related to choice of ball. Only flexion took place with his throws from both distances. 


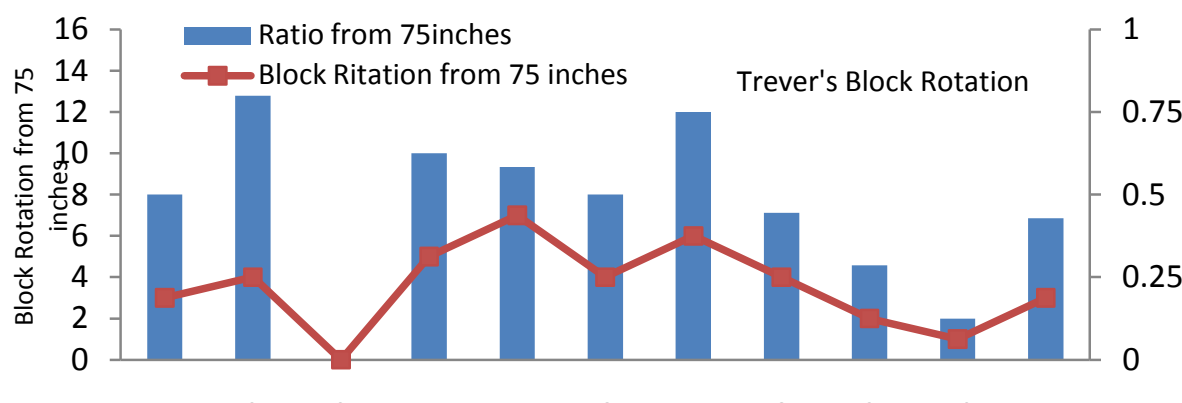

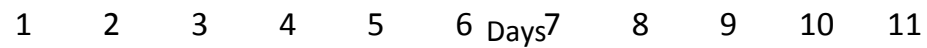
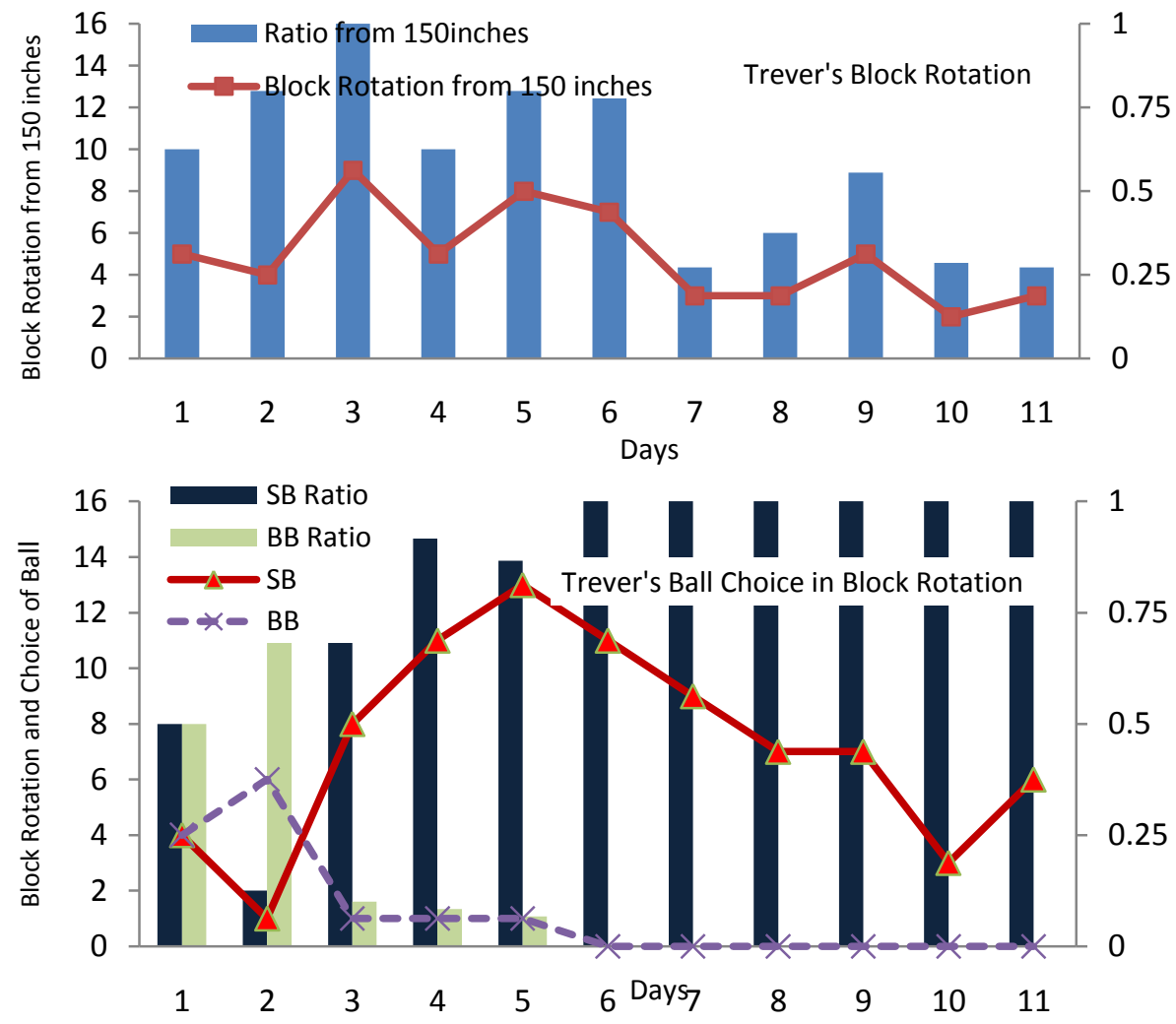

Figure 40. Trever's ratios of block rotations were calculated with number of block rotation actions divided by the total numbers of attempts scoring at distances of 75 inch and 150 inch. SB indicates number of small ball choices and BB indicates number of big ball choices when block rotation was observed. SB ratio is a ratio of use of small balls with block rotation to total number of block rotations observed on each day trial. BB ratio is a ratio of use of big balls with block rotation to total number of block rotations observed on each day trial.

Trever's block rotation action was observed throughout the entire experimental sessions, but its frequency gradually decreased towards the end of the experimental sessions in Figure 40. The trunk action occurred in both distances and stayed untill the 
last day of experiment. The action was produced more often when throwing a small ball to a target regradless of the distances from the target. Only a few cases of block rotations were observed when using a big ball on the first few days of the experiement.
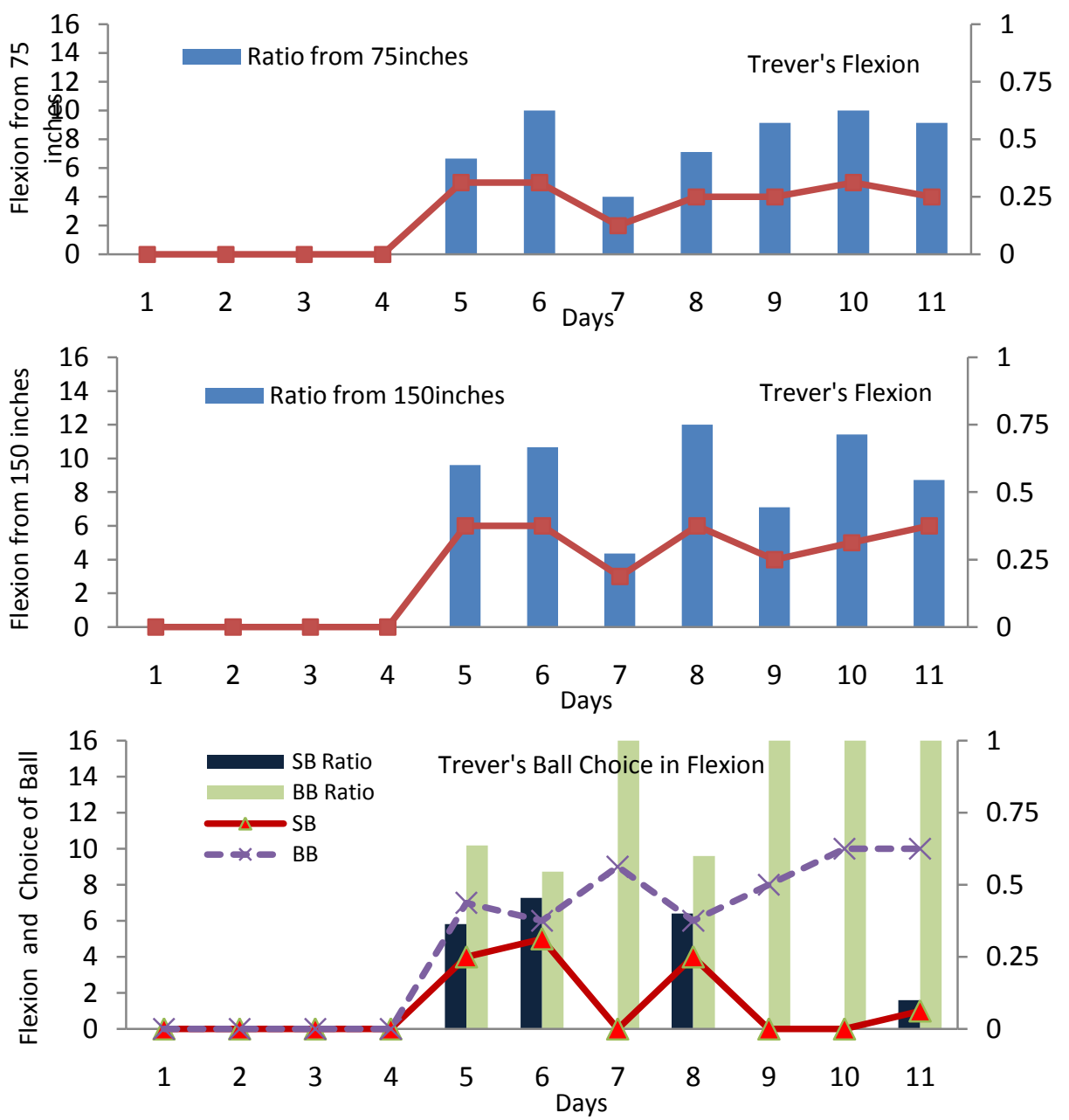

Figure 41. Trever's ratios of flexion were calculated with number of flexion actions divided by the total numbers of attempts scoring at distances of 75 inch and 150 inch. SB indicates number of small ball choices and BB indicates number of big ball choices when flexion was observed. SB ratio is a ratio of use of small balls with flexion to total number of flexion observed on each day trial. BB ratio is a ratio of use of big balls with flexion to total number of flexion observed on each day trial.

Flexion action was alao produced in Trever's throws and emerged from Day 5 in Figure 41. The action was maintained until the end of the experiements. In comparion 
with Figure 40, the flequency of flexion action seems more stable than the flequency of block rotation. There was no observable changes accoriding to changes in a distance from a target in Trever's data in Figures 40 and 41. The execution of flexion action occurred more when using big balls instead of small balls.
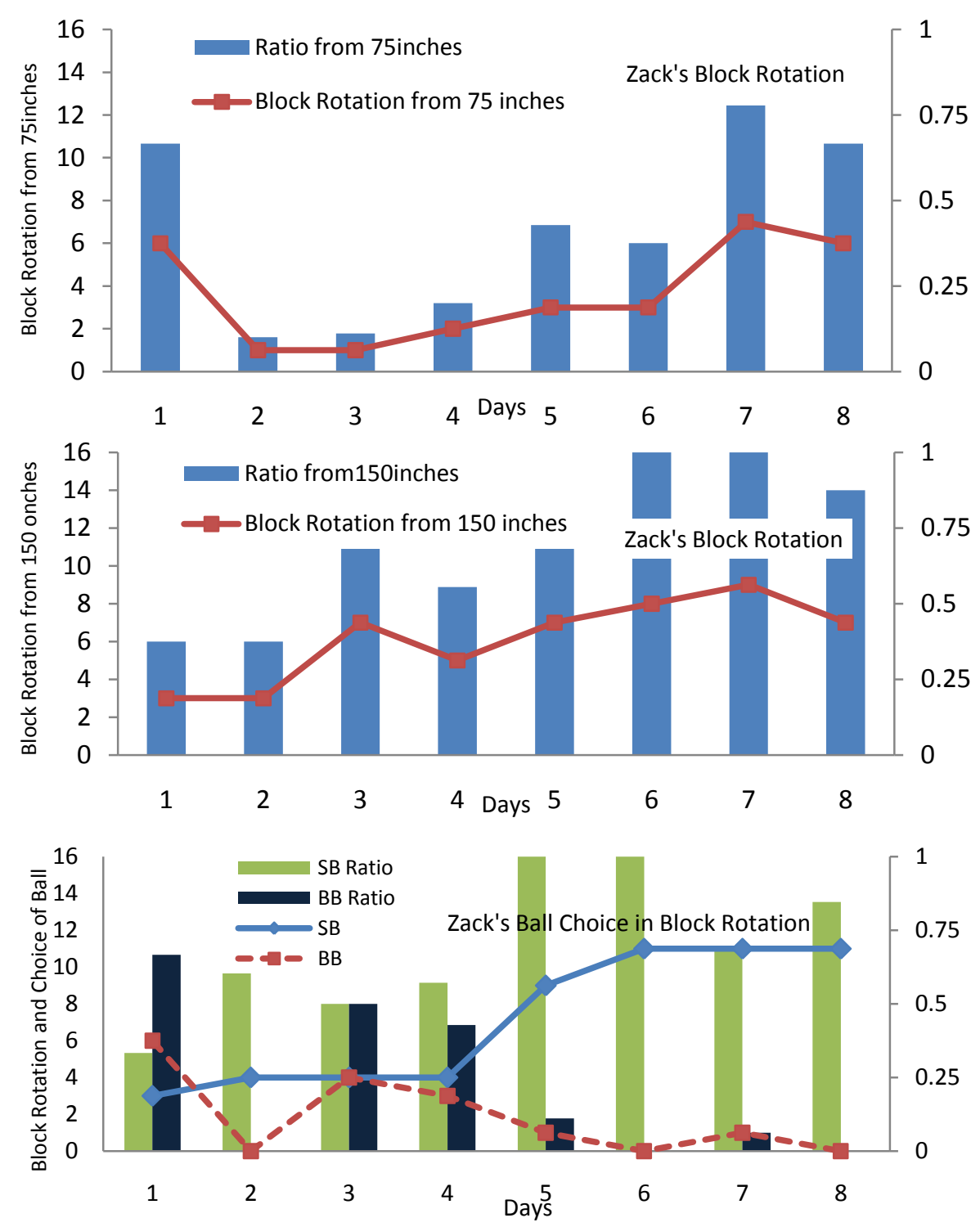

Figure 42. Zack's ratios of block rotations were calculated with number of block rotation actions divided by the total numbers of attempts scoring at distances of 75 inch and 150 inch. SB indicates number of small ball choices and BB indicates number of big ball choices when block rotation was observed. SB ratio is a ratio of use of small balls with block rotation to total number of block rotations observed on each day trial. BB ratio is a ratio of use of big balls with block rotation to total number of block rotations observed on each day trial. 
In Figure 42 block rotation of Zack's throws was observed at distance of 75 inches and 150 inches. The numbers of it occurances increased towards the end of experimental sessions at both distances in Figure 42. The more numbers of the action were, however, recorded in throwng at a target 150 inches away. Again, the use of small balls was observed frequently when throwing with block rotation excecutions during the entire sessions. Block rotation in throwing with use of a big ball was limited to a few days in the beginning of experimental sessions and then diminished. 


\section{CHAPTER FIVE}

\section{Discussion}

Task constraint is an important factor in determining the type of task demands a movement educator needs to consider when designing a series of tasks. The task progression designed by modification of relevant constraints was believed to be able to facilitate developmental changes in movement education. Movement skills are classified according to several types, according to task demands such as environmental predictability, object manipulation, body transportation, and executing as a whole movement and a series of parts of movements (Schmidt \& Wrisberg, 2008). Traditionally, movement study has discussed the skill classification taxonomy in task demands imposed by a task goal and environmental condition. It provides a movement educator with a layout of the constraints faced by a learner. This implies that the modification of task constraints as the pedagogical intervention is important for learners in order to experience a desirable task condition.

Introducing an ecological view expands pedagogical intervention in movement education and will lead from a movement-educator paradigm to a student-centered paradigm in instruction and implementation. Not only understanding task constraints, but also careful consideration of the learner's physical and psychological traits, as well as psychomotor competency would be included in the information necessary for designing a task and selecting equipment, in order to facilitate a desirable movement pattern for a specific task goal. Imposing constraints to encourage a movement should be an important part of the instructional process. 
The data of this study presented the movement responses presumably as a result of the dynamic interactions among the constraints imposed by a performer, task, and environment. The movement patterns in throwing were examined as the products of the interaction between the constraints of tasks in Experiment 1 and Experiment 2. The interaction presumed by an ecological view of movement changes will be discussed in this chapter.

To identify the task constraints encouraging four year-old children to produce a movement pattern that is a desirable response, this study applied the experimental setting, without any instructions on the skill executions and the decision- making in a series of throwing tasks. The properties of balls and targets were considered the constraints; (1) ball size; (2) target size; (3) target orientation; (4) target height; and (5) the distances from the targets. The properties of a thrower accounted for the constraints as well: (1) eye-height level; and (2) hand size. The responses in the throwing tasks were recorded as the modifications were made in a systemic way. The changes in the response patterns were investigated because of varying modifications with constraints.

\section{Experiment 1}

The varying heights of horizontal hoops, the targets, were applied in the throwing task of Experiment 1. Throwing pattern observed was over- hand throw from all participants in attempts to score. Only a few attempts were made with under-hand throws in the very last trials from one child. The targets created a unique visual layout in accordance with the height of children, at below eye-height and above eye-height from the ground, which was different from the usual practice of mounting the targets 
vertically. Throwing targets are, generally, of a circular shape and hung on the wall vertically, in common movement education settings.

Scoring at a horizontal hoop by using a ball with 2.5 inches of diameter might be perceived as a novel task for them, which is less likely to involve previous experiences in throwing and subject them to the imposed constraints when they make a movement. Task novelty is important to test the dynamic relationship among the constraints because the goal is to demonstrate a process where the outcome could not have been anticipated by phylogeny or previous experiences (Thelen, 1995).

Using a small ball might encourage the children to produce a one-handed throw, discouraging two-handed throws like basketball shooting. In a previous study (Choi et al., 2009) it appeared that over-hand throwing might be a pattern used most in throwing for young children. Just a few under-hand throws were observed in the end of the study from the ones who were less competent and scored less in the task. Under-hand throwing might be an efficient way of throwing to score in the given task. They might not be ready to differentiate the classes of physical properties of each orientation (e.g., between horizontal and vertical orientations). The few attempts made by a child, who scored less during all the attempts, bring up a discussion on the perspective of dynamical systems. Hypothetically, a child who has not experienced many over-hand throw attempts displays the dynamic stability with a likely-stronger disturbance in the system. We often observe this with uncoordinated movement patterns. The fluctuations in the movement patterns (i.e., incoordination in a movement) can be seen as a procedure to gain equilibrium among the constraints and as a stronger drive imbedded in the system toward attaining stability. The observation from a child's few under-hand throws may imply the 
hypothetic procedure toward achieving another set of dynamic stability in throwing movement related to a novel target orientation (e.g., a horizontal hoop).

Since the hoops were placed at two levels in accordance with the children' eye height levels, the height difference might be perceived as a clear distinction between two levels in height, which enabled them to have the distinctive optical perceptions. Unlike a target hung vertically, the horizontal hoops may be gauged with the absolute quality of height differences from the ground. The target was applied so that the constraints from the heights might be appreciated well. In ecological terms, constraints emerge, gaining or losing importance in their ability to influence movement with the task modifications resulting from different interaction between and among constraints (Gagen \& Getchell, 2006). Therefore, the extent to which the absolute quality of height and size of a target can be appreciated may depend on how we arrange the demands of a task like the use of target orientation and its position.

The participants' selections appeared to produce bigger humerus action when they threw the target at above eye-height level. Individual range of each participant's humerus angle were different to the extent which they lifted their upper arm to aim the target before releasing a ball. 
Table 10

Range of Humerus Angle

\begin{tabular}{lllll}
\hline & \multicolumn{3}{l}{ Low target } & \multicolumn{2}{l}{ High target } \\
\cline { 2 - 5 } & Max & Min & Max & Min \\
\hline Jonah & $116.2581^{0}$ & $57.0004^{0}$ & $147.308^{0}$ & $83.4558^{0}$ \\
Oloe & $104.2511^{0}$ & $53.8109^{0}$ & $145.7089^{0}$ & $93.8192^{0}$ \\
Trever & $133.1563^{0}$ & $56.3928^{0}$ & $177.1966^{0}$ & $60.0916^{0}$ \\
Payton & $96.2146^{0}$ & $24.3092^{0}$ & $170.2358^{0}$ & $64.1011^{0}$ \\
\hline
\end{tabular}

Humerus angle at high target distributed at relatively higher degrees collectively than humerus angle at low target. However, some humerus actions at low target were more than those at high target as seen in Table 10. That is, the humerus angle measured from all participants indicate the maximum degree of humerus angle at low target isn't always smaller than the minimum degree of angle at high targets. Four year-old throwers are more likely to lift the upper arms higher when aiming at high target in many cases, but they did not always produce bigger arm actions with throwing at a high target than doing it at a low target.

In dynamical systems terms, without accumulated experiences the horizontal hoop task might not be easily generalized to throwing at a vertical hoop. That is, producing a trajectory for a ball flight to score at a horizontal hoop is not linked to the well-stabilized attractor in scoring at a vertically mounted target (Thelen \& Smith, 1994). The attractor means a hypothetical state, a certain range of behavioral outputs, where an organism will settle into this dynamic stability (Thelen, 2002). A system with a well- 
stabilized attractor may not readily change its movement pattern but a system with a lessstabilized attractor may be subject to a new set of constraints in a novel task to make the change.

The four year-old children might explore the preferable and efficient state in upper arm action they would settle into during the experimental attempts. They made a smooth transition in humerus arm action when moving from high target to low target and controlled the ball flights in accordance with the change of the target height. The transitional phase as shifting from aiming at the higher target to the lower one existed. The maximum degree of humerus angle at low targets was not always smaller than the minimum degree of angle at high targets. The range of angle at each level of target became stretched out widely in some cases. They appeared to experience disturbance in the existing attractor, presumably established by aiming at a vertically mounted target.

The four year-old children responded to changes in the height of a target in relation to their eye height level and demonstrated lifting up the humerus to create higher trajectory at a high target. The strategy with the upper arm action cannot be believed to be effective for achieving the goal. However, it might be one of the solutions for scoring at the hoops, something individuals with the immature throwing skill might do. In a pedagogical sense, imposing a variety of constraints through multiple tasks may not produce the best outcomes from a learner's performance. An instruction in using underhand tossing would be given for a learner before presenting the same throwing task in Experiment 1. They would make the right choice in selection of throwing patterns. They were capable of responding differently according to the levels of trajectories because humerus angles could be adjusted within a single parameter. ETA advocates this 
application of the local variations within a parameter by multiple tasks. Clearly, in a larger sense, we need to instruct a learner on the response alternatives (e.g., over-hand throw and under hand throw). Then, as ETA addresses, he or she may choose one to achieve the functional goal of a task.

\section{Experiment 2}

\section{Choice of Ball and Hoop}

Strategically, choosing a small ball to successfully hit a larger target would be a better decision for scoring with the given throwing task in this study. That is, choosing a big ball to hit a small target will not help scoring. To make a strategic right decision with the task, a four- year child should perceive the absolute quality of the size of the targets and distance from where they throw a ball and understand the relation between the physical properties of the targets and those of the two sized balls. There were no instructions given to the children's decision-making process during the experiment in order to assess the extent to which they comprehend the strategic relation between the constraints of the throwing task in the various levels.

The pair of small ball-large target was most observed in the long distance throw. With the short distance throw, 75 inches away from a thrower, the participants' choices varied because it was a relatively easier task, presumably not requiring any strategic decision for success. These children might know that they could score with any size of ball at any size of hoop from 75 inches regardless of the absolute quality of their properties (e.g., the size of target and hoop). In many cases, the large ball thrown from 150 inches was not able to reach the proximity of a target. It appears that the choices might not be completely made according to the size of target and the ball. Instead, due to 
experiencing the short ball flight, they might choose the small ball because it allowed them to increase the range of motion in the upper body. The constraint of two-handed throws with a large ball discourages a wide range of upper body movement so that they could produce forceful throws for a longer ball flight, reaching a distant target.

However, the choice of balls at a distance of 75 inches appears variable (Table 8). The trends of each child's choice pattern presented in Figure 28 displays the implications behind each child's choice. First, Trever's and Payton's trends are identical, showing the use of the small ball as a preferred choice pattern at both targets. Second, Jonah's and Zack's trends are practically the same patterns with each other, throwing the big ball at the large target and throwing the small ball at the small target. As data of long distance throws in Figure 29 presents, Jonah's adjustment in the choice of balls according to the size of the target appears more dramatically changed at the small target comparing with Zack's data. Oloe's adjustment in his choice over time seems rather unique from the rest of the participants in the short distant throws. He chose the big ball more regardless of the size of targets but with his long distant throws the small ball more as the other participants did.

\section{Response Selection for Forceful Throw}

The increment of distance from a target may be believed as a constraint encouraging the movement pattern for a forceful throwing action. People usually throw harder to score when they are given the task of throwing at a distance. To transfer bigger force to a ball flight, the specific movement patterns are seen in throwing such as adding a body part (e.g., stepping) and increasing a range of motion in upper body and a throwing arm. The observation in Experiment 2 was to see if the four year-old children 
produced the relevant movement pattern for a forceful throw simply by being asked to throw a ball to hit a target from a further distance. The empirical evidence from the examination of each child's response may consolidate the existing instructional strategies in movement education and refine them to design a new pedagogically valid instruction for young learners.

Each child responded differently to the increment of distance from the targets. Some of them produced, however, rather similar movement choices compared to each other to achieve the goal in the distance throw. Their individual choices did not appear to be unanimous. Stepping action was observed in Jonah's, Oloe's, and Zack's throws. Oloe used only homo-lateral stepping but there was no change in his stepping action with the long distance throws. However, in the observation of Jonah's and Zack's contra-lateral stepping actions the number of the stepping action increased when hitting the distant targets. The use of contra-lateral stepping action should be the most efficient movement pattern for force production. The distance of 150 inches from the target may be a constraint leading to contra-lateral stepping but not forming homo-lateral stepping.

In the observation of upper body action, Jonah, Zack, Trever, and Oloe chose either block rotation or flexion, or both. Trever was the one that used the both types of trunk actions. He used block rotation only at the beginning of the experimental days and used flexion action later. The number of flexion actions gradually increased and became more frequent than the number of block rotations in the end. Jonah and Zack used only block rotation, which increased the number of the actions from 150 inches away. Only flexion action was observed in Oloe's throws at the both distances from the targets. More 
flexion actions appeared with the long distance throws but they occurred dispersedly. There was no consistent pattern in his flexion action.

The choice of the two-sized balls was examined as the response selection in relation to flexion and block rotation production in the throwing attempts. Overall, there was the distinctive pattern of pairing the use of small ball-block rotation in Jonah's, Zack's, and Trever's data. The pair of big ball-flexion was seen in Oloe's and Trever's throws. Based on the observation it appeared that one-handed throw with a small ball may create a constraint encouraging block rotation, and two-handed throw with a big ball may affect the emergence of flexion instead.

The measure of observable changes may not be a sophisticated tool to assess the movement production in response to task variations. Kinesthetic responses from muscles, ligaments and joints will take place, but will never be assessed with observation, which might be believed to emerge as the result of interaction among constraints of the forceful throws. The observable-discrete responses instead are meaningful to this study because they may be representing a performer's understanding of how to respond to the parameter of constraint imposed by task, environment and performer. Choice entails knowledge and experiences, which are to be gained with at least some of the alternatives (Davis \& Strand, 2007). Building up a performer's own movement responses paired with the constraints perceived as changing a task condition is an important step to gaining proficiency in decision making and performing a skill in a natural setting. Therefore, a learner needs to explore what choice of movement brings the maximum certainty in achieving a task goal. Unlike adults, presumably, the four year-old children in this study must have little experience in goal-orientated movement tasks. From the ontogenetic skill performance 
(e.g., throwing) the distinct patterns of Jonah's, Zack's and Oloe's throws may present the empirical evidences that they might be capable of comprehending the interaction well among constraints as changing a task condition in the way the developmentalists in dynamical systems theory explain changes in movements.

\section{Suggestions}

This study was designed to examine pedagogically valid constraints on throwing tasks for young children. The findings in this study support the potential of pedagogical benefit from using constraints for desirable movement production. The movement responses in the experimental conditions might not be the ones considered the most effective throwing skill acquisition because no instructional interventions were applied on the responses of the children. However, they were still capable of detecting physical properties as structural constraints and responding accordingly. A task equipped with a set of physical properties will be crucial to add pedagogical strength to a lesson. With a proper instructional intervention: (1) A target mounted horizontally at above a child-eye height level may facilitate using a circular, upward back swing: (2) The same target orientation, but at below a child-eye height level may lead to underhand throw proficiency faster: (3) Learning contra-lateral stepping action may be easier when aiming a distant target: and (4) One hand throwing may produce trunk rotation.

A lesson may be structured to guide a child to explore an alternative movement, positively related to a skill acquisition, where his or her movement would not be the ones completely directed by a set of verbal instructions provided by an instructor. They may not hold the verbal information long enough to rehearse a skill performance after 
finishing the instruction. Each child may discover movements that are meaningful to young children's learning experience.

An instructor's role_is that of a designer as well as a facilitator. The tasks are intentionally designed as a way of containing various constraints that ultimately lead children to choose as closely as possible a preferred movement or response. If the number of alternatives is limited in considering one's capability, he or she makes a choice far from one's preference. The instructor incorporates multiple options at the parameter of a critical point where relevant constraints emerge to lead a specific response (i.e., a desirable response to a task goal). Providing a learner with more alternatives will increase instructional power in developmental change in movement education. Frequent assessment should be done in an ongoing manner to collect the necessary information on response selection, choice, and outcome.

What children might learn may be beyond gaining a proficiency in achieving a functional goal. By engaging a myriad of decision- making processes and cognitive functioning of ordering among given options and relating to one's own capability, they may acquire psychomotor proficiency, transferable to other learning areas, which expand their knowledge structures. As educators, we believe in a learner's chances of growing in multiple aspects of his or her life. We are open to a new instructional approach to maximize a learner's grounds to take him or her to the next level. An ecological approach in movement education may be the one to create a learning environment where we enhance perceptual decision-making process to become much sensible to task condition in relation with a child's own capability in a skill performance. 


\section{REFERENCES}

Adolph, K. E. (1995). A psychophysical assessment of toddlers' ability to cope with slopes. Journal of Experimental Psychology: Human Perception and Performance, 21, 734-750.

Adolph, K. E. (2002). Babies' steps make giant strides toward a science of development. Infant Behavior \& Development, 25, 86-90.

Adolph, K. E., Eppler, M. A., \& Gibson, E. J. (1993). Crawling versus walking infants' perception of affordance for locomotion over sloping surfaces. Children Development, 64, 1158-1174.

Adolph, K. E., Eppler, M. A., Marin, L., Weise, I. B., \& Clearfield, M. W. (2000). Exploration in the service of prospective control. Infant Behavior \& Development, $23,441-460$.

Adolph, K. E., Vereijken, B., \& Denny, M. A. (1998). Learning to crawl. Child Development, 69, 1299-1312.

Adolph, K. E., Vereijken, B., \& Shrout, P. (2003). What change in infant walking and why. Child Development, 74, 475-497.

Alexander, K., \& Penney, D. (2005). Teaching under the influence: feeding Games for Understanding into the Sport Education development-refinement cycle. Physical Education \& Sport Pedagogy, 10, 287-302.

Balan, C. M., \& Davis, W. E. (1993). Ecological task analysis: An approach to teaching physical education. Journal of Physical Education Recreation Dance, 64, 54-61.

Barton, S. (1994). Chaos, self-organization, and psychology. American Psychologist, 49, $5-14$. 
Bernstein, N. (1967). The coordination and regulation of movements. London: Pergamon.

Bingham, G. P., Schmidt, R. C., \& Rosenblum, L. D. (1989). Hefting for maximum distance throw: A smart perceptual mechanism. Journal of Experimental Psychology: Human Perception and Performance, 15, 507-528.

Block, M. E. (1993). Can children with mild mental retardation perceive affordances for action? Adapted Physical Activity, 10, 137-145.

Brown, M. E. (1950a). Daily activity inventory and progress record for those with atypical movement: Part 1. American Journal of Occupational Therapy, 4, 195204.

Brown, M. E. (1950b). Daily activity inventory and progress record for those with atypical movement: Part 2. American Journal of Occupational Therapy, 4, 261272.

Brown, M. E. (1951). Daily activity inventory and progress record for those with atypical movement: Part 3. American Journal of Occupational Therapy, 5, 23-29, 38.

Bruett, T. L., \& Overs, R. P. (1969). A critical review of 12 ADL scales. Physical Therapy, 49, 857-862.

Bulger, S. M., Townsend, J. S., \& Carson, L. M. (2001). Promoting responsible student decision-making in elementary physical education, Journal of Physical Education, Recreation \& Dance, 72, 18-23.

Bunker, D., \& Thorpe, R. (1982). A model for teaching games in secondary school. Bulletin of Physical Education, 18, 5-8. 
Burton, A. W. (1990). Assessing the perceptual-motor interaction in developmentally disabled and non-handicapped children. Adapted Physical Activity Quarterly, 7, $325-337$.

Burton, A. W., \& Davis, W. E. (1991). Ecological task analysis: Translating movement behavior theory into practice. Adapted Physical Activity Quarterly, 8, 154-178.

Burton, A. W., \& Davis, W. E. (1992). Optimizing the involvement and performance of children with physical impairments in movement activities. Pediatric Exercise Science, 4, 236-248.

Burton, A. W., \& Davis, W. E. (1996). Ecological task analysis. Utilizing intrinsic measures in research and practice. Human Movement Science, 15, 285-314.

Burton, A. W., Greer, N. L., \& Wiese D. M. (1992). Changes in overhand throwing patterns as a function of ball size. Pediatric Exercise Science, 4, 50-67.

Burton, A. W., Greer, N. L., \& Wiese-Bjornstal, D. M. (1993). Variations in grasping and throwing patterns as a function of ball size. Pediatric Exercise Science, 5, 25-41.

Burton, A. W., \& Miller, A. E. (1998). Movement skill assessment. Champaign, IL: Human Kinetics.

Burton, A. W., \& Welch, B. A. (1990). Dribbling performance in first-grade children: Effect of ball and hand size and ball-size preferences. The Physical Educator, 47, $48-51$.

Carson, L. M. (1985). Carson Assessment of Motor Pattern. Unpublished manuscript, West Virginia University.

Carson, L. M., Bulger, S. M., \& Townsend, J. S. (2007). Enhancing responsible student decision-making in physical activity. In W. Davis \& G. Broadhead (Eds.), 
Ecological task analysis and movement (pp. 141-157).

Champaign, IL: Human Kinetics.

Choi, Y., Hawkins, A.H., \& Langley, J. (2008). Changes in throwing pattern as a function of task variation. Research Quarterly for Exercise \& Sport, 79 (Suppl. 1), A-46.

Choi, Y., Hawkins, A.H., \& Langley, J. (2009, April) Effect of Task Variation on Perceptual Judgment in Throwing. Research Quarterly for Exercise \& Sport, 80 (Suppl. 1), A-46.

Cooper, J. O., Heron, T. E., \& Heward, W. (1987). Applied behavior analysis. Upper Saddle River New Jersey: Prentice-Hall, Inc.

Davis, W., \& Broadhead, G. (Eds.). (2007). Ecological task analysis and movement. Champaign, IL: Human Kinetics.

Davis, W. E., \& Burton, A.W. (1991). Ecological task analysis: Translating movement behavior theory into practice. Adapted Physical Activity Quarterly, 8, 154-177.

Davis, W. E., \& Strand, J. (2007). Conceptualizing choice as central to the ETA applied model: Broadening the vision. In W. Davis \& G. Broadhead (Eds.), Ecological task analysis and movement (pp. 53-82).

Champaign, IL: Human Kinetics.

Davis, W.E., \& van Emmerik, R. E.A. (1995). An ecological task analysis approach for understanding motor development retardation: Philosophical and theoretical underpinnings. In A. Vermeer and W. E. Davis (Eds.). Physical and motor development with mental retardation (pp. 1-32). Basel: Karger. 
Eppler, M. A., Adolph, K. E., \& Weiner, T. (1996). The developmental relationship between infants' exploration and action on slanted surfaces. Infant Behavior and Development, 19, 259-264.

Gagen, L. M., \& Getchell, N. (2006). Using 'constraints' to design developmentally appropriate movement activities for early childhood education. Early Childhood Education Journal, 34, 227-232.

Gesell, A. (1929). Maturation and infant behavior pattern. Psychological Review, 36, 307-319.

Gibson, E. J. (1982). The concept of affordances in development: The renascence of functionalism. In W. A. Collins (Eds.), The Minnesota Symposia on Child Psychology: Vol. 15. The concept of development (pp.55-81). Hillsdale, NJ: Erlbaum.

Gibson, E. J. (1988). Exploratory behavior in the development of perceiving, acting, and the acquiring of knowledge. Annual Review of Psychology, 39, 1-41.

Gibson, E. J. (2000). Where is the information for affordances? Ecological Psychology, $12,53-56$.

Gibson, E. J., Riccio, G., Schmuckler, M. A., Stoffregen, T. A., Rosenberg, D., \& Taormina, J. (1987). Detection of the traversability of surfaces by crawling and walking infants. Journal of Experimental Psychology: Human Perception and Performance, 13, 533-544.

Gibson, E. J., \& Walk, R. D. (1960). The visual cliff. Scientific American, 202, 64-71.

Gibson, J. J. (1979). An ecological approach to visual information. Boston: HoughtonMifflin. 
Goldfield, E. C., Kay, B. A., \& Warren, W. H. (1993). Infant bouncing: The assembly and tuning of action systems. Child Development, 64, 1128-1142.

Greeno, J. G. (1994). Gibson's affordance. Psychological Review, 2, 336-342.

Griffin, L.L., Mitchell, S. A., \& Oslin, J. L. (1997). Teaching sport concepts and skills: A tactical games approach. Champaign, IL: Human Kinetics.

Gutteridge, M. (1939). A study of motor achievement of young children. Archives of Psychology, 244, 1-178.

Halverson, L. E., Roberton, M. A., \& Langendorfer, S. (1982). Development of the overarm throw: Movement and ball velocity changes by seventh grade. Research Quarterly for Exercise and Sport, 53, 198-205.

Hastie, P. A., \& Curtner-Smith, M. D. (2006). Influence of a hybrid Sport Education Teaching Games for Understanding unit on one teacher and his students. Physical Education \& Sport Pedagogy, 11.1-28

Haywood, K. M., \& Getchell, N. (2008). Life span motor development (5th ed.), Champaign, IL: Human Kinetics.

Isaacs, L. (1972). Effects of ball size, ball color and preferred color on the catching ability of young children. Unpublished doctoral dissertation, University of Wisconsin.

Isaacs, L. (1980). Effects of ball size, ball color and preferred color on the catching ability of young children. Perceptual and Motor Skills, 51, 583-586

Jones, K. S. (2003). What is an affordance? Ecological Psychology, 15, 107-114.

Kazdin, A. E. (1982). Single case research designs: Methods for clinical and applied settings. Oxford, NY: Oxford University Press. 
Kugler, P. N. (1986). A morphological perspective on the origin and evolution of movement patterns. In M. G. Wade \& H. T. A. Whiting (Eds.), Motor development in young children: Aspects of coordination and control (pp. 459525). Dordrecht: Martinus Nijhoff.

Kugler, P. N., Kelso, J. A. S., \& Turvey, M. T. (1980). On the concept of coordinative structures as dissipative structures: Theoretical lines of convergence. In G. E. Stelmach, \& J. Requin (Eds.), Tutorials in motor behavior (pp. 3-47). New York: North Holland.

Kugler, P. N., Kelso, J. A. S., \& Turvey, M. T. (1982). On the concept of coordination of naturally developing system. In J. A. S. Kelso \& J. E. Clark (Eds.), The development of movement control and coordination (pp. 5-78). New York: Wiley.

Kugler, P. N., \& Turvey, M. T. (1987). Information, natural law, and the self-assembly of rhythmic movement. Hillsdale, NJ: Erlbaum.

Langendorfer, S. J.(1987). Pre-longitudinal screening of overarm striking development performed under two environmental conditions. In J. E. Clark \& J. H. Humphrey (Eds.). Advances in motor development research Vol.1 (pp.17-48). New York, NY: AMS press, Inc.

Langendorfer, S. J., \& Roberton, M. A. (2002). Individual pathways in the development of forceful throwing. Research Quarterly for Exercise and Sport, 72, 245-256.

Lufting, R. L. (1989). Assessment of learners with special needs. Boston: Allyn \& Bacon. Magill, R. A. (1993). Motor learning: Concepts and applications (4th ed.). Dubuque, IA: Brown \& Benchmark. 
Mark, L. S. (1987). Eyeheight-scaled information about affordance: A study of sitting and stair climbing. Journal of Experimental Psychology, 3, 361-370.

McGraw, M. B. (1943). The neuromuscular maturation of the human infant. New York: Columbia University Press.

Meadly, D. (1941). A study of the catching ability of children in grade one to four. Unpublished Master's thesis, University of Iowa.

Monty, R. A., \& Perlmuter, L. C. (1987). Choice, control, and motivation in the young and aged. In M.L. Maehr \& D. A. Kleiber (Eds.), Advances in motivation and achievement, 5, 99-122. Greenwich, CT: JAI Press.

Mohr, D. J., Townsend, J. S., \& Bulger, S. M. (2002). Maintaining the PASE: A day in the life of sport education. Journal of Physical Education, Recreation, \& Dance, 73, 36-43.

Morris, G. (1976). Effects ball and background color have upon the catching performances of elementary school children. Research Quarterly, 47, 409-416.

Morris, M., Matyas, T., Iansek, R., \& Cunnington, R. (1996). Rehabilitation promotes functional movement in atypical populations. Behavioral and Brain Sciences, 19, 82-83.

Mullally, G., \& Mullally, M. (2007). An ecological task analysis based approach for physiotherapists in pediatrics. In W. Davis \& G. Broadhead (Eds.), Ecological task analysis and movement (pp. 219-245). Champaign, IL: Human Kinetics.

National Association for Sport and Physical Education an Association of the American Alliance for Health, Physical Education, Recreation and Dance. (2004). Moving 
into the future: National standards for physical education ( $2^{\text {nd }}$ ed.). Reston, VA: Author.

Nelson, J. K., Thomas, J. R., \& Nelson, K. R. (1991) Longitudinal change in throwing performance: gender differences. Research Quarterly for Exercise \& Sport, 62, 105-108.

Nelson, J. K., Thomas, J. R., Nelson, K. R., \& Abraham, P. C. (1986). Gender differences in children's throwing performance: Biology and environment. Research Quarterly for Exercise and Sport, 57, 280-287.

Newell, K.M. (1984). The development of coordination: Significance of task constraints. Paper presented at the meeting of the American Association for the Advancement of Science, New York, NY.

Newell, K.M. (1986). Constraints on the development of coordination. In M. G. Wade \& H. T. A. Whiting (Eds.), Motor development in children: Aspects of coordination and control (pp. 341-361). Boston, MA: Nijhoff.

Payne, V. G. (1982). Simultaneous investigation of effects of distance of projection and object size on object reception by children in grade 1. Perceptual and Motor Skills, 54, 1183-1187.

Payne, V. G., \& Koslow, R. (1981). Effect of varying ball diameters on catching ability of young children. Perceptual and Motor Skill, 53, 739-744.

Peterson, P. (1979). Direct instruction reconsidered. In P. Peterson \& H. Walberg (Eds.), Research on teaching: Concepts, findings, and implications (pp. 57-69). Berkely, CA: McCutchan. 
Piaget, J. (1985). The equilibration of cognitive structures. Chicago: University of Chicago Press. (Original work published in French in 1981)

Ridenour, M. (1974). Influence of object size, speed and direction on perception of a moving object. Research Quarterly, 45, 293-301.

Ridenour, M. (1979). Influence of ball size and background patterns on perception of visual direction of a moving object. Perceptual and Motor Skills, 49, 343-346.

Roberton, M. A. (1978). Longtudinal evidence for developmental stage in the forceful overarm throw. Journal of Human Movement Studies, 4, 167-175.

Roberton, M. A. (1987). Developmental level as a function of the immediate environment. In J. E., Clark, \& J. H., Humphrey (Eds.). Advances in motor development research Vol.1 (pp.1-16). New York, NY: AMS press, Inc.

Roberton, M. A., \& Halverson, L. E. (1984). Developing children - Their changing movement: A guide for teachers. Philadelphia: Lea \& Febiger.

Roberton, M. A., Halverson, L. E., \& Erbaugh, S (1981). Interrelationship between developmental levels and ball velocity in the overarm throws of kindergarten children [Abstract]. In G. Roberts \& D. Landers (Eds.), Psychology of motor behavior and sport (p.202). Champaign, IL: Human Kinetics.

Roberton, M. A., \& Konczak, J. (2001). Predicting children's overarm throw ball velocities from their developmental levels in throwing. Research Quarterly for Exercise and Sport, 72, 91-103.

Roberton, M. A., \& Langendorfer, S. J. (1980). Testing motor development sequences across 9-14 years. In C. Nadeau, W. Halliwell, K. Newell, \& G. Roberts (Eds.), 
Psychology of motor behavior and sport (pp.269-279). Champaign, IL: Human Kinetics.

Roberton, M. A., \& Langendorfer, S. J. (2002). Individual pathways in the development of forceful throwing. Research Quarterly for Exercise and Sport, 72, 245-256.

Runion, B. P., Roberton, M. A., \& Langendorfer, S. J. (2003). Forceful overarm throwing: A comparison of two cohorts measured 20 years apart. Research Quarterly for Exercise and Sport, 74, 324-330.

Rutter, B. G. (1987). Towards an ecological model of apprehension. Unpublished Doctoral Dissertation. University of Illinois at Urbana-Champaign.

Saltzman, E., \& Kelso, J. A. S. (1987). Skilled actions: A task-dynamic approach. Psychological Review, 94, 84-106.

Scarantino, A. (2003). Affordance explained. Philosophy of Science, 70, 949-961.

Schmidt, R. A., \& Wrisberg, C. A. (2008). Motor learning and performance: Situationbased learning approach. Champaign, IL: Human Kinetics.

Shirly, M. M. (1931). The first two years: A Study of Twenty-Five Babies. Vol. 1. Postural and Locomotor Development. Minneapolis: Univeristy of Minnesota Press,

Siedentop, D. (1994). Quality PE through positive sport experiences: Sport education. Champaign, IL: Human Kinetics.

SimulCam ${ }^{\text {TM }}$ technology (2007). Dartfish (Version 4.5) [Computer software]. Alpharetta, GA: Author.

Smith, L. B., \& Thelen, E. (1993). Dynamic systems in development: Application. Cambridge, MA: Bradford Book/MIT Press. 
Soar, R. S. (1977). An integration of findings from four studies of teacher effectiveness. In G. Borich \& K. Fenton (Eds.), The appraisal of teaching: Concepts and process (pp. 96-103). Reading, MA: Addison-Wesley.

Southard, D. (1998). Mass and velocity: Control parameters for throwing. Research Quarterly for Exercise and Sport, 69, 355-367.

Southard, D. (2002). Change in throwing pattern: Critical values for control parameter of velocity. Quarterly for Exercise and Sport, 7 , 396-407.

Southard, D. (2007). Change in throwing pattern: Manipulating a control parameter in overhand throwing. In W. Davis \& G. Broadhead (Eds.), Ecological task analysis and movement (pp. 97-113). Champaign, IL: Human Kinetics.

Stalling, J. (1977). How instructional process relate to child outcomes. In G. Borich \& K. Fenton (Eds.), The appraisal of teaching: Concepts and process (pp. 104-113). Reading, MA: Addison-Wesley.

Thelen, E. (1986). Treadmill-elicited stepping in seven-month-old infants. Child Development, 57, 1498-1506.

Thelen, E. (1989). Self-organization developmental processes: Can systems approaches work? In M. Gunnar \& E. Thelen (Eds.), The Minnesota Symposia on Child Psychology: Vol. 22. Systems in Development (pp.77-117). Hillsdale, NJ: Erlbaum.

Thelen, E. (1992). Development as a dynamic system. Current Directions in Psychological Science, 1, 189-193.

Thelen, E. (1994). Three month old infants can learn task specific patterns of inter-limb coordination. Psychological Science, 5, 280-285. 
Thelen, E. (1995). Motor development: A new synthesis. American Psychologist, 50, 7995.

Thelen, E. (2002). Self- organization in developmental processes: Can system approaches work? In M. H. Johnson, Y. Munakata, \& R. O. Gilmore, (2 ${ }^{\text {nd }}$ ed. $)$, Brain Development and Cognition, (pp.336-374). Boston, MA: Blackwell Publisher.

Thelen, E., \& Fisher, D. M. (1982). Newborn stepping: An explanation for a “disappearing reflex.” Developmental Review, 7, 39-65.

Thelen, E., \& Fisher, D. M. (1983). The organization of spontaneous leg movements in newborn infants. Journal of Motor Behavior, 15, 353-377

Thelen, E., Kelso, J. A. S., \& Fogel, A. (1987). Self-organizing system and infant motor development. Developmental Review, 7, 39-65.

Thelen, E., \& Smith, L. B. (1994). A dynamic systems approach to the development of cognition and action. Cambridge, MA: The MIT Press.

Thomas, J., \& French, K. (1985). Gender differences across age in motor performance: A meta-analysis. Psychological Bulletin, 98, 260-282.

Thorpe, R. D. \& Bunker. D. J. (1989). A changing focus in games teaching. In L. Almond (Ed.), The place of physical education in schools. London: Kogan Page

Turvey, M. T., \& Carello, C. (1996). Dynamics of Bernstein's level of synergies. In M. L. Latash, \& M. T. Turvey (Eds.), Dexterity and its development (pp. 339-376). Mahwah, NJ: Erlbaum.

Ulrich, D. A. (1985). Test of Gross Motor Development. Austin, TX: PRO-ED.

Ulrich, D. A., Riggen, K. J., Ozmun, J. C., Screws, D. P., \& Cleland, F. E. (1989). Assessing movement control in children with mental retardation: A 
generalizability analysis of observers. American Journal of Mental Retardation, 94, 170-176.

Van geert, P. (1998). We almost had a great future behind us: The contribution of nonlinear dynamics to developmental science in the making. Developmental Science, $1,143-159$.

Vereijken, B., Van Emmerik, R. E. A., Whiting, H. T. A., \& Newell, K. M. (1992). Freezing degree of freedom in skill acquisition. Journal of Motor Behavior. 24, $133-142$.

Walter, C. B., \& Kamm, K. (1996). Optimal search strategies for optimal motor solutions: Self-determination or informed guidance? Behavioral and Brain Sciences, 19, 91-92.

Wang, M. C. (1983). Development and consequences of students' sense of personal control. In J. Levine \& M. C., Wang, (Eds.), Teacher and Student Perceptions: Implications for learning (pp. 213-247). Hillsdale, NJ: Erlbaum.

Wang, M. C. \& Stiles, B. (1976). An investigation of children's concept of selfresponsibility for their school learning. American Educational Research Journal, 13, 159-179.

Warren, W. H. (1984). Perceiving affordances: Visual guidance of stair climbing. Journal of Experimental Psychology: Human Perception and Performance, 10, 683-703.

Warren, W. H. (1989). The perception-action coupling. In H. Bloch \& B. I. Bertenthal (Eds.), Sensory-motor organizations and development in infancy and early childhood (pp.23-37). Dordrect, The Netherlands: Kluwer Academic. 
Warren, W. H., \& Whang, S. (1987). Visual guidance of walking through apertures: Body-scaled information for affordances. Journal of Experimental Psychology: Human Perception and Performance, 13, 371-383.

Wessel, J. A., \& Kelly, L. (1986). Achievement-based curriculum development in physical education. Philadelphia, PA: Lea \& Febiger.

Whitall, J., Sanghvi, S., \& Getchell, N. (2007). Ecological task analysis and applied research: A preliminary study of perception-action judgment in children with learning disabilities. In W. Davis \& G. Broadhead (Eds.), Ecological task analysis and movement (pp.83-94). Champaign, IL: Human Kinetics.

William, K., Haywood, K. M., \& Painter, M. (1996). Environmental versus biological influences on gender differences in the overarm throw for force: Dominant and nondominant arm throws. Women in Sport and Physical Activity Journal, 5, 29-48.

Yan, J. H., Payne, G., \& Thomas, J. R. (2000). Developmental kinematics of young girls' overarm throwing. Research Quarterly for Exercise and Sport, 71, 92-98. 


\section{APPENDIX A}

\section{Distributions of Changes in Humerus Angle in Experiment 1}

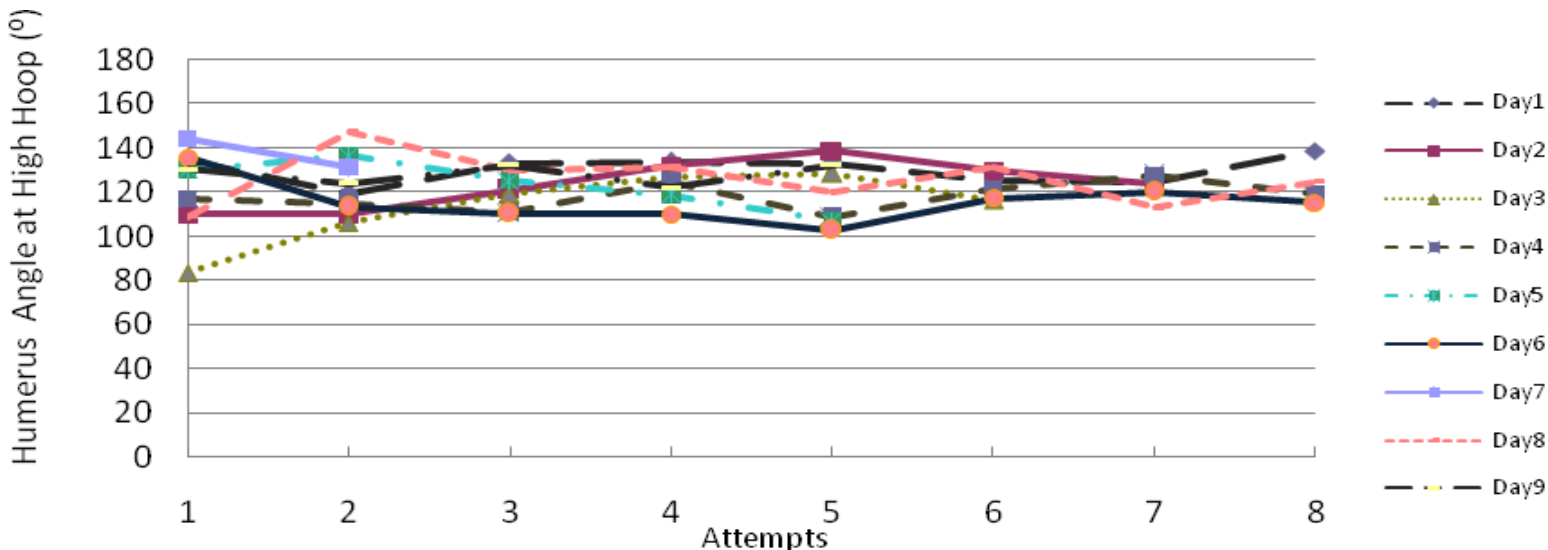

Figure 1A. Jonah's humerus angle aiming at high target; range $=56.4019$ Max: $147.308^{\circ}$ Min: $83.4558^{\circ}$

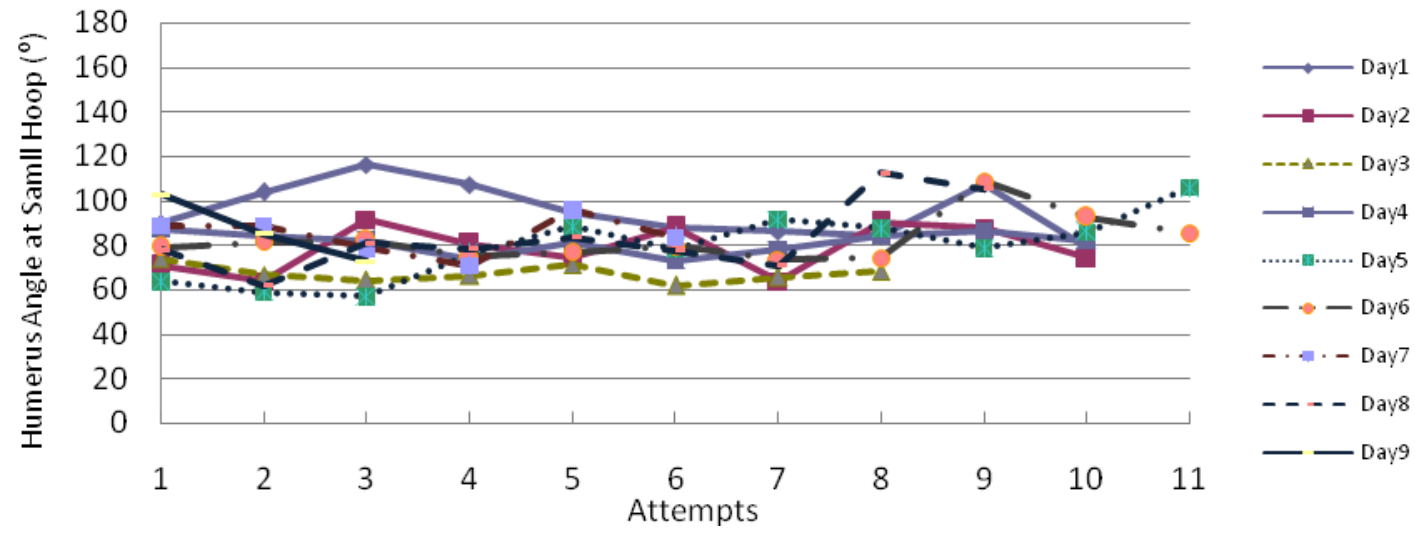

Figure 2A. Jonah's humerus angle aiming at low target; range=60.2541 Max: $116.2581^{\circ}$ Min: $57.0004^{\circ}$

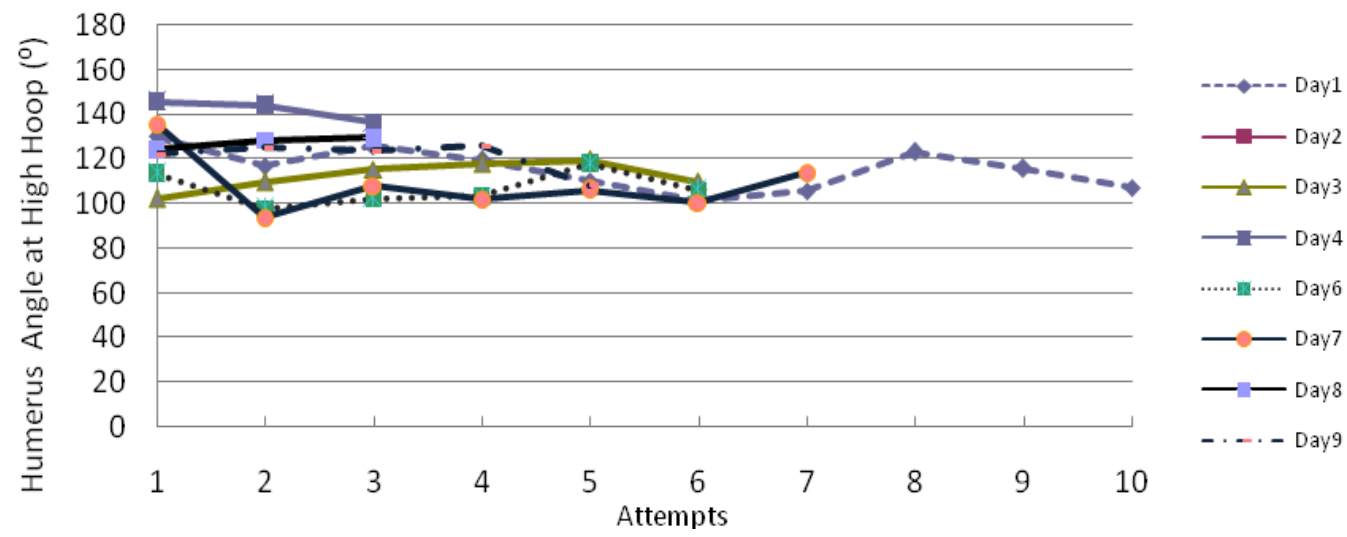

Figure 3 A. Oloe's humerus angle aiming at high target; range $=52.8897$ Max: $145.7089^{\circ}$ Min: $93.8192^{\circ}$ 


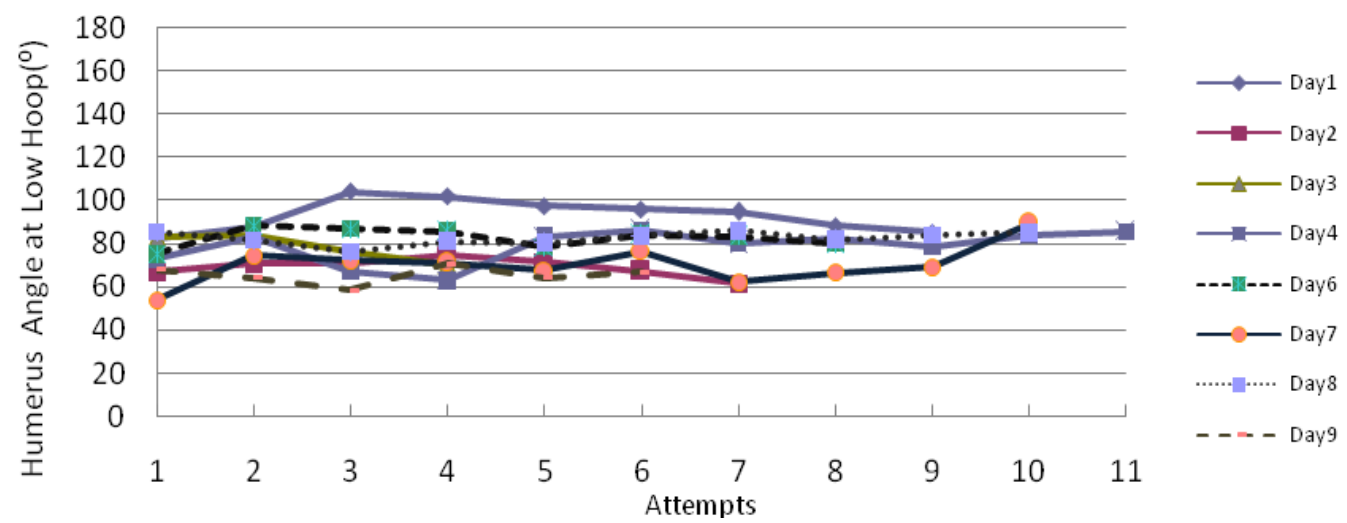

Figure 4A. Oloe's humerus angle aiming at low target; range= 51.4402 Max: $104.2511^{\circ}$ Min: $53.8109^{\circ}$

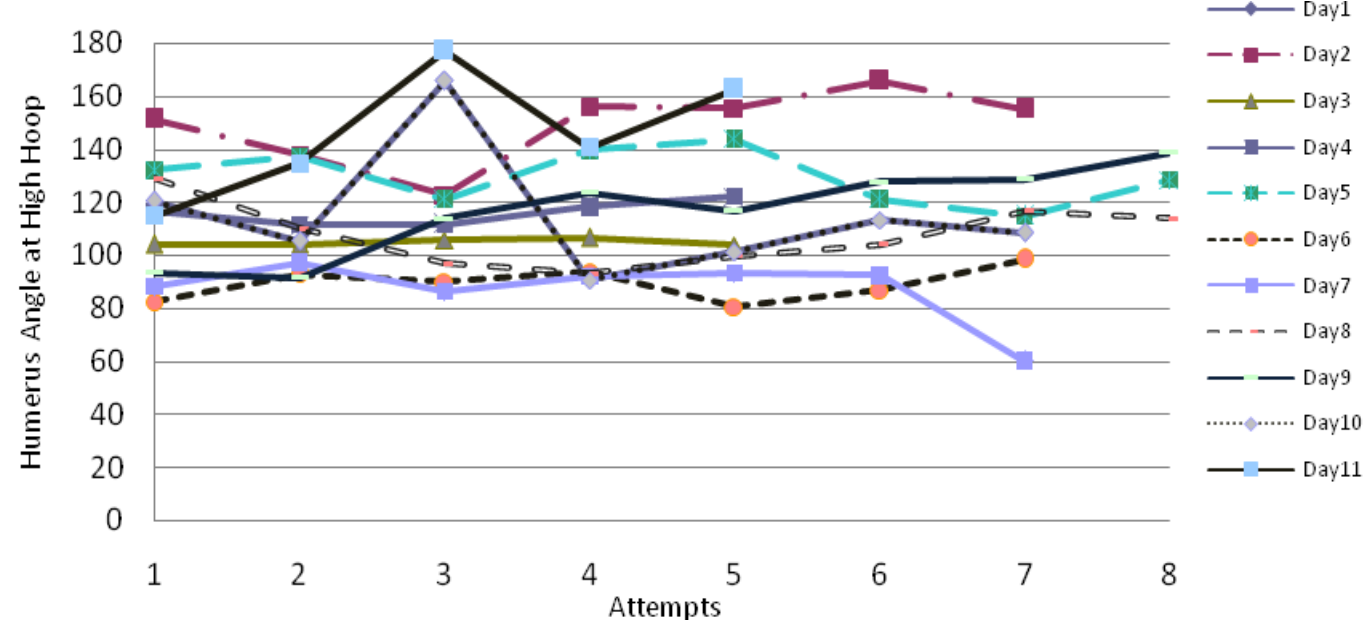

Figure 5A. Trever's humerus angle aiming at high target; range $=118.105$ Max: $177.1966^{\circ}$ Min: $60.0916^{\circ}$

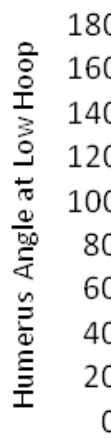
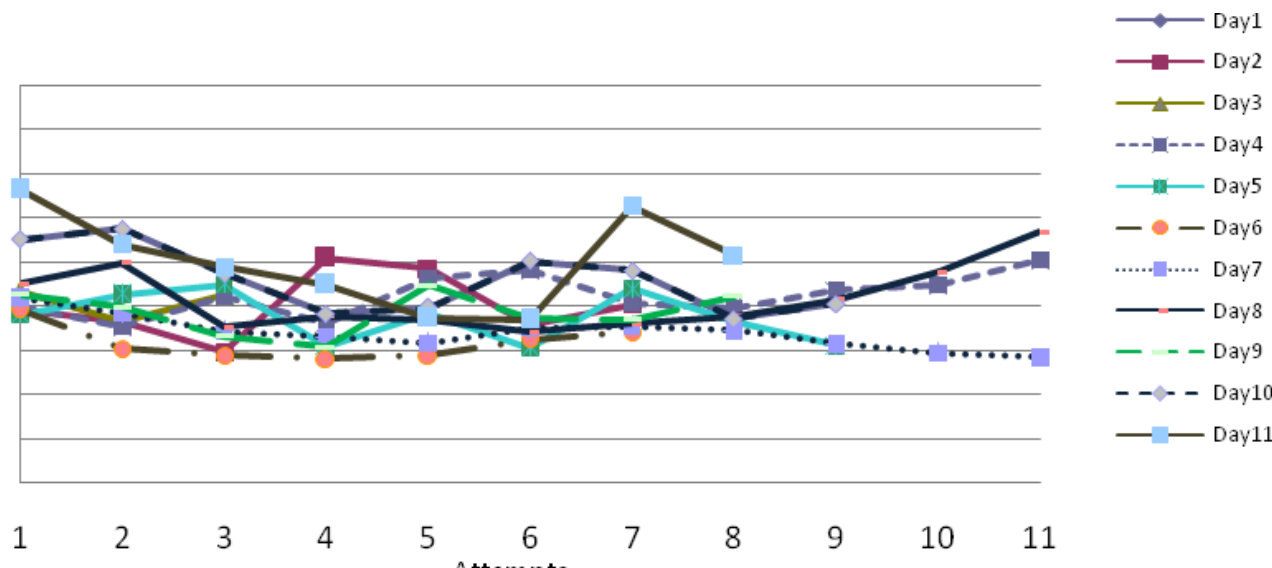

Figure 6A. Trever's humerus angle aiming at low target; range $=76.7635$ Max: $133.1563^{\circ}$ Min: $56.3928^{\circ}$ 


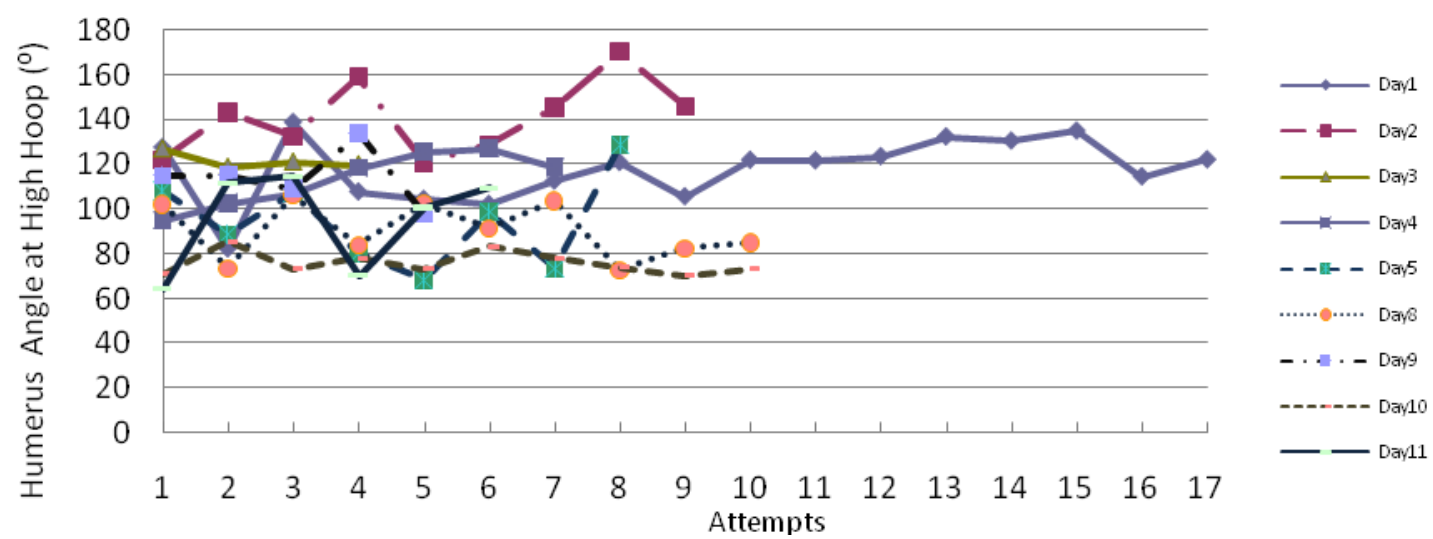

Figure 7A. Payton's humerus angle aiming at high target; range =107.1347 Max: $170.2358^{\circ}$ Min: $64.1011^{\circ}$

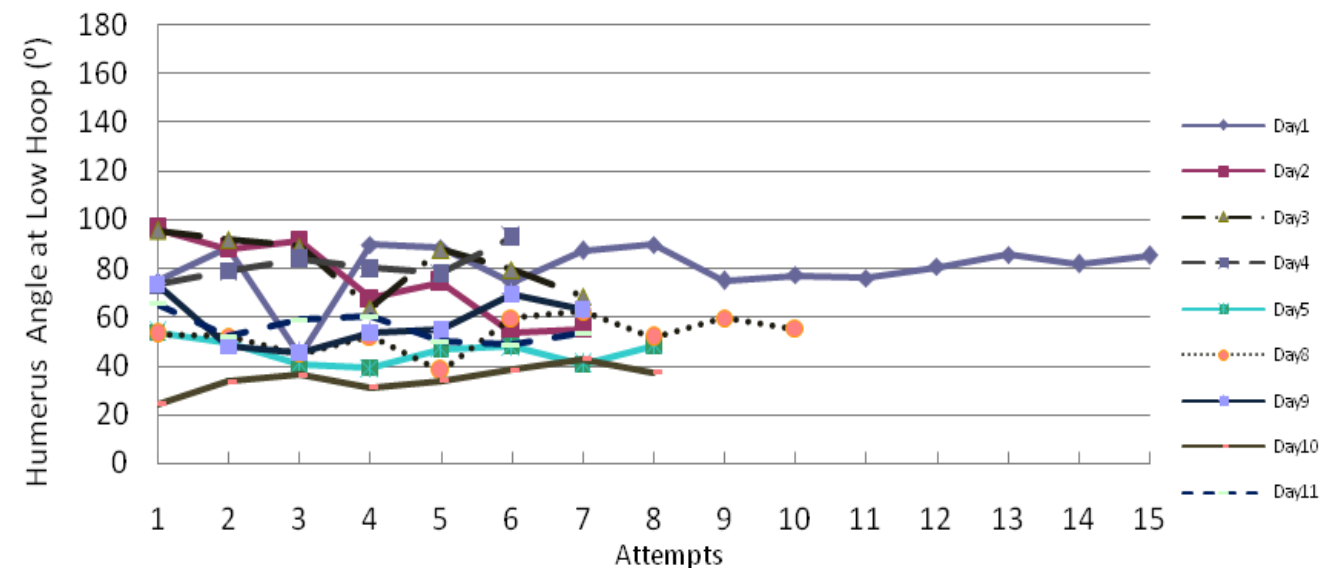

Figure 8A. Payton's humerus angle aiming at high target; range=72.9054 Max: $96.2146^{\circ}$ Min: $24.3092^{\circ}$ 


\section{APPENDIX B}

Scoring Rates: Choices of Balls and Hoops in Experiment 2

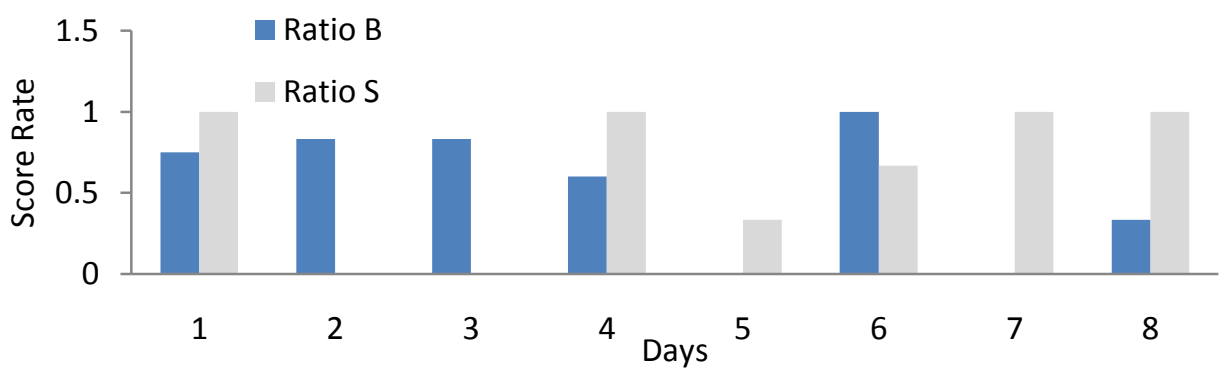

Figure 9A. Zack's scoring ratios at big hoop from a distance of 75 inches: Ratio B indicates scoring rates with use of big balls. Ratio $\mathrm{S}$ indicates scoring rates with use of small balls.

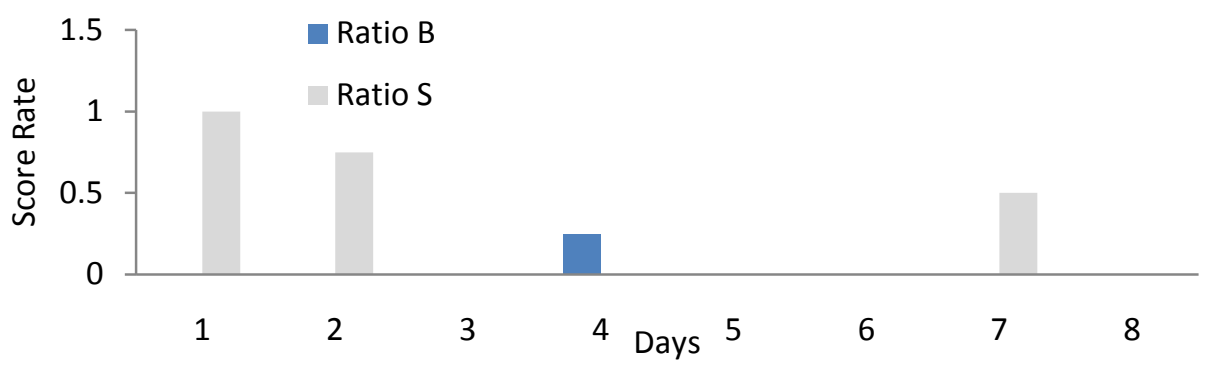

Figure 10A. Zack's scoring ratios at small hoop from a distance of 75 inches: Ratio B indicates scoring rates with use of big balls. Ratio $\mathrm{S}$ indicates scoring rates with use of small balls.

Table 1A

Zack's Scores in the Short Distance Throws

\begin{tabular}{lccccccccc}
\hline \multicolumn{2}{l}{ Big hoop from 75 inches } & & & & & & & \\
\hline Days & 1 & 2 & 3 & 4 & 5 & 6 & 7 & 8 & Total \\
Score B & 3 & 5 & 5 & 3 & 0 & 2 & 0 & 1 & 19 \\
Score S & 1 & 0 & 0 & 1 & 2 & 2 & 5 & 5 & 16 \\
Attempt B & 4 & 6 & 6 & 5 & 1 & 2 & 1 & 3 & 28 \\
Attempt S & 1 & 0 & 0 & 1 & 6 & 3 & 5 & 5 & 21 \\
\hline
\end{tabular}

\begin{tabular}{|c|c|c|c|c|c|c|c|c|c|}
\hline \multicolumn{10}{|c|}{ Small hoop from 75 inches } \\
\hline Days & 1 & 2 & 3 & 4 & 5 & 6 & 7 & 8 & Total \\
\hline Score B & 0 & 0 & 0 & 1 & 0 & 0 & 0 & 0 & 1 \\
\hline Score S & 3 & 3 & 0 & 0 & 0 & 0 & 1 & 0 & 7 \\
\hline Attempt B & 1 & 0 & 2 & 4 & 0 & 1 & 1 & 0 & 9 \\
\hline Attempt S & 3 & 4 & 1 & 0 & 0 & 1 & 2 & 1 & 12 \\
\hline
\end{tabular}


Note. Score B (S) presents a score with use of big balls (small balls). Attempt B (S) presents a number of attempts with big ball (small balls) at each target.

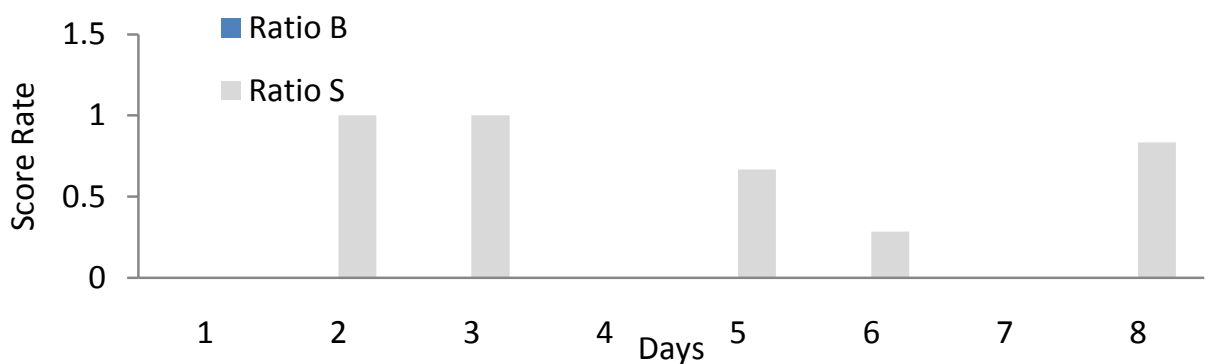

Figure 11A. Zack's scoring ratios at big hoop from a distance of 150 inches: Ratio B indicates scoring rates with use of big balls. Ratio $\mathrm{S}$ indicates scoring rates with use of small balls.

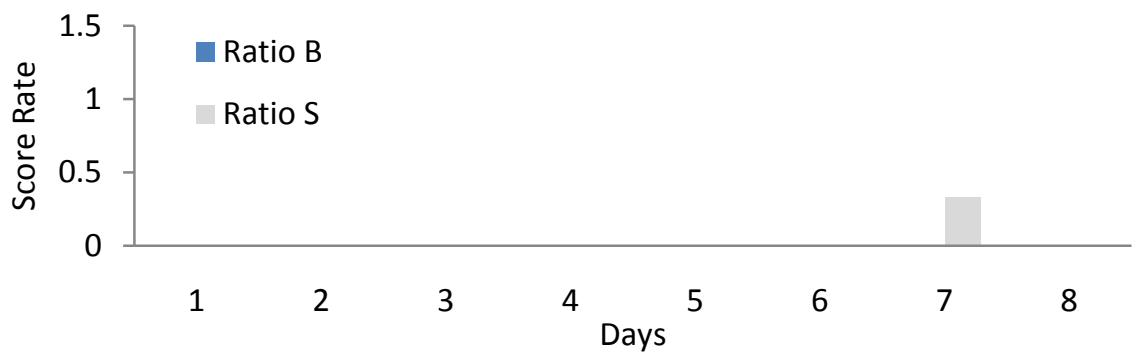

Figure 12A. Zack's scoring ratios at small hoop from a distance of 150 inches: Ratio B indicates scoring rates with use of big balls. Ratio $\mathrm{S}$ indicates scoring rates with use of small balls.

Table 2A

Zack's Scores in the Long Distance Throws

\begin{tabular}{|c|c|c|c|c|c|c|c|c|c|}
\hline \multicolumn{10}{|c|}{ Big hoop from 150 inches } \\
\hline Days & 1 & 2 & 3 & 4 & 5 & 6 & 7 & 8 & Total \\
\hline Score B & 0 & 0 & 0 & 0 & 0 & 0 & 0 & 0 & 0 \\
\hline Score S & 0 & 1 & 2 & 0 & 6 & 2 & 0 & 5 & 16 \\
\hline Attempt B & 8 & 4 & 4 & 6 & 0 & 0 & 0 & 1 & 23 \\
\hline Attempt S & 0 & 1 & 2 & 2 & 9 & 7 & 5 & 6 & 32 \\
\hline \multicolumn{10}{|c|}{ Small hoop from 150 inches } \\
\hline Days & 1 & 2 & 3 & 4 & 5 & 6 & 7 & 8 & Total \\
\hline Score B & 0 & 0 & 0 & 0 & 0 & 0 & 0 & 0 & 0 \\
\hline Score S & 0 & 0 & 0 & 0 & 0 & 0 & 1 & 0 & 1 \\
\hline Attempt B & 0 & 0 & 0 & 1 & 0 & 1 & 1 & 0 & 3 \\
\hline Attempt S & 0 & 3 & 0 & 0 & 0 & 1 & 3 & 1 & 8 \\
\hline
\end{tabular}


Note. Score B (S) presents a score with use of big balls (small balls). Attempt B (S) presents a number of attempts with big ball (small balls) at each target.

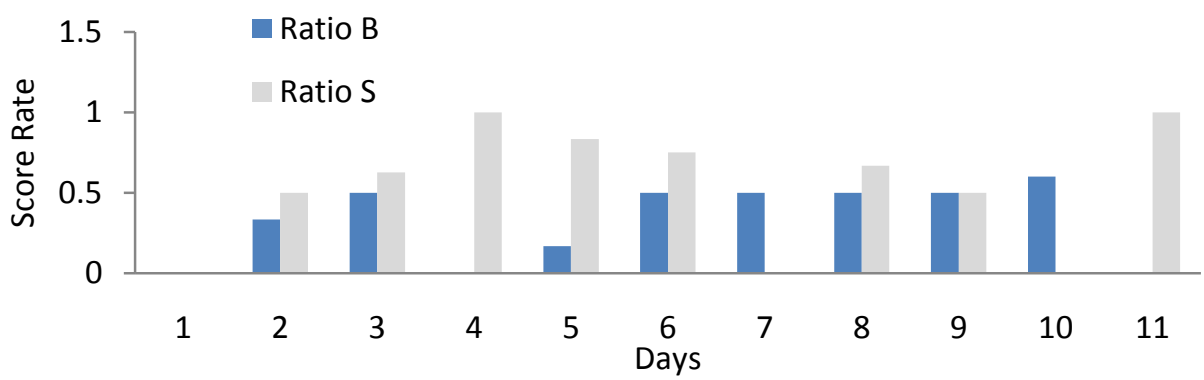

Figure 13A. Trever's scoring ratios at big hoop from a distance of 75 inches: Ratio B indicates scoring rates with use of big balls. Ratio $\mathrm{S}$ indicates scoring rates with use of small balls.

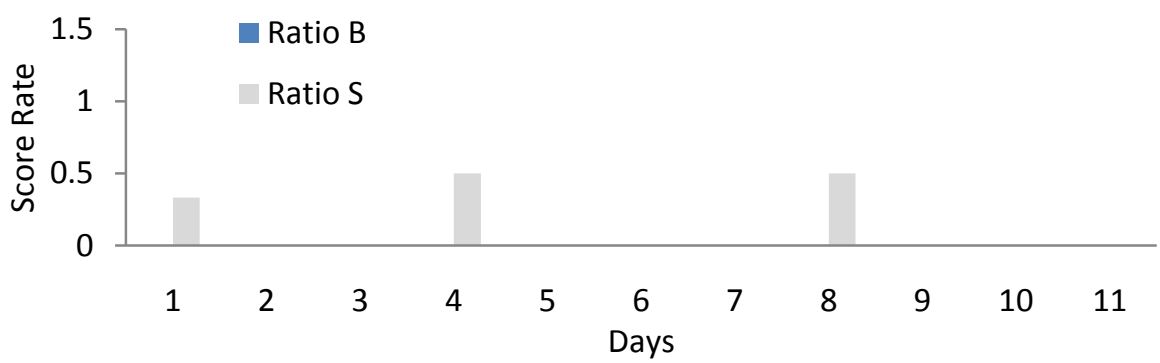

Figure 14A. Trever's scoring ratios at small hoop from a distance of 75 inches: Ratio B indicates scoring rates with use of big balls. Ratio $\mathrm{S}$ indicates scoring rates with use of small balls.

Table 3A

Trever's Scores in the Short Distance Throws

\begin{tabular}{|c|c|c|c|c|c|c|c|c|c|c|c|c|}
\hline \multicolumn{13}{|c|}{ Big Hoop from 75 inches } \\
\hline Days & 1 & 2 & 3 & 4 & 5 & 6 & 7 & 8 & 9 & 10 & 11 & Total \\
\hline Attempt B & 2 & 3 & 2 & 1 & 6 & 4 & 2 & 2 & 2 & 5 & 3 & 32 \\
\hline Attempt S & 1 & 2 & 8 & 4 & 6 & 4 & 2 & 3 & 2 & 0 & 3 & 35 \\
\hline Score B & 0 & 1 & 1 & 0 & 1 & 2 & 1 & 1 & 1 & 3 & 0 & 11 \\
\hline Score S & 0 & 1 & 5 & 4 & 5 & 3 & 0 & 2 & 1 & 0 & 3 & 24 \\
\hline
\end{tabular}

\begin{tabular}{|c|c|c|c|c|c|c|c|c|c|c|c|c|}
\hline \multicolumn{13}{|c|}{ Small Hoop from 75 inches } \\
\hline Days & 1 & 2 & 3 & 4 & 5 & 6 & 7 & 8 & 9 & 10 & 11 & Total \\
\hline Attempt B & 1 & 0 & 0 & 1 & 0 & 0 & 0 & 2 & 2 & 1 & 0 & 7 \\
\hline Attempt S & 3 & 0 & 1 & 2 & 0 & 0 & 4 & 2 & 1 & 2 & 1 & 16 \\
\hline Score B & 0 & 0 & 0 & 0 & 0 & 0 & 0 & 0 & 0 & 0 & 0 & 0 \\
\hline Score S & 1 & 0 & 0 & 1 & 0 & 0 & 0 & 1 & 0 & 0 & 0 & 3 \\
\hline
\end{tabular}


Note. Score B (S) presents a score with use of big balls (small balls). Attempt B (S) presents a number of attempts with big ball (small balls) at each target.

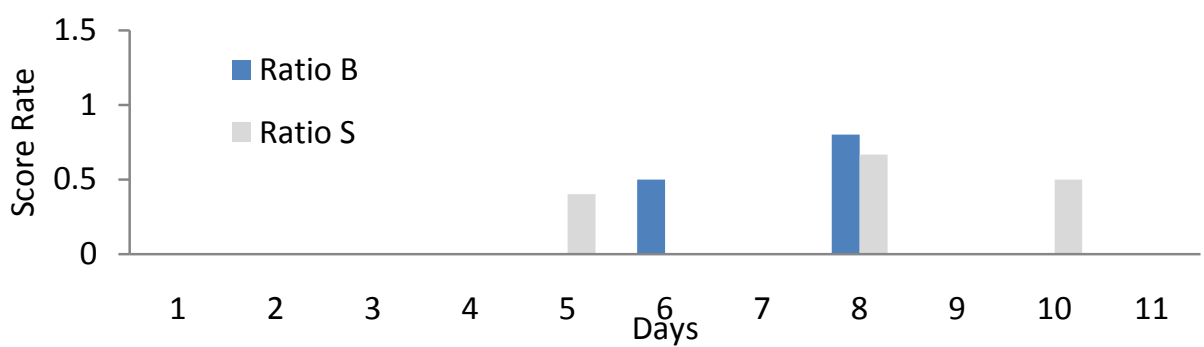

Figure 15A. Trever's scoring ratios at big hoop from a distance of 150 inches: Ratio B indicates scoring rates with use of big balls. Ratio $\mathrm{S}$ indicates scoring rates with use of small balls.

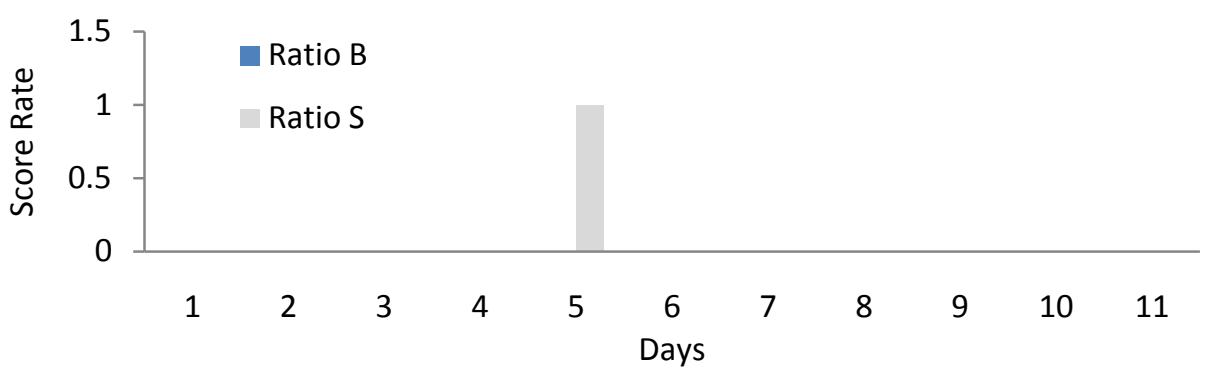

Figure 16A. Trever's scoring ratios at small hoop from a distance of 150 inches: Ratio B indicates scoring rates with use of big balls. Ratio $\mathrm{S}$ indicates scoring rates with use of small balls.

Table 4A

Trever's Scores in the Long Distance Throws

\begin{tabular}{lcccccccccccc}
\hline Big Hoop from 150 inches \\
\hline Days & 1 & 2 & 3 & 4 & 5 & 6 & 7 & 8 & 9 & 10 & 11 & Total \\
Attempt B & 2 & 3 & 1 & 0 & 1 & 2 & 7 & 5 & 3 & 4 & 5 & 33 \\
Attempt S & 2 & 2 & 7 & 6 & 5 & 3 & 0 & 3 & 4 & 2 & 4 & 38 \\
Score B & 0 & 0 & 0 & 0 & 0 & 1 & 0 & 4 & 0 & 0 & 0 & 5 \\
Score S & 0 & 0 & 0 & 0 & 2 & 0 & 0 & 2 & 0 & 1 & 0 & 5 \\
\hline
\end{tabular}

\begin{tabular}{lcccccccccccc}
\hline Small Hoop from 150 inches \\
\hline Days & 1 & 2 & 3 & 4 & 5 & 6 & 7 & 8 & 9 & 10 & 11 & Total \\
Attempt B & 1 & 0 & 0 & 1 & 0 & 0 & 1 & 0 & 1 & 1 & 1 & 6 \\
Attempt S & 3 & 0 & 1 & 1 & 4 & 4 & 3 & 0 & 1 & 0 & 1 & 18 \\
Score B & 0 & 0 & 0 & 0 & 0 & 0 & 0 & 0 & 0 & 0 & 0 & 0 \\
Score S & 0 & 0 & 0 & 0 & 4 & 0 & 0 & 0 & 0 & 0 & 0 & 4 \\
\hline
\end{tabular}


Note. Score B (S) presents a score with use of big balls (small balls). Attempt B (S) presents a number of attempts with big ball (small balls) at each target.

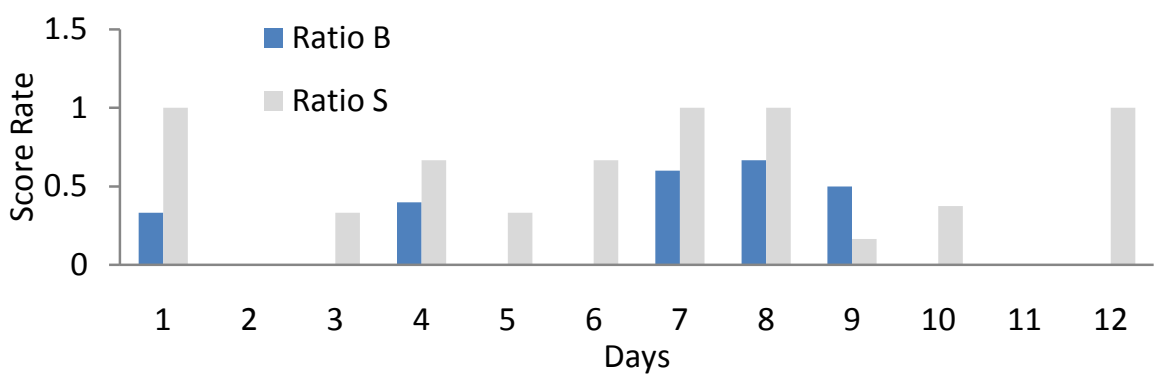

Figure 17A.Payton's scoring ratios at big hoop from a distance of 75 inches: Ratio B indicates scoring rates with use of big balls. Ratio $\mathrm{S}$ indicates scoring rates with use of small balls.

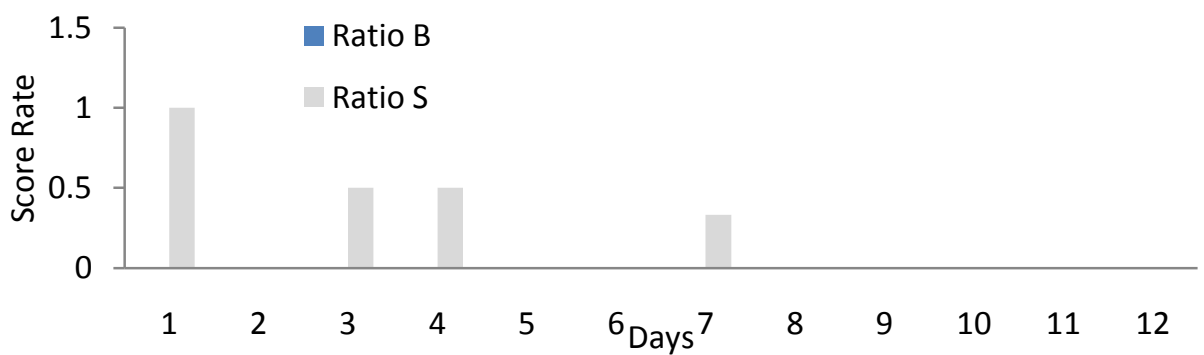

Figure 18A. Payton's scoring ratios at small hoop from a distance of 75 inches: Ratio B indicates scoring rates with use of big balls. Ratio $\mathrm{S}$ indicates scoring rates with use of small balls.

Table 5A

Payton's Scores in the Short Distance Throws

\begin{tabular}{lccccccccccccc}
\hline Big hoop from 75 inches \\
\hline Days & 1 & 2 & 3 & 4 & 5 & 6 & 7 & 8 & 9 & 10 & 11 & 12 & Total \\
Score B & 1 & 0 & 0 & 2 & 0 & 0 & 3 & 4 & 1 & 0 & 0 & 0 & 11 \\
Score S & 1 & 0 & 1 & 2 & 1 & 2 & 2 & 1 & 1 & 3 & 0 & 4 & 18 \\
Attempt B & 3 & 1 & 0 & 5 & 3 & 1 & 5 & 6 & 2 & 1 & 1 & 1 & 29 \\
Attempt S & 1 & 2 & 3 & 3 & 3 & 3 & 2 & 1 & 6 & 8 & 4 & 4 & 40 \\
\hline \multicolumn{1}{l}{} & & & & & & & & & & \\
\hline Small hoop from & 75 & inches & & & & & & & & & & \\
\hline Days & 1 & 2 & 3 & 4 & 5 & 6 & 7 & 8 & 9 & 10 & 11 & 12 & Total \\
Score B & 0 & 0 & 0 & 0 & 0 & 0 & 0 & 0 & 0 & 0 & 0 & 0 & 0 \\
Score S & 1 & 0 & 1 & 1 & 0 & 0 & 1 & 0 & 0 & 0 & 0 & 0 & 4 \\
Attempt B & 1 & 0 & 1 & 1 & 0 & 1 & 0 & 0 & 0 & 0 & 0 & 0 & 4 \\
Attempt S & 1 & 2 & 2 & 2 & 1 & 1 & 3 & 3 & 0 & 1 & 2 & 0 & 18 \\
\hline
\end{tabular}


Note. Score B (S) presents a score with use of big balls (small balls). Attempt B (S) presents a number of attempts with big ball (small balls) at each target.

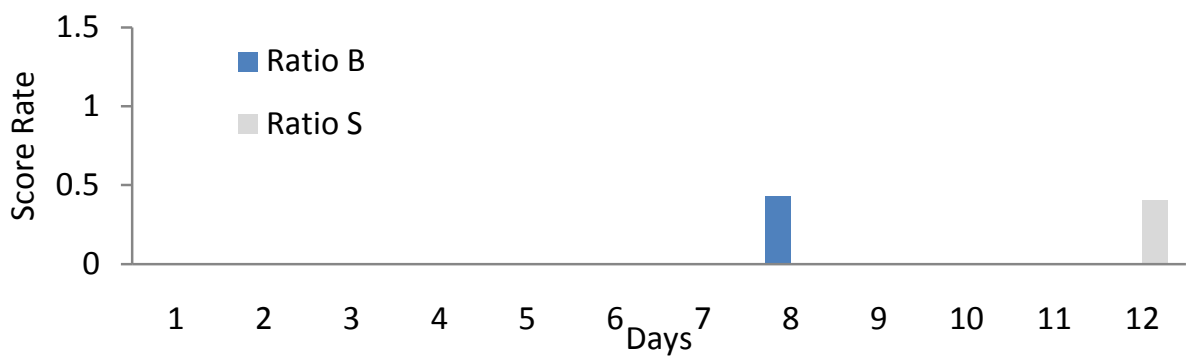

Figure 19A. Payton's scoring ratios at big hoop from a distance of 150 inches: Ratio B indicates scoring rates with use of big balls. Ratio $\mathrm{S}$ indicates scoring rates with use of small balls.

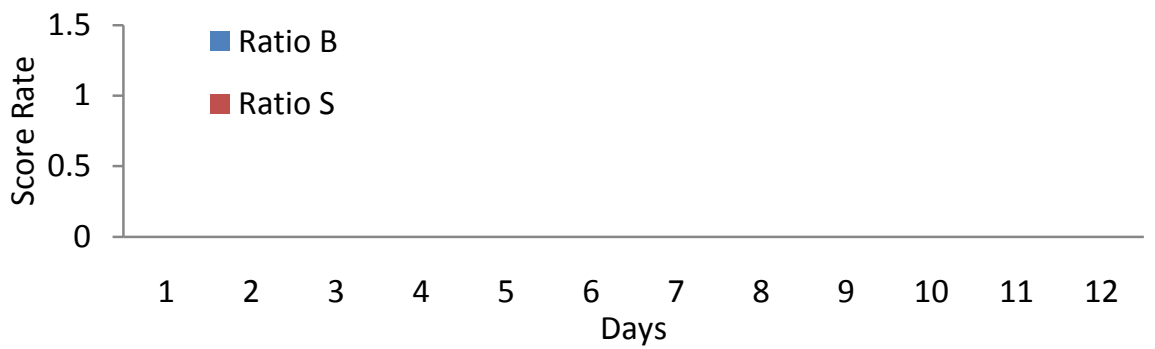

Figure 20A. Payton's scoring ratios at small hoop from a distance of 150 inches: Ratio B indicates scoring rates with use of big balls. Ratio S indicates scoring rates with use of small balls.

\section{Table 6A}

Payton's Scores in the Long Distance Throws

\begin{tabular}{|c|c|c|c|c|c|c|c|c|c|c|c|c|c|}
\hline \multicolumn{14}{|c|}{ Big hoop from 150 inches } \\
\hline Days & 1 & 2 & 3 & 4 & 5 & 6 & 7 & 8 & 9 & 10 & 11 & 12 & Total \\
\hline Attempt B & 2 & 2 & 0 & 3 & 2 & 2 & 1 & 7 & 1 & 0 & 0 & 2 & 22 \\
\hline Attempt S & 2 & 3 & 1 & 1 & 3 & 5 & 6 & 0 & 7 & 9 & 8 & 5 & 50 \\
\hline Score B & 0 & 0 & 0 & 0 & 0 & 0 & 0 & 3 & 0 & 0 & 0 & 0 & 3 \\
\hline Score S & 0 & 0 & 0 & 0 & 0 & 0 & 0 & 0 & 0 & 0 & 0 & 2 & 2 \\
\hline
\end{tabular}

\begin{tabular}{llllllllllllll}
\hline Small hoop from 150 inches \\
\hline Days & 1 & 2 & 3 & 4 & 5 & 6 & 7 & 8 & 9 & 10 & 11 & 12 & Total \\
Attempt B & 1 & 1 & 1 & 0 & 0 & 0 & 1 & 0 & 0 & 0 & 0 & 0 & 4 \\
Attempt S & 2 & 1 & 3 & 1 & 2 & 1 & 0 & 1 & 0 & 0 & 1 & 0 & 12 \\
Score B & 0 & 0 & 0 & 0 & 0 & 0 & 0 & 0 & 0 & 0 & 0 & 0 & 0 \\
Score S & 0 & 0 & 0 & 0 & 0 & 0 & 0 & 0 & 0 & 0 & 0 & 0 & 0 \\
\hline
\end{tabular}

Note. Score B (S) presents a score with use of big balls (small balls). Attempt B (S) presents a number of attempts with big ball (small balls) at each target. 


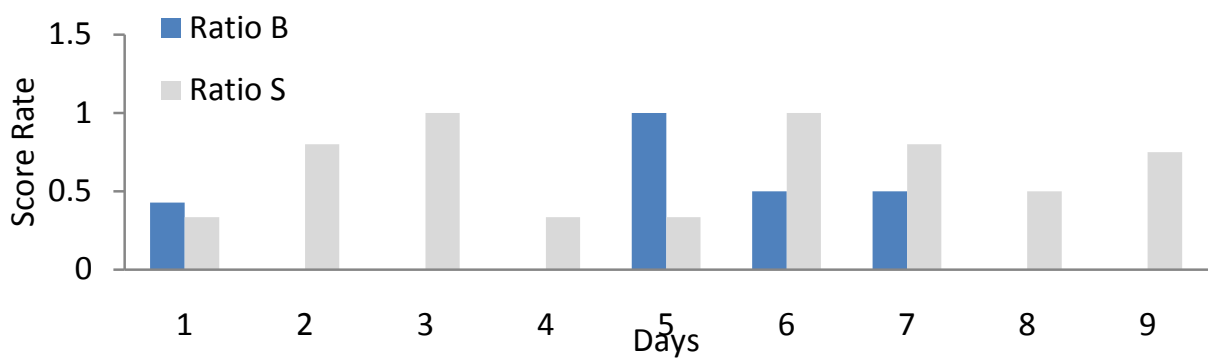

Figure 21A .Oloe's scoring ratios at big hoop from a distance of 75 inches: Ratio B indicates scoring rates with use of big balls. Ratio $\mathrm{S}$ indicates scoring rates with use of small balls.

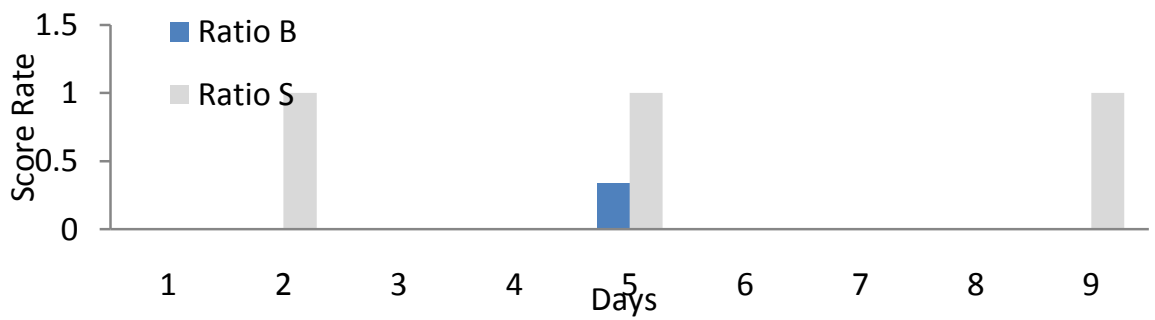

Figure 22A .Oloe's scoring ratios at small hoop from a distance of 75 inches: Ratio B indicates scoring rates with use of big balls. Ratio $\mathrm{S}$ indicates scoring rates with use of small balls.

\section{Table 7A}

Oloe's Scores in the Short Distance Throws

\begin{tabular}{|c|c|c|c|c|c|c|c|c|c|c|}
\hline \multicolumn{11}{|c|}{ Big hoop from 75 inches } \\
\hline Days & 1 & 2 & 3 & 4 & 5 & 6 & 7 & 8 & 9 & Total \\
\hline Attempt B & 7 & 2 & 1 & 3 & 1 & 2 & 2 & 1 & 1 & 20 \\
\hline Attempt S & 3 & 5 & 5 & 6 & 3 & 5 & 5 & 6 & 4 & 42 \\
\hline Score B & 3 & 0 & 0 & 0 & 1 & 1 & 1 & 0 & 0 & 6 \\
\hline Score S & 1 & 4 & 5 & 2 & 1 & 5 & 4 & 3 & 3 & 28 \\
\hline \multicolumn{11}{|c|}{ Small hoop from 75 inches } \\
\hline Days & 1 & 2 & 3 & 4 & 5 & 6 & 7 & 8 & 9 & Total \\
\hline Attempt B & 0 & 3 & 0 & 0 & 3 & 1 & 2 & 0 & 1 & 10 \\
\hline Attempt S & 0 & 1 & 0 & 0 & 1 & 0 & 1 & 1 & 1 & 5 \\
\hline Score B & 0 & 0 & 0 & 0 & 1 & 0 & 0 & 0 & 0 & 1 \\
\hline Score S & 0 & 1 & 0 & 0 & 1 & 0 & 0 & 0 & 1 & 3 \\
\hline
\end{tabular}

Note. Score B (S) presents a score with use of big balls (small balls). Attempt B (S) presents a number of attempts with big ball (small balls) at each target. 


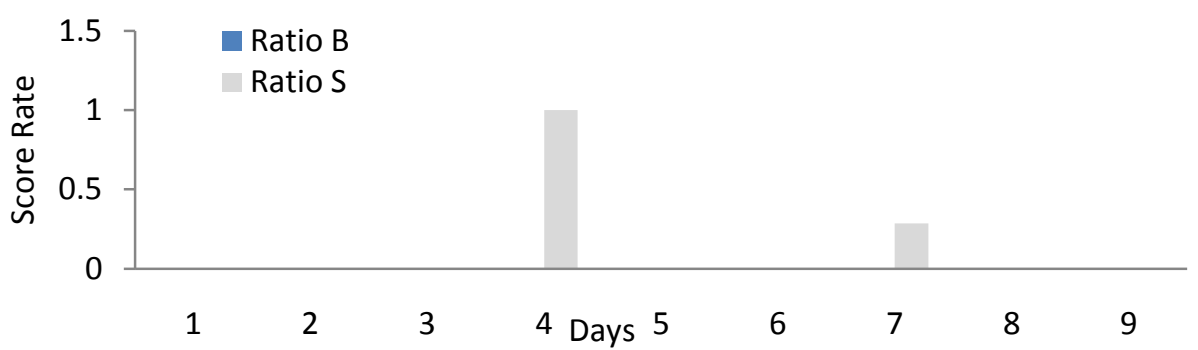

Figure 23A .Oloe's scoring ratios at big hoop from a distance of 150 inches: Ratio B indicates scoring rates with use of big balls. Ratio $\mathrm{S}$ indicates scoring rates with use of small balls.

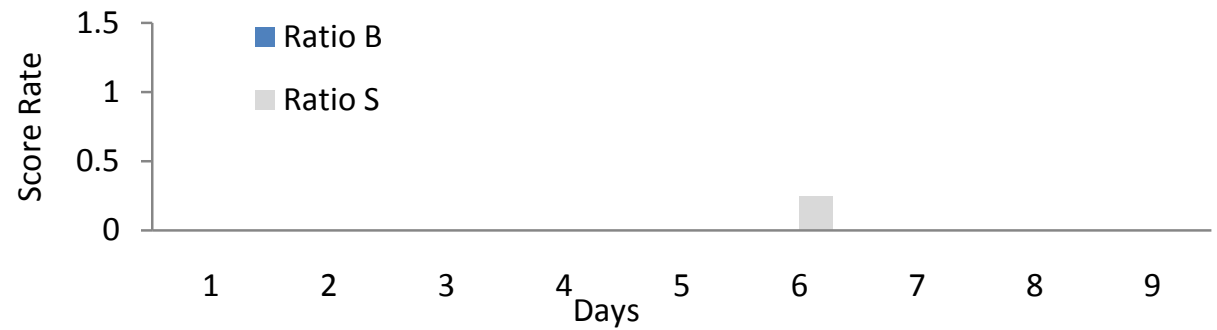

Figure 24A. Oloe's scoring ratios at small hoop from a distance of 150 inches: Ratio B indicates scoring rates with use of big balls. Ratio $\mathrm{S}$ indicates scoring rates with use of small balls.

\section{Table 8A}

Oloe's Scores in the Long Distance Throws

\begin{tabular}{|c|c|c|c|c|c|c|c|c|c|c|}
\hline \multicolumn{11}{|c|}{ Big hoop from 150 inches } \\
\hline Days & 1 & 2 & 3 & 4 & 5 & 6 & 7 & 8 & 9 & Total \\
\hline Attempt B & 2 & 3 & 1 & 8 & 2 & 2 & 0 & 3 & 1 & 22 \\
\hline Attempt S & 5 & 4 & 2 & 1 & 1 & 1 & 7 & 5 & 4 & 30 \\
\hline Score B & 0 & 0 & 0 & 0 & 0 & 0 & 0 & 0 & 0 & 0 \\
\hline Score S & 0 & 0 & 0 & 1 & 0 & 0 & 2 & 0 & 0 & 3 \\
\hline
\end{tabular}

\begin{tabular}{|c|c|c|c|c|c|c|c|c|c|c|}
\hline \multicolumn{11}{|c|}{ Small hoop from 150 inches } \\
\hline Days & 1 & 2 & 3 & 4 & 5 & 6 & 7 & 8 & 9 & Total \\
\hline Attempt B & 0 & 0 & 1 & 0 & 5 & 1 & 1 & 1 & 0 & 9 \\
\hline Attempt S & 0 & 1 & 1 & 0 & 2 & 4 & 0 & 0 & 2 & 10 \\
\hline Score B & 0 & 0 & 0 & 0 & 0 & 0 & 0 & 0 & 0 & 0 \\
\hline Score S & 0 & 0 & 0 & 0 & 0 & 1 & 0 & 0 & 0 & 1 \\
\hline
\end{tabular}

Note. Score B (S) presents a score with use of big balls (small balls). Attempt B (S) presents a number of attempts with big ball (small balls) at each target. 


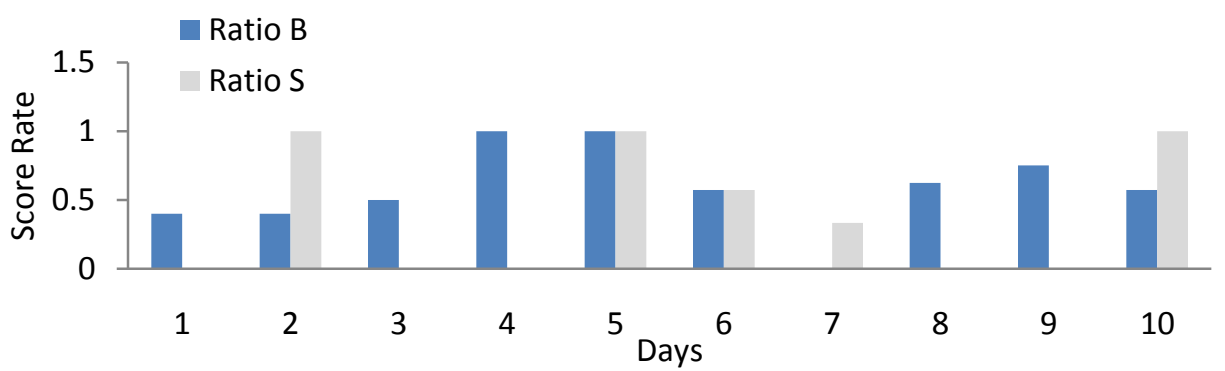

Figure 25A. Jonah's scoring ratios at big hoop from a distance of 75 inches: Ratio B indicates scoring rates with use of big balls. Ratio $\mathrm{S}$ indicates scoring rates with use of small balls.

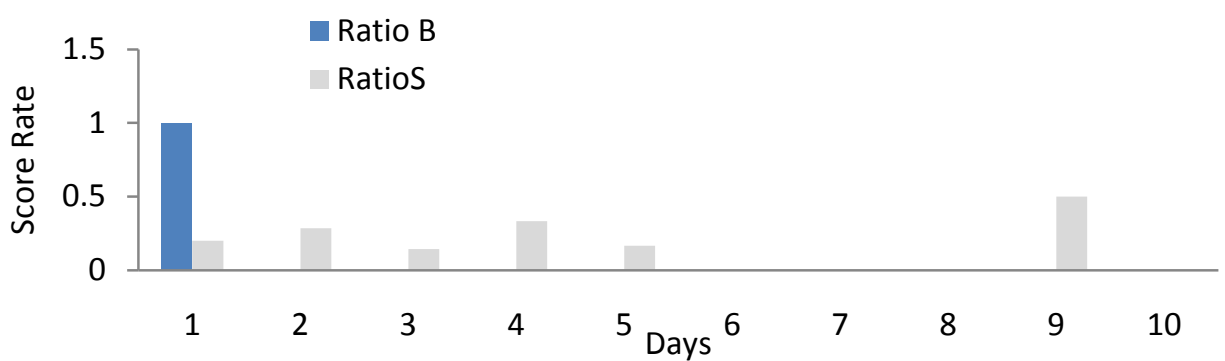

Figure 26A. Jonah's scoring ratios at small hoop from a distance of 75 inches: Ratio B indicates scoring rates with use of big balls. Ratio $\mathrm{S}$ indicates scoring rates with use of small balls.

\section{Table 9A}

Jonah's Scores in the Short Distance Throws

\begin{tabular}{|c|c|c|c|c|c|c|c|c|c|c|c|}
\hline \multicolumn{12}{|c|}{ Big hoop from 75 inches } \\
\hline Days & 1 & 2 & 3 & 4 & 5 & 6 & 7 & 8 & 9 & 10 & Total \\
\hline Attempt B & 5 & 5 & 2 & 1 & 4 & 7 & 5 & 8 & 4 & 7 & 48 \\
\hline Attempt S & 0 & 1 & 0 & 0 & 1 & 7 & 3 & 1 & 0 & 1 & 14 \\
\hline Score B & 2 & 2 & 1 & 1 & 4 & 4 & 0 & 5 & 3 & 4 & 26 \\
\hline Score S & 0 & 1 & 0 & 0 & 1 & 4 & 1 & 0 & 0 & 1 & 8 \\
\hline \multicolumn{12}{|c|}{ Small hoop from 75 inches } \\
\hline Days & 1 & 2 & 3 & 4 & 5 & 6 & 7 & 8 & 9 & 10 & Total \\
\hline Attempt B & 1 & 0 & 0 & 0 & 1 & 0 & 0 & 0 & 0 & 3 & 5 \\
\hline Attempt S & 5 & 7 & 7 & 6 & 6 & 0 & 0 & 0 & 4 & 0 & 35 \\
\hline Score B & 1 & 0 & 0 & 0 & 0 & 0 & 0 & 0 & 0 & 0 & 1 \\
\hline Score S & 1 & 2 & 1 & 2 & 1 & 0 & 0 & 0 & 2 & 0 & 9 \\
\hline
\end{tabular}

Note. Score B (S) presents a score with use of big balls (small balls). Attempt B (S) presents a number of attempts with big ball (small balls) at each target. 


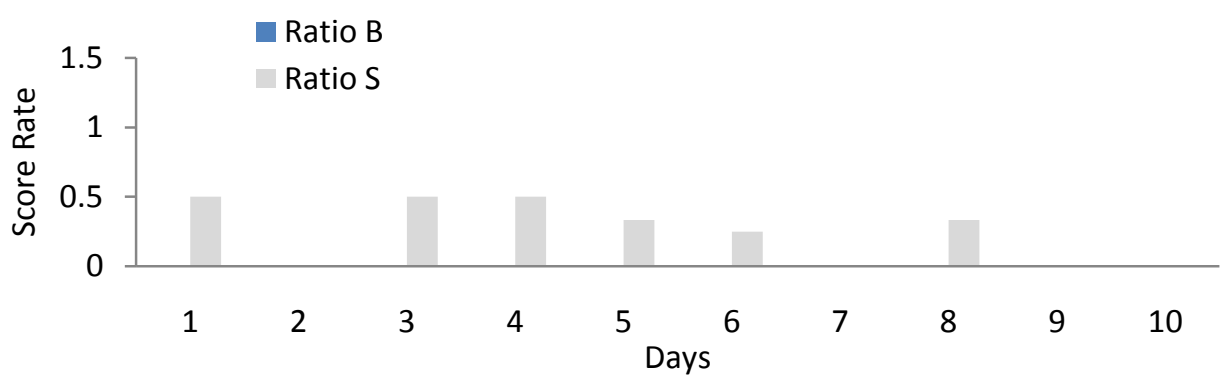

Figure 27A. Jonah's scoring ratios at big hoop from a distance of 150 inches: Ratio B indicates scoring rates with use of big balls. Ratio S indicates scoring rates with use of small balls.

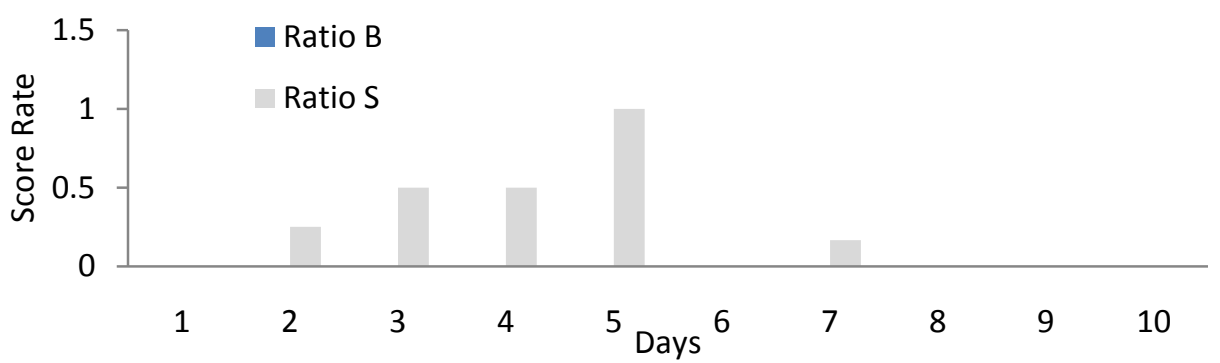

Figure 28A. Jonah's scoring ratios at small hoop from a distance of 150 inches: Ratio B indicates scoring rates with use of big balls. Ratio $\mathrm{S}$ indicates scoring rates with use of small balls.

Table 10 A

Jonah's Scores in the Long Distance Throws

\begin{tabular}{|c|c|c|c|c|c|c|c|c|c|c|c|}
\hline \multicolumn{12}{|c|}{ Big hoop from 150 inches } \\
\hline Days & 1 & 2 & 3 & 4 & 5 & 6 & 7 & 8 & 9 & 10 & Total \\
\hline Attempt B & 8 & 3 & 1 & 1 & 2 & 1 & 2 & 3 & 3 & 1 & 25 \\
\hline Attempt S & 2 & 3 & 4 & 4 & 3 & 4 & 1 & 3 & 3 & 3 & 30 \\
\hline Score B & 0 & 0 & 0 & 0 & 0 & 0 & 0 & 0 & 0 & 0 & 0 \\
\hline Score S & 1 & 0 & 2 & 2 & 1 & 1 & 0 & 1 & 0 & 0 & 8 \\
\hline
\end{tabular}

\begin{tabular}{|c|c|c|c|c|c|c|c|c|c|c|c|}
\hline \multicolumn{12}{|c|}{ Small hoop from 150 inches } \\
\hline Days & 1 & 2 & 3 & 4 & 5 & 6 & 7 & 8 & 9 & 10 & Total \\
\hline Attempt B & 0 & 0 & 0 & 0 & 1 & 1 & 0 & 1 & 1 & 0 & 4 \\
\hline Attempt S & 0 & 4 & 2 & 2 & 1 & 1 & 6 & 1 & 1 & 0 & 18 \\
\hline Score B & 0 & 0 & 0 & 0 & 0 & 0 & 0 & 0 & 0 & 0 & 0 \\
\hline Score S & 0 & 1 & 1 & 1 & 1 & 0 & 1 & 0 & 0 & 0 & 5 \\
\hline
\end{tabular}

Note. Score B (S) presents a score with use of big balls (small balls). Attempt B (S) presents a number of attempts with big ball (small balls) at each target. 


\section{APPENDIX C}

\section{Approval from Institutional Review Board}

\section{$\mathrm{API}$}

Andrew Hawkins

WVU IRB

Message Board

My Personal. Info

Overseer

Activity List

Create Protocol

Create Emeraency Use

- Activity List

Research Team

Create Protocol

Create Emergency Use

Activity List

Signature

Assign Proxy

Activity List

Logout
IRB PROTOCOL - Details

Tracking \#

H-20736

PI

Hawkins, Andrew

Title

Changes in Throwing Pattern and Perceptual Judgment as the Function of Task Variation for Young Children Version

18

Status

Approved

Status Date

2/4/2010 8:37:18 AM

Board

Board Gold

Meeting Date

Approval Date

02/04/2010

Expiration Date 


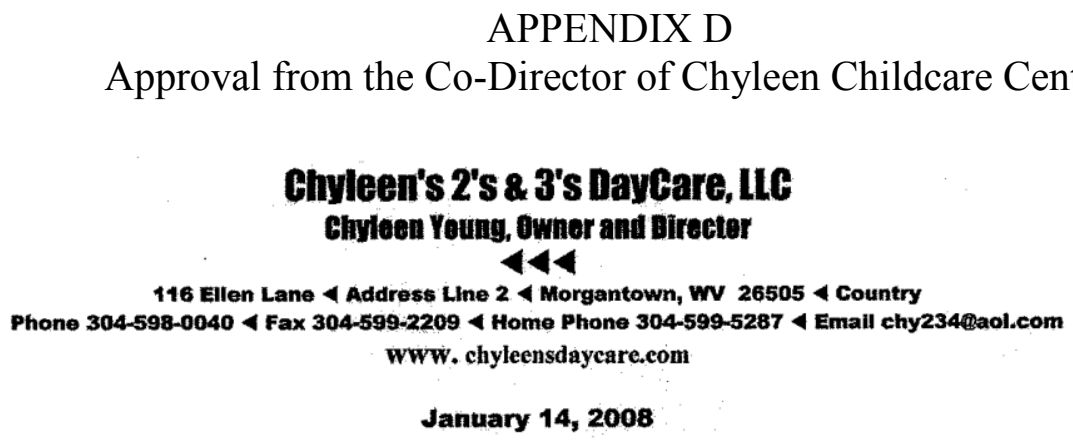

To Whom Ever it May Concern:

We, Chyleen's 2's, 3's, and 4's Daycare, LLC, give permission allowing Yoojin Choi, a doctoral student in the Physical Education/ Teacher Education program, to observe and to do field work at our center for the spring semester 2008. We look forward to the collaboration.

Thank you,

Kay Peluso, Co-Director

. . . On

10 


\section{APPENDIX E \\ Informed Consent Forms \\ Cover Letter}

Jan 30, 2007

\section{Dear Parents:}

My name is Yoojin Choi. I am a doctoral students majoring in Motor development within the school of Physical Education at West Virginia University. As the part of my doctoral thesis, I am studying the function of task variations of changes in throwing patterns of young children. The task variation will be created by the investigator and provided your child.

I am asking that your child participate in this study, which is described in more depth within the Consent Form that is attached. By signing the consent form, you are agreeing to your child's participation in this study. Your child will perform each throwing task designed for the purpose of the study. Each task is required to demonstrate the throwing movement that is encouraged in the normal physical education setting with young children. The study examines the change of throwing pattern and the choice of balls according to the given experimental settings. The information will be collected merely for the purpose of this study and will be kept completely confidential. Your child's name will be coded to protect your child's privacy. Your consenting to participate is voluntary, and you may withdraw at any time without penalty.

If you have any questions about this study after reading this letter and the attached consent form, please feel free to contact Yoojin Choi at 293-3295. ext. 5250 or ychoi@mix.wvu.edu

Sincerely,

Yoojin Choi

Doctoral Student 


\section{APPENDIX F \\ Informed Consent Forms}

PARENTAL or GUARDIAN CONSENT and INFORMATION FORM

(Change in Throwing Pattern and Perceptual Judgment as the Function of Task Variation for Young Children)

Introduction. I, have been asked to allow my child to participate in this research study. Yoojin Choi, who is conducting this research to fulfill the requirements for a doctoral dissertation in Physical Education at West Virginia University, has explained the study to me.

Purpose of the study. Purpose of the study is to learn more about a curricular design for preschool movement programs.

Description of Procedures. This study will be performed at Chyleen Child Care Center. My child will be asked to make throws with different sized balls and targets/hoops. These attempts will be recorded on videotape. My child will rotate through two stations built for the purpose of the study. Each station will be provided my child with the different throwing tasks. The changes of throwing patterns in given each task will be examined. My child will perform each throwing task for $3 \mathrm{~min}$. This experiment will take place for a 2 week-period. Four children including my child will participate in this study.

Benefits. I understand that the results of this study could determine the effects that participating in such movement programs has on children. I also understand that my child may benefit by a quality movement instruction program.

Risks and Discomforts. In any movement instruction program there are inherent risks, such as falling or bumping into something or someone, however, all activities are carefully selected to be appropriate for preschool children and their parents. In addition, all activities are closely supervised. The experiments will be supervised by two graduate students who have experienced in the instruction and supervision of young children in a physical activity program.

Please initial here after reading this page

Date 
(Change in Throwing Pattern and Perceptual Judgment as the Function of Task Variation for Young Children)

Confidentiality. I understand that any information obtained as a result of my child's participation in this research will be kept as confidential as legally possible. I understand that all information will be coded for confidentiality so neither my child nor I can be identified. My name or that of my child or any information from which we might be identified may not be published without my consent. The videotape containing my child's performance will be destroyed after the study is published.

Voluntary Participation. Participation in this study is voluntary. I understand that I may withdraw my child from this study at any time. Refusal to participate or withdrawal will involve no penalty or loss of benefits for my child or me. I have been given the opportunity to ask questions about the research, and I have received answers concerning areas I did not understand. I have been offered a summary of the results of the study whether my child or I participate or not.

Upon signing this from, I will receive a copy.

I willingly consent to my child's participation in this research.

Signature of Parent or Guardian

Signature of Investigator or Investigator's Representative
Date

Date
Time

Time

Contact persons. For more information about this study, I can contact Yoojin Choi, at 293-3295 ext 5250, her supervisor, Dr. Andrew Hawkins, at 293-3295 ext. 5210, or the director of Motor Development Center, Dr. Linda M. Carson, at 293-3295 ext. 5276. For additional information regarding my child's rights as a research subject, I may contact the Executive Secretary of the Institutional Review Board at 293-7073. 


\section{APPENDIX G \\ Demographic Questionnaire}

CODE\#

\section{PARENT QUESTIONNAIRE}

Question: Circle your answer according to the corresponding number.

1. Is your participating child: (1) Male (2) Female

2. What is the age of your participating child? (1) $3 \quad$ (2) $4 \quad$ (3) 5

Child's birthday: / /

3. How many semesters have the participating child previously participated in the KinderSkill Program?
(1) 0
(2) 1 (3) 2
(4) 3
(5) 4
(6) $5 \quad$ (7) 6

4. How much time does the participating child spend participating in physical activity each week?

(1) less than 1 hour (2) 1-2 hours (3) 2-3 hours (4) 3-4 hours (5) more than 4 hours

5. Is the participating child currently enrolled in any other physical activity program?
(1) yes (2) no

if yes, please list program here: 
APPENDIX H

Test of Gross Motor Development: Object Manual Subtest

\begin{tabular}{|c|c|c|c|c|c|c|}
\hline Skill & Materials & Directions & Performance Criteria & Trial 1 & Trial2 & Score \\
\hline \multirow[t]{5}{*}{ Throw } & \multirow{5}{*}{$\begin{array}{l}\text { A tennis } \\
\text { ball, a } \\
\text { wall, tape, } \\
\text { and } 20 \text { feet } \\
\text { of clear } \\
\text { space }\end{array}$} & \multirow{5}{*}{$\begin{array}{l}\text { Attach a piece of } \\
\text { tape on the floor } \\
20 \text { feet from the } \\
\text { wall. Have the } \\
\text { child stand } \\
\text { behind the } 20 \\
\text { foot line facing } \\
\text { the wall. Tell the } \\
\text { child to throw the } \\
\text { ball hard at the } \\
\text { wall. Repeat a } \\
\text { second trial. }\end{array}$} & $\begin{array}{l}\text { 1. Wind up is initiated } \\
\text { with downward } \\
\text { movement of hand/arm }\end{array}$ & & & \\
\hline & & & $\begin{array}{l}\text { 2. Rotates hip and } \\
\text { shoulders to a point } \\
\text { where the non-throwing } \\
\text { side faces the wall. }\end{array}$ & & & \\
\hline & & & $\begin{array}{l}\text { 3. Weight is transferred } \\
\text { by stepping with the foot } \\
\text { opposite the throwing } \\
\text { hand. }\end{array}$ & & & \\
\hline & & & $\begin{array}{l}\text { 4. Follow through beyond } \\
\text { ball release diagonally } \\
\text { across the body toward } \\
\text { the non preferred side. }\end{array}$ & & & \\
\hline & & & & \multicolumn{2}{|c|}{ Skill Score } & \\
\hline \multirow[t]{5}{*}{ Kick } & \multirow{5}{*}{$\begin{array}{l}\text { An } 8-10 \\
\text { inch } \\
\text { playground } \\
\text { ball, or } \\
\text { soccer ball, } \\
\text { a bean bag, } \\
30 \text { feet of } \\
\text { clear } \\
\text { space, and } \\
\text { tape. }\end{array}$} & \multirow{5}{*}{$\begin{array}{l}\text { Mark off one line } \\
30 \text { feet away } \\
\text { from a wall and } \\
\text { another line that } \\
\text { is } 20 \text { feet from } \\
\text { wall. Place the } \\
\text { ball on top of the } \\
\text { bean bag on the } \\
\text { line nearest the } \\
\text { wall. Tell the } \\
\text { child to stand on } \\
\text { the other line. } \\
\text { Tell the child to } \\
\text { run up and kick } \\
\text { the ball hard } \\
\text { towards the wall. } \\
\text { Repeat a second } \\
\text { trial. }\end{array}$} & $\begin{array}{l}\text { 1.Rapid and continuous } \\
\text { approach to the ball }\end{array}$ & & & \\
\hline & & & $\begin{array}{l}\text { 2.An elongated step or } \\
\text { leap immediately prior to } \\
\text { ball contact }\end{array}$ & & & \\
\hline & & & $\begin{array}{l}\text { 3. Non-kicking foot } \\
\text { placed even with or } \\
\text { slightly back of the ball. }\end{array}$ & & & \\
\hline & & & $\begin{array}{l}\text { 4. Kicks ball with instep } \\
\text { of preferred foot (shoe } \\
\text { laces) or toe. }\end{array}$ & & & \\
\hline & & & & Skill Sc & & \\
\hline \multirow[t]{3}{*}{ Catch } & \multirow{3}{*}{$\begin{array}{l}\text { A } 4 \text { inch } \\
\text { plastic } \\
\text { ball, } 15 \\
\text { feet of } \\
\text { clear space } \\
\text { and tape. }\end{array}$} & \multirow{3}{*}{$\begin{array}{l}\text { Mark off two } \\
\text { lines } 15 \text { feet } \\
\text { apart. The child } \\
\text { stands on one } \\
\text { line and the } \\
\text { tosser on the } \\
\text { other. Toss the } \\
\text { ball underhand } \\
\text { directly to the }\end{array}$} & $\begin{array}{l}\text { 1.Preparation phase } \\
\text { where hands are in front } \\
\text { of the body and elbows } \\
\text { are flexed. }\end{array}$ & & & \\
\hline & & & $\begin{array}{l}\text { 2. Arms extend while } \\
\text { reaching for the ball as it } \\
\text { arrives. }\end{array}$ & & & \\
\hline & & & $\begin{array}{l}\text { 3. Ball is caught by hands } \\
\text { only. }\end{array}$ & & & \\
\hline
\end{tabular}




\begin{tabular}{|c|c|c|c|c|c|c|}
\hline & & $\begin{array}{l}\text { child with a } \\
\text { slight arc aiming } \\
\text { for their chest. } \\
\text { Tell the child to } \\
\text { catch the ball } \\
\text { with both hands. } \\
\text { Only count those } \\
\text { that are between } \\
\text { the child's } \\
\text { shoulders and } \\
\text { belt. Repeat a } \\
\text { second trial. }\end{array}$ & & \multicolumn{2}{|c|}{ Skill Score } & \\
\hline & & & & Trial 1 & Trial 2 & Score \\
\hline \multirow[t]{5}{*}{ Dribble } & \multirow{5}{*}{$\begin{array}{l}\text { An } 8-10 \\
\text { inch } \\
\text { playground } \\
\text { ball for } \\
\text { children } \\
\text { aged } 3-5 \text {, } \\
\text { a } \\
\text { basketball } \\
\text { for } \\
\text { children } \\
\text { aged } 6- \\
10 \text { and a } \\
\text { flat, hard } \\
\text { surface. }\end{array}$} & \multirow{5}{*}{$\begin{array}{l}\text { Tell the child to } \\
\text { dribble the ball } 4 \\
\text { times without } \\
\text { moving their feet } \\
\text { using one hand } \\
\text { and then dribble } \\
\text { across the gym } \\
\text { and back. The } \\
\text { time back and } \\
\text { forth is collected. } \\
\text { Repeat a second } \\
\text { trial. }\end{array}$} & $\begin{array}{l}\text { 1.Contacts the ball with } \\
\text { one hand about belt level. }\end{array}$ & & & \\
\hline & & & $\begin{array}{l}\text { 2. Pushes ball with finger } \\
\text { tips (not a slap). }\end{array}$ & & & \\
\hline & & & $\begin{array}{l}\text { 3. Ball contacts surface in } \\
\text { front of or to the outside } \\
\text { of foot on the preferred } \\
\text { side }\end{array}$ & & & \\
\hline & & & $\begin{array}{l}\text { 4. Maintains control of } \\
\text { ball for } 4 \text { consecutive } \\
\text { bounces without having } \\
\text { to move the feet to } \\
\text { retrieve it. }\end{array}$ & & & \\
\hline & & & & \multicolumn{2}{|c|}{ Skill Score } & \\
\hline \multirow[t]{6}{*}{ Striking } & \multirow{5}{*}{$\begin{array}{l}\text { An 4-inch } \\
\text { lightweight } \\
\text { ball, } \\
\text { plastic bat, } \\
\text { and a } \\
\text { batting tee }\end{array}$} & \multirow{5}{*}{$\begin{array}{l}\text { Place the ball on } \\
\text { the batting tee at } \\
\text { the child's belt } \\
\text { level. Tell the } \\
\text { child to hit the } \\
\text { ball hard. Repeat } \\
\text { a second trial. }\end{array}$} & $\begin{array}{l}\text { 1.Dominant hand grips } \\
\text { bat above non dominant } \\
\text { hand }\end{array}$ & & & \\
\hline & & & $\begin{array}{l}\text { 2. Non preferred side of } \\
\text { body face the imaginary } \\
\text { tosser with feet parallel }\end{array}$ & & & \\
\hline & & & $\begin{array}{l}\text { 3. Hip and shoulder } \\
\text { rotation during swing }\end{array}$ & & & \\
\hline & & & $\begin{array}{l}\text { 4. Transfers body weight } \\
\text { to front foot }\end{array}$ & & & \\
\hline & & & 5. Bat contacts ball & & & \\
\hline & & & & \multicolumn{2}{|c|}{ Skill Score } & \\
\hline \multirow[t]{3}{*}{$\begin{array}{l}\text { Underhand } \\
\text { Roll }\end{array}$} & \multirow{3}{*}{$\begin{array}{l}\text { A tennis } \\
\text { ball for } \\
\text { children } \\
\text { ages } 3 \text { to } \\
6: \text { a } \\
\text { softball for } \\
\text { children } \\
\text { ages } 7 \text { to } \\
\text { 10: two }\end{array}$} & \multirow{3}{*}{$\begin{array}{l}\text { Place the two } \\
\text { cones against a } \\
\text { wall so they are } 4 \\
\text { feet apart. Attach } \\
\text { a piece of tape on } \\
\text { the floor } 20 \text { feet } \\
\text { from the wall. } \\
\text { Tell the child to } \\
\text { roll the ball hard }\end{array}$} & $\begin{array}{l}\text { 1.Preferred hand swing } \\
\text { down and back, reaching } \\
\text { behind the trunk while } \\
\text { chest face cones. }\end{array}$ & & & \\
\hline & & & $\begin{array}{l}\text { 2. Strides forward with } \\
\text { foot opposite the } \\
\text { preferred hand toward the } \\
\text { cons. }\end{array}$ & & & \\
\hline & & & 3. Bends knees to lower & & & \\
\hline
\end{tabular}




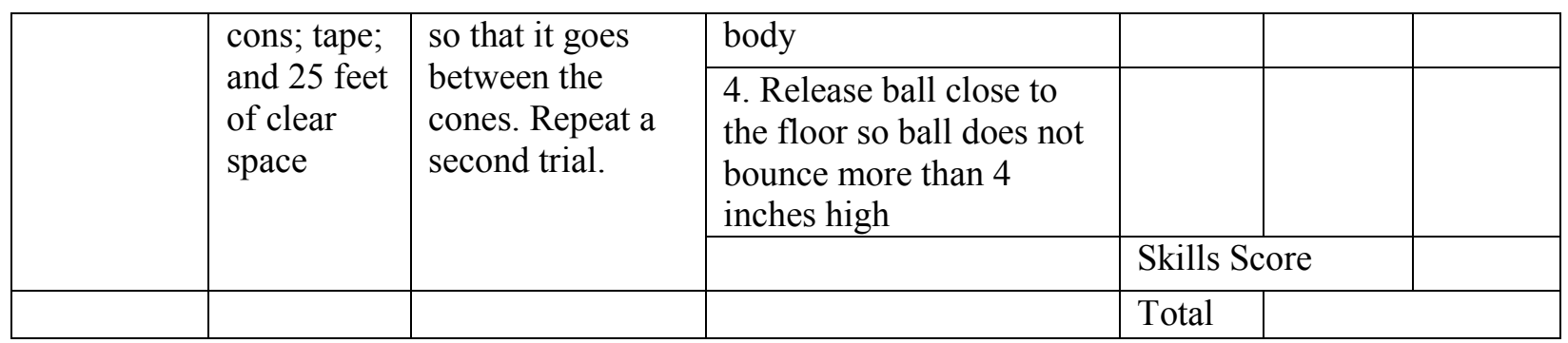




\section{APPENDIX I}

\section{PROTOCOL OF EXPERIMENTS: REMINDERS FOR INSTRUCTOR}

* Do not provide any instructions in throwing.

* Make sure a child stays at a certain distance (e.g., 75 and 150 inches) from the targets.

- Help a child understand what a goal is (e.g., show a child how a ball passes through a hoop).

- Use a prompt 'ready, throw the ball' at every attempt: Set this as a routine.

* Do not hand in a ball to a child Experiment 2.

* Try to encourage a child to throw a ball differently when he or she does not make a goal continuously; (1) say 'can you show me a different way to throw? (2) Take some time between attempts; and (3) show how a ball goes through a hoop again, anytime a child struggles.

* Create a positive atmosphere by using positive feedbacks and encouragement: (1) Make sure to give a positive feedback (e.g., good job!) ONLY when a child makes a goal, (2) when he or she fails, give encouragement instead. 